Florida International University FIU Digital Commons

$11-8-2016$

\title{
Latina Lesbian Students: Understanding their Experiences and Perceived Sexual Identity Development at a Hispanic-Serving Institution
}

Gisela P. Vega

Florida International University, xvegag@fiu.edu

DOI: $10.25148 /$ etd.FIDC001234

Follow this and additional works at: https://digitalcommons.fiu.edu/etd

Part of the Higher Education Commons

\section{Recommended Citation}

Vega, Gisela P., "Latina Lesbian Students: Understanding their Experiences and Perceived Sexual Identity Development at a HispanicServing Institution" (2016). FIU Electronic Theses and Dissertations. 2722.

https://digitalcommons.fiu.edu/etd/2722 


\section{FLORIDA INTERNATIONAL UNIVERSITY}

Miami, Florida

\section{LATINA LESBIAN STUDENTS: UNDERSTANDING THEIR EXPERIENCES AND PERCEIVED SEXUAL IDENTITY DEVELOPMENT AT A HISPANIC-SERVING INSTITUTION}

A dissertation submitted in partial fulfillment of the requirements for the degree of

DOCTOR OF EDUCATION

in

HIGHER EDUCATION

by

Gisela Ponce Vega

2016 
To: Dean Michael R. Heithaus

College of Arts, Sciences and Education

This dissertation, written by Gisela Ponce Vega, and entitled Latina Lesbian Students: Understanding Their Experiences and Perceived Sexual Identity Development at a Hispanic-serving Institution, having been approved in respect to style and intellectual content, is referred to you for judgment.

We have read this dissertation and recommend that it be approved.

Hilary Landorf

Thomas G. Reio, Jr.

Suzanna Rose

Tonette S. Rocco, Major Professor

Date of Defense: November 8, 2016

The dissertation of Gisela Ponce Vega is approved.

Dean Michael R. Heithaus
College of Arts, Sciences and Education

College of Arts, Sciences and Education

Andrés G. Gil

Vice President for Research and Economic Development and Dean of the University Graduate School

Florida International University, 2016 
(C) Copyright 2016 by Gisela Ponce Vega

All rights reserved. 


\section{DEDICATION}

To my mother Catalina Ponce Vega, whose life and spirit has been my inspiration and guide. She instilled in me a love and passion for education, and her appetite for being a life-long learner. Thank you for teaching me the value of unconditional love and the importance of an education. This is dedicated in her honor and memory, and to my father Juan Vega Moran. Thank you papa for teaching me the value of hard work and perseverance. Thank you both for your unwavering faith, unconditional love, and endless support.

This is also dedicated to my siblings Carmen and Omar, and my beautiful nieces and nephews, Jennifer, Alexandra, Catalina, Daniel, Gioncarlo, and Benjamin. Finally, to my darling Madelin, my life-long mentor and friend Jo, and the women who participated in this study. Their strength, struggles, and resilience have kept me strong and focused. 


\section{ACKNOWLEDGMENTS}

I would like to thank and express my deepest gratitude to my committee members, Dr. Hilary Landorf, Dr. Thomas G. Reio, Dr. Suzanna Rose, and Dr. Tonette S. Rocco. I am especially grateful to my chair Dr. Rocco for her guidance, support, and,

most importantly, for never giving up on me. She is the consummate mentor, from whom I have learned much and to whom I am eternally grateful.

I would also like to acknowledge Suzanne Gallagher, Craig McGill, Carolyn Meeker, Chaundra Whitehead, and Lori Ann Gionti, my amazing peer review team and colleagues, who always supported me, made me laugh, and kept me going even when things got tough. Thank you to my dear friends Consuelo Boronat, Jeannette Cruz, Kate Kominars, Estela Penabad, Sue Beebe, and Maritza Rosario, whose unwavering support, love and understanding were a blessing during this process. I would lastly like to thank my MPAS family, my supervisor Dorret Sawyers, and all those friends and loved ones, whose constant support and encouragement kept me moving forward. 


\section{ABSTRACT OF THE DISSERTATION \\ LATINA LESBIAN STUDENTS: UNDERSTANDING THEIR EXPERIENCES AND PERCEIVED SEXUAL IDENTITY DEVELOPMENT AT A HISPANIC-SERVING INSTITUTION}

by

Gisela Ponce Vega

Florida International University, 2016

Miami, Florida

Professor Tonette S. Rocco, Major Professor

The purpose of this phenomenological study was to explore the experiences of 15 Latina lesbian students and their perceived sexual identity development at a predominately Hispanic-serving Institution (HSI). Participants for this study were purposefully selected using criteria, convenience, and snowball sampling.

Using a conceptual framework comprised of the four tenets consistent across the spectrum of all sexual identity development models, participants' experiences were described, analyzed, and interpreted to inform the study. Data were collected through individual face-to-face interviews, using an interview protocol, and were analyzed using inductive, deductive, and comparative analyses.

Three themes emerged during the inductive analysis: (a) the trifecta: family, religion and gender, (b) the paradox of being Latina and lesbian, and (c) institutional care. In the deductive analysis, a rubric of a priori codes was derived from their (a) cultural perspectives, (b) identity awareness, and the four tenets sexual minorities consistently experience which included: (c) alienation, (d) social exclusion, (e) 
disclosure, and (f) self-acceptance of a non-heterosexual identity. The deductive analysis confirmed that participants' experiences and perceived levels of sexual identity development were determined by the challenge or support they received from family, peers, and their Hispanic-serving institution overall. The comparative analysis revealed an overlap of the inductive and deductive themes. Among 15 participants, the inductive themes of (a) the trifecta: family, religion and gender, (b) the paradox of being Latina and lesbian, and (c) institutional care were present in all segments of the deductive analysis.

The findings highlighted the complex and challenging experiences of Latina lesbians as they attempt to navigate their intersections of sexuality, gender, and culture in the context of higher education. The study makes a critical contribution to understanding the experiences and sexual identity development of Latina lesbian students at an HSI. The study concluded that while Latina lesbian students struggle to reconcile their Latina and lesbian identities, their experiences at a HSI can be a source of challenge or support in their overall well-being and identity development. 


\section{TABLE OF CONTENTS}

CHAPTER

PAGE

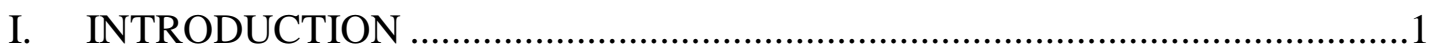

Background of the Problem ............................................................................

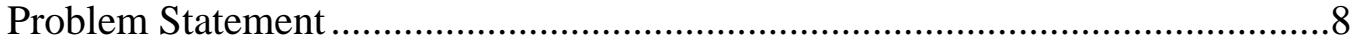

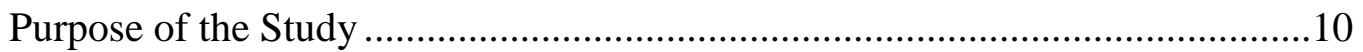

Research Questions ...................................................................................... 10

Conceptual Framework ............................................................................10

Sexual Identity Development........................................................................11

Significance of the Study …………….......................................................12

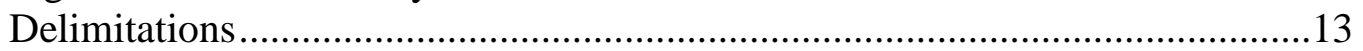

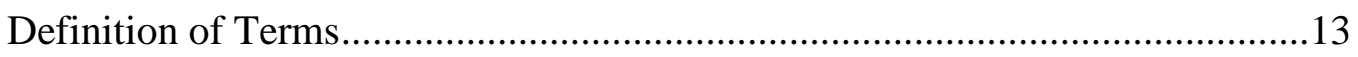

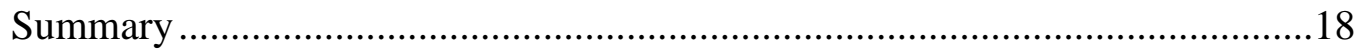

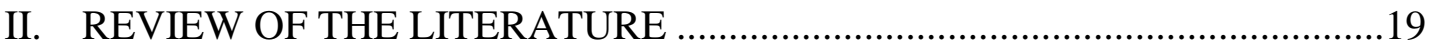

Sexual Identity Development Models..............................................................19

Shared Themes Across Models.......................................................................26

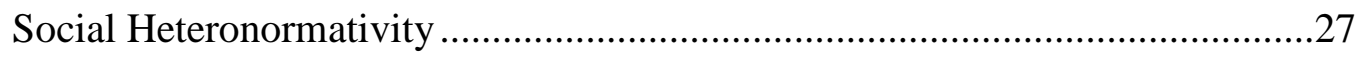

Effects of Social Heteronormativity ................................................................3

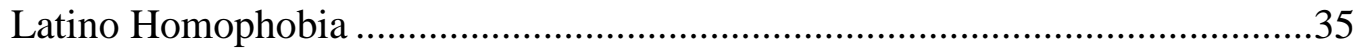

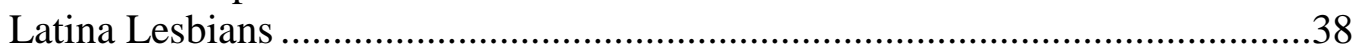

Paucity of Research on Latina Lesbian.............................................................42

Heteronormativity within Higher Education .....................................................43

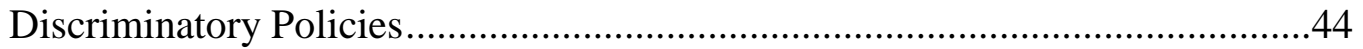

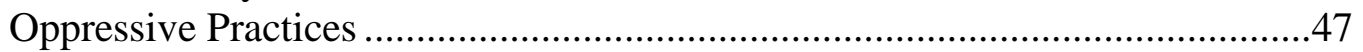

Heteronormativity at Hispanic-Serving Institutions .........................................50

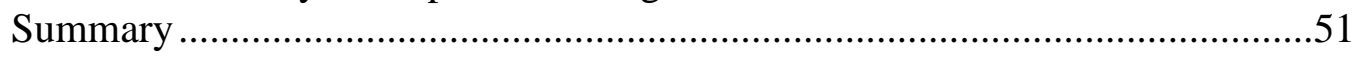

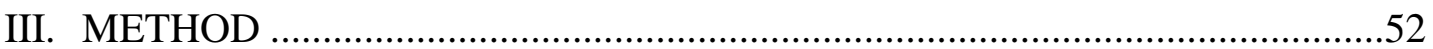

Purpose of the Study …………………………………...........................52

Research Questions ..................................................................................52

Researcher's Autobiography, Assumptions and Journal Process ........................53

Phenomenological Framework ………………………...............................59

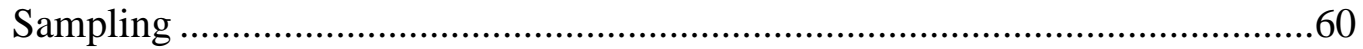

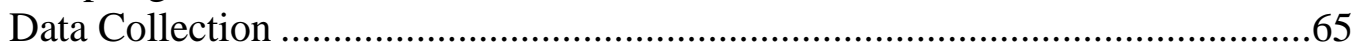

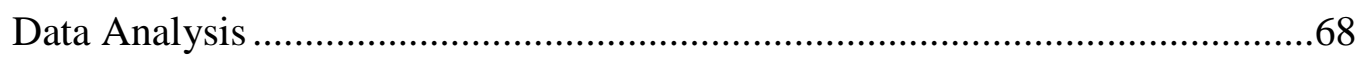

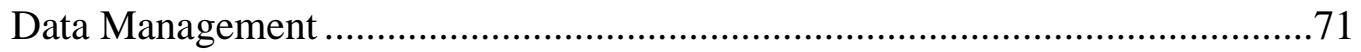

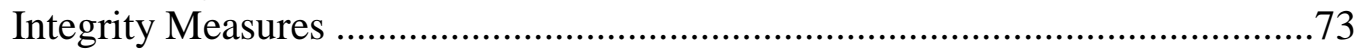

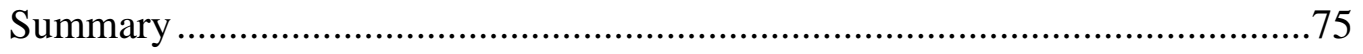

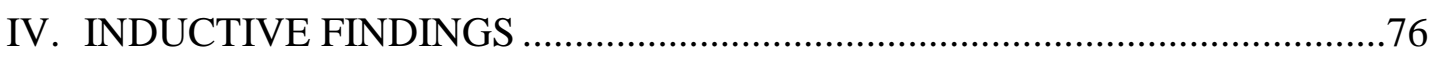

The Trifecta: Family, Religion and Gender Roles ...............................................76

The Paradox of Being Latina and Lesbian.........................................................89 


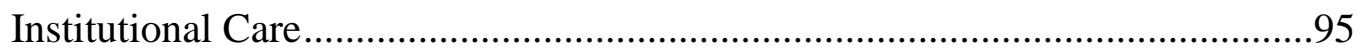

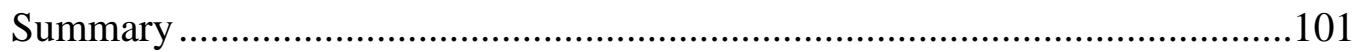

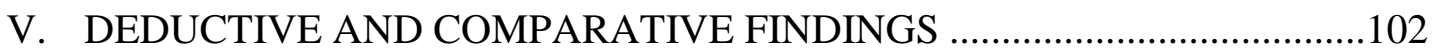

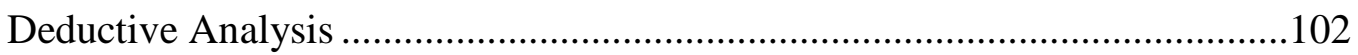

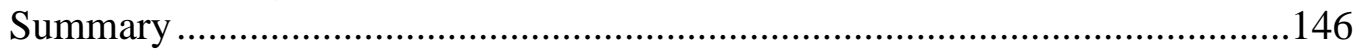

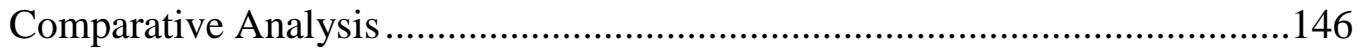

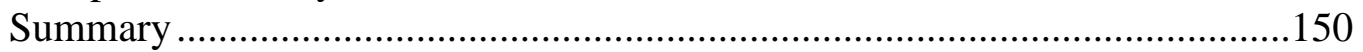

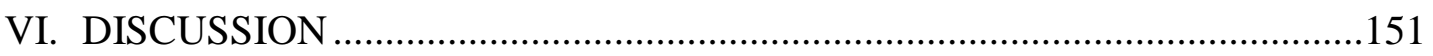

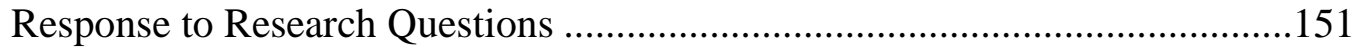

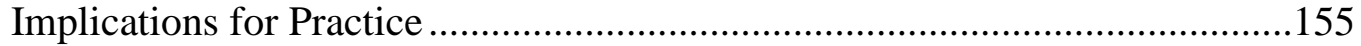

Recommendations for Future Research ......................................................162

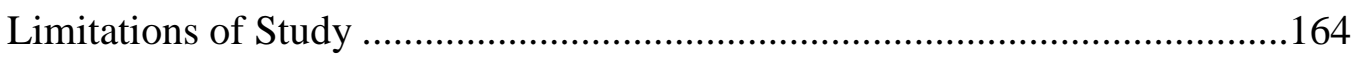

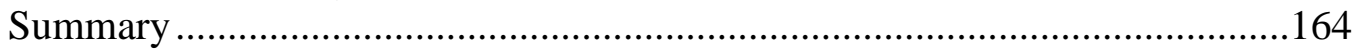

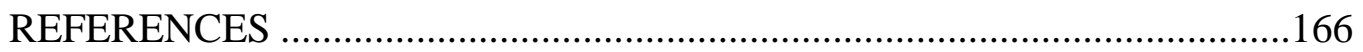

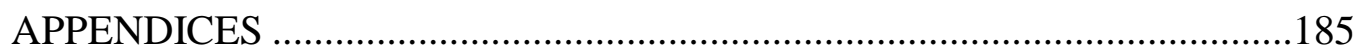

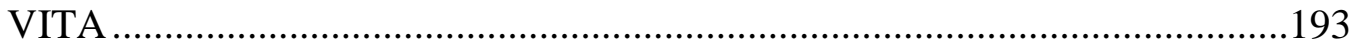




\section{CHAPTER I}

\section{INTRODUCTION}

Identity is not just a private, individual matter, but a complex negotiation between the person and society.

(Josselson, 1996, p.31)

The purpose of the phenomenological study was to gather insights into the experiences of Latina lesbian students and their sexual identity development at a predominately Hispanic-Serving Institution. Chapter I begins with the background of the problem, the statement of the problem, the purpose of the study, the research questions guiding the study, and the conceptual framework. Subsequently, the significance of the study, delimitations, and definition of terms are addressed.

\section{Background of the Problem}

Trying to construct a sexual minority identity in a heteronormative campus environment puts sexual minority students at risk of not succeeding in college and can negatively affect their sexual identity development (Abes \& Jones, 2004; Chickering \& Reisser, 1993; Cramer 2014; Rankin, Weber, Blumenfeld, \& Frazer, 2010; Rockman, 2013; Windmeyer, 2006). A sexual minority is someone who experiences prejudice, social oppression, and discrimination because of their sexual orientation or gender expression (Chung, 2001; Rocco, 2006), and encompasses all non-heterosexual individuals, which generally includes lesbian, gay, bisexual, transgender and queer individuals, also signified by the acronyms LGBT or LGBTQ. Heterosexuals are "individuals who are attracted to and love members of the opposite sex" (Sanlo, 1998, p. 414). Heteronormativity is the process through which social institutions and social policies reinforce the belief that human beings fall into the two distinct categories of 
male and female and that only opposites attract. It reinforces the dominant belief that only two sexes/genders exist in order to fulfill complementary roles, and that all intimate relationships ought to exist only between males and females (Dreyer, 2008; Queen, Farrell, \& Gupta, 2004), which leads to heterosexist behaviors in a normative society. Heterosexism is the assumption that everyone is heterosexual, and the belief that those who are heterosexual are inherently better than those of other sexual orientations (Hill, 2006). Heterosexism is further described as “...the societal/cultural, institutional, and individual beliefs and practices that assume that heterosexuality is the only natural, normal, acceptable sexual orientation” (Wall \& Evans, 2000, p. 169). Ultimately, a university's heteronormative environment can influence a sexual minority student's decision to come out or not come out (Rankin, et al., 2010; Rockman, 2013).

In heteronormative institutions, sexual minority students experience a higher rate of psychological stress because of the homophobia they encounter (Al-Timimi, 2003; Cramer, 2014; DiFluvio, 2011; Moradi, Worthington, \& Fasinger, 2009). Heteronormativity is the assumption that heterosexuality is the only normal sexual orientation and the irrational fear of sexual minorities is often expressed as homophobia. Homophobia is a term that expresses the hostility and discrimination sexual minorities experience by individuals who have a fear of homosexuality (Birden, 2005; Sanlo, 1998). These negative experiences leave sexual minority students overwhelmed when attempting to negotiate the development of their own sexual identity (Al-Timimi, 2003; Herek, 2004). 
Heteronormativity enhances homophobia, which can lead to individuals exhibiting negative behaviors towards sexual minorities (Cramer, 2014; Dryer, 2008). Extreme homophobia can lead individuals to commit hate crimes (Alden, \& Parker, 2005; Herek, 2009). In 2011, the FBI Hate Crimes Statistics data revealed 6,222 reported hate crimes in the United States. Of these crimes, $20.8 \%(1,306)$ resulted from sexual orientation bias and 9.3\% (579) took place at schools or colleges (U.S. Department of Justice, 2012). Examples of these hate crimes include numerous homophobic murders and suicides of college students such as the 2000 murder of 19 year-old gay Gallaudet University student, Eric Plunkett; in 2008, the murder of 19 year-old gay student from Pace University, Kevin Micheal Pravia; and in the Fall of 2010, Tyler Clementi, an 18 year-old freshman at Rutgers University who ended his life after learning that his roommate streamed video footage of Tyler being intimate with another male in his residence hall room (Rothaus, 2010). Within the past six years, instances of homophobic suicides and murders have included Raymond Chase, a 19 year-old student at Johnson and Wales, who in 2010, hung himself in his residence hall room; in 2011, Robert Champion, an openly gay 26-year-old drum major from Florida A\&M University was beaten to death while being hazed by his fellow band members; and in July 2013, 17 year-old Carlos Vigil of New Mexico, committed suicide after years of being bullied for being gay (Carter, 2013; Huffington, 2013). According to The National Education Policy Center, bullying has become so prevalent that more than $85 \%$ of sexual minorities have been harassed in school and $20 \%$ have been physically attacked. School located bullying has severe implications in the lives of sexual minority students (O'Malley Olsen, Kann, Vivolo-Kantor, Kinchen, \& 
McManus, 2014). The homophobic aggression directed towards sexual minorities has led to suicide rates that are three to four times higher than their heterosexual peers (Biegel \& Kuehl, 2010).

For many sexual minorities, college is a time when they begin exploring their sexual identity and engage in the coming-out process, in which one understands their sexual identity is not heterosexual and discloses to others their non-heterosexual identity (Hill \& Grace, 2009, p.87). The identity development of an individual who is a sexual minority has been categorized as being more complex than other psychosocial identities (D’Augelli, 1990; Rankin et al., 2010; Wall \& Evans, 2000). A salient example of the complexity can be seen when one compares the identity development of heterosexual college students to that of sexual minority college students. Heterosexual college students tend to progress through a series of identity development tasks with appropriate levels of challenge and support (Chickering \& Reisser, 1993). However, for sexual minority college students, the challenges of coping with alienation, isolation, discrimination, self-esteem, disclosure, and establishing same-sex relationships puts sexual minority students at a disadvantage when compared to their heterosexual counter parts (Dugan \& Yurman, 2011; Rankin, et al., 2010; Sanlo, 2004). Having little or no support with these challenges in college, a sexual minority student's identity development is inhibited, which can ultimately lead to dissatisfaction with their experiences, frustration, depression, mental health issues, substance abuse and suicide (Marshal, Dietz, Friedman, Stall, Smith, McGinley, \& Brent, 2011; Pride, 2010; Reason \& Rankin, 2006). On campus, sexual minority students experience harassment and discrimination, fear for their physical safety, and they conceal their sexual orientation to avoid 
mistreatment and abuse (Brown, Clark, Gortmaker, \& Robinson-Keilig, 2004; DiFluvio, 2011; Rankin, 2003). In 2010, Campus Pride issued a national report on the State of Higher Education for LGBT people that confirmed incidents of harassment and discrimination towards sexual minorities on college campuses are continuing to rise at alarming rates. The study indicates that $23 \%$ of sexual minority staff, faculty, and students reported experiencing harassment and $39 \%$ of transgender students, faculty, \& staff reported experiencing overt and blatant types of harassment on campus. The survey was administered to over 5,000 students, staff, administrators and faculty at various institutions of higher education across the nation. Campus Pride's findings sustain the need for college student professionals to implement new approaches, practices and policies to bring about positive changes on campus for sexual minorities. The widespread negative attitudes, harassment, and violence directed toward sexual minorities on campuses not only influence their sexual identity development and emotional wellbeing but also their academic success and persistence (Eyermann \& Sanlo, 2002; Rankin et al., 2010; Teman \& Lahman, 2010; Wall \& Evans, 2000).

These issues are exacerbated by colleges' inability to effectively meet and support the cognitive, affective and health needs of sexual minority students on their campuses (Cress, 1999; Renn, 2010; Walls et al., 2010). Sexual minority students are unable to focus on their academic studies as a consequence of feeling isolated, fear, and anger (Stage \& Downey, 1999; Noack, 2004; Woodford et al., 2013). Lesbian, Gay, Bisexual and Transgender students are a marginalized group and are often confronted with the harsh realities of having little or no established academic, social support groups or programs on campus. The lack of intervention from heteronormative institutions leads 
students to further withdraw from the campus community, disconnecting from academic and social involvement, leading ultimately to dropout (Flannery \& Quinn-Leering, 2000; Rockman, 2013). The lack of response of colleges and universities when addressing the issues impacting this marginalized group creates a hostile environment, negatively impacting the students' abilities to learn as well as their personal development and their lives (Rankin, 2006; Rankin et al., 2010; Renn, 2010).

Much of the current literature on sexual minorities focuses on White, middle class males at predominately White institutions (Rankin, et al., 2010; Sanlo, 2004). Little has been done in documenting the experience of sexual minorities of color at Historically Black institutions (Tyre, 2009; Renn, 2012), and Latina lesbians have not been examined at all within the context of a Hispanic-Serving institution (HSI) (Espín 1993; PeñaTalamantes, 2013). An HSI is defined as a non-profit, degree-granting institution with full-time equivalent undergraduate enrollments of at least $25 \%$ Hispanic students (Onorato, 2010; Owles, 2009; Nora \& Crisp, 2009). Documenting the experiences of Latina lesbians at an HSI is important given the rapidly growing Latino population within the United States and the marginalization Latina lesbians often experience within Latino communities (Espín, 2012; Torres \& Pertusa, 2003).

According to the latest United States census data, $16 \%$ of the U.S. population (almost 50 million) are of Latino or Hispanic origin (U.S. Census Bureau Report, 2011). Hispanics accounted for over half of the population growth in the United States between 2000 and 2011, making it the fastest growing minority group in the nation (Ennis, RiosVargas, \& Albert, 2011; Humes, Jones, \& Ramirez, 2011; U.S. Census Bureau Report, May 2011). It is important to note that although the term Hispanic includes individuals 
with a shared language, there continues to be ongoing debate over how this diverse group is classified. The classification of Hispanic was a term developed by the United States government to classify people who had a shared common Spanish language. It does not recognize the differences in values, experiences, gender, ethnicity, sexual orientation or cultures of the group (Onorato, 2010; Owles, 2009). Subsequently, the terms Latino and Latina have been used in order to remove this government-imposed definition typically referring to Spanish origin, but to also capture the variety within the Latino community aside from having the common language (Gonzalez \& Gandara, 2005; Rood, 2008).

In Miami, Florida, the Latino culture incorporates a variety of different countries. According to the 2011 U.S. Census, 65\% of Miami-Dade County's population is of Latino descent. Although these countries have differing cultural norms and dialects, there are certain cultural standards across them on the issue of sexual orientation (Agronick, O'Donnell, Stueve, Doval, Dugan, \& Vargo, 2004; Greene, 1994; Morals, 1992, Rosario, Schrimshaw, \& Hunter, 2004). The intolerance and homophobia exhibited in the Latino culture toward sexual minorities is considered to be more intense than that exhibited in the dominant Anglo culture (Greene, 1994; Encarnación, 2011; Kahn, 2013; Severson et al., 2013).

Homophobia and intolerance within the Latino culture stems from the stigma associated with homosexuality and is strongly related to perceived notions of religious and social constructions of gender and sexuality (Ellison, Acevedo, \& Ramos-Wada, 2011; Encarnación, 2011; Ryan, Huebner, Diaz, \& Sanchez,2009). Additionally, a collective Latino value and constraint concerning the makeup of the family unit (that it consists of one man, one woman, and children), coupled with religious views that 
homosexuality is wrong, situates Latina lesbians as a marginalized and oppressed group (Agronick et al., 2004; Sandfort, Melendez, \& Diaz, 2013; Chaturvedi, 2014).

Within Latino families, LGBT people face much discrimination. Latina lesbians oftentimes face discrimination, abuse, and even rejection from their loved ones when attempting to integrate who they are culturally with their identity as lesbians (Espín, 2012; García \& Torres, 2009; Peña-Talamantes, 2013). Aside from the marginalization Latina lesbians face among different Latino communities, they also fall into a segment of the population that has not been examined closely within the context of higher education (Abes \& Jones, 2004; Espín 1993; Peña-Talamantes, 2013; Torres \& Pertusa, 2003).

There are currently 435 Hispanic-Serving Institutions (HSI) in the United States (Hispanic Association of College \& Universities, 2016). With the increasing Latino population nationally, the growing number of Latino students attending colleges, and universities, and the homophobia within the Latino community, and it is critical to understand the experiences of Latina lesbian students in Hispanic-serving institutions to inform best practices. Within this study the experiences of 15 Latina lesbians at an HSI, the elements that perpetuate heteronormativity and oppression towards Latina lesbians among the Latino community in college was examined.

\section{Problem Statement}

Identity development models have been used in higher education to describe and understand the development of college students. These models help practitioners understand how students go about discovering who they are in the context of their experiences and environment, while assisting them in achieving their maximum potential to succeed in college and in life (Jones \& Abes, 2013; Torres, Jones, \& Renn, 2009). 
Research concerning students of color and women indicates that environmental factors such as a positive psychological climate, (i.e., faculty, staff and students' positive behaviors, attitudes, perceptions and openness towards students of color and females,) and behavioral climate (i.e., the interactions between different racial and ethnic groups on campus) as well as having campus support systems (i.e., support centers and inclusive non-discrimination policies) positively impact student identity development and success in higher education (Mayhew, Grunwald, \& Dey, 2006; Pascarella \& Terenzini, 2005; Turner, 2004). University and college administrators have a responsibility to provide all college students with a safe environment to learn, free of discrimination and harassment to experiment with their identity development (McEwen, 2003; Winston, Creamer, \& Miller, 2001). Although there is currently a body of literature on sexual minorities' identity development at traditionally White institutions, the experiences of Latina lesbians and their identity development at HSIs is absent from the current literature (Rankin, Sanlo, \& Schoenberg, 2002; Renn, 2012; Tyre, 2009).

Given the rapid growth of the Latino population in the United States (U.S. Census Bureau, 2011; Ennis et al., 2011) the marginalization experienced by Latina lesbians, and the pervasive homophobic and heterosexist climate within Latino communities (Agronick et al., 2004; Green, 1994; Ryan et al., 2009; Encarnación, 2011), this study provides critical insights for best practices in higher education.

In analyzing the narratives of Latina lesbians at an HSI and what is most central to their sexual identity development and experience, this research informs future practitioners, specifically those at HSIs, in order to help them create welcoming and safe campus environments for Latina lesbian students. Additionally, this study has begun to 
address the paucity of literature on Latina lesbian's sexual identity development in higher education.

\section{Purpose of the Study}

The purpose of this phenomenological study was to gather insights into the experiences of Latina lesbian students and their sexual identity development at a predominately Hispanic-serving institution (HSI).

\section{Research Questions}

The phenomenon of interest was the unique experiences of Latina lesbian students at an HSI, and their perceived sexual identity development. The primary research question that guided this study was: How do Latina lesbian students describe their experiences and their perceived sexual identity development at a Hispanic-serving institution? The following subsidiary questions also informed the study:

1. From the perspectives of these students, which college experiences have been related to their sexual identity development?

2. From the perspectives of these students, what cultural factors have influenced their sexual identity development?

3. From the perspectives of these students, what college factors have influenced their sexual identity development?

4. From the perspective of these students, what would make the LGBTQ experience at an HSI better for Latina lesbians?

\section{Conceptual Framework}

Higher education practitioners utilize a variety of different theories and models to aid in the student development process. Identity development models are of particular 
importance because they help make sense of students' experiences (Evans, Forney, Guido, Patton, \& Renn, 2010). As a result of their own identities, students create a lens through which they filter their college experiences to make meaning on various levels (McEwens, 2003; Sanlo, 1998; Torres, Jones, \& Renn, 2009). Identity development models tend to focus on students' cognitive, affective, and behavioral development. These models examine how students reason and make sense of their experiences on an intellectual level, a psychosocial level, and how they develop on emotional, interpersonal and ethical dimensions (Cress 1995; Kuh, Kinzie, Schuh, \& Whitt, 2010). The sexual identity models that were examined in order to develop the conceptual framework for this study are discussed below.

\section{Sexual Identity Development}

Models that look at the identity development of sexual minorities are referred to as sexual identity development models. These models have been utilized in higher education for over 30 years and were adopted by higher education professionals in an effort to best serve sexual minority students on campus (Bilodeau \& Renn, 2004). Sexual identity development models have varied in perspectives ranging from staged linear theories (Cass, 1979), to life-span and diversity theories that rely on one's social context and personal experiences (D’Augelli, 1994; Marine, 2011).

While there are various types of sexual identity models available to explore the development experiences of sexual minority college students, there are four basic tenets that are consistent across sexual identity development models. They include: (a) alienation "the experience of seeing oneself as different", (b) social exclusion "not fitting into the heteronormative majority", (c) disclosure, also known as "Coming out" or the 
need to announce oneself as a sexual minority, and (d) self-acceptance of a nonheterosexual identity (Cass, 1979; Bilodeau \& Renn, 2004; Henrickson, 2013). These four tenets, derived from the various types of sexual identity models mentioned previously, will be used to support and inform this study's conceptual framework.

\section{Significance of the Study}

According to the seminal report of the American Council on Education of 1937, “The Student Personnel Point of View," a student affairs professional's main purpose is the education of the whole student. Educating the student is inclusive of both their cognitive and affective development. This report set out the purpose of student affairs in relationship to the work done with students. Despite the fact that the student affairs professional purpose is to educate the whole student, sexual minorities still remain virtually invisible (Rankin et. al 2010; Tetreault, Fette, \& Meidlinger, 2013).

Within academic affairs currently there are no student academic success or retention models available for sexual minorities. Schools that infuse LGBT studies into their academic curriculum, while growing, are still limited to 40 institutions in the United States (Rankin, et. al., 2010). The existing research only addresses the concerns over the discrimination and fear that sexual minority students experience regarding their physical safety on campus (Brown, et al., 2005; Rankin, 2003; Rankin, et al., 2010).

There is a significant gap in the research and literature that describes the experience of Latina lesbian students on an HSI campus from both a student affairs and academic affairs point of view. The contribution of this research may assist professionals in both student affairs and academic affairs in understanding the needs of Latina lesbians at HSIs in order to create affirming non-heteronormative places and practices on campus. 
Information gained from this study could further assist higher education academic administrators and student affairs practitioners in developing best practices and policies to better meet the needs of Latina lesbian students. The study could also have implications on future research and services offered to Latina lesbians to better assist them with their overall cognitive and affective well-being on campus.

\section{Delimitations}

This study was limited to the 15 Latina lesbians attending one urban, public HSI located in south Florida, where 67\% of the total enrollment is comprised of Hispanic students. This study was further delimited to undergraduate Latina lesbian students between the ages of 18-24 who attended an institution located in Miami-Dade County where $58.5 \%$ of the 2.4 million residents speak Spanish.

\section{Definition of Terms}

In this next section, the central concepts of the study are defined in order to provide clarity for the reader.

\section{Campus Climate}

The overall actions, behaviors, policies and attitudes of an institution which create a formal and informal environment; a function of culture and based on the members' values and beliefs (Noack, 2004; Rankin \& Reason, 2008).

\section{Closet}

A term used to describe the hiding of one's sexual orientation (Sanlo, 1998).

\section{Coming Out/Out of the Closet/Being Out}

Denotes that one is declaring or has declared openly that one is bisexual, gay, lesbian, queer or transgender. "It is the recognition and disclosure of one's sexual 
minority identity to others. In contrast, to 'stay in the closet' is to hide or deny one's gender identity or sexual orientation either from one's self or from others" (Bayly, 2007, p.18).

\section{Familismo}

A Latino cultural value, refers to the importance of strong family loyalty, closeness, and getting along with and contributing to the wellbeing of the nuclear family, extended family, and kinship networks (Ayón, Marsiglia, \& Bermudez-Parsai, 2010, p.3).

\section{Gender Expression}

The physical manifestation of one's gender identity, usually expressed through clothing, mannerisms and chosen name. Gender expression matches one's gender identity rather than the biological sex (Fausto-Sterling, 2000).

\section{Gender Identity}

Is socially constructed. It is an individual's internal sense of being male or female which may or may not match the biological sex (Wall \& Evans 2001, p.169)

\section{Gender Non- Conforming}

An individual whose behavior or appearance does not conform to prevailing cultural and social expectations about what is acceptable or appropriate to their gender role (Yes Institute, 2015).

\section{Gender Role}

To interact within society as a member of a specific gender (i.e. man or woman) by following often arbitrary rules assigned by society that define what clothes, behaviors, thoughts, feelings, relationships, etc. are considered appropriate and inappropriate for members of each sex. (Bayly, 2007, p.18) 


\section{Heteronormativity}

The processes through which social institutions and social policies reinforce the belief that human beings fall into two distinct sex/gender categories: male/man and female/woman. This belief (or ideology) produces a correlative belief that those two sexes/genders exist in order to fulfill complementary roles, i.e., that all intimate relationships ought to exist only between males/men and females/women (Queen et. al., 2004, p.3).

\section{Heteropatriarchy}

The combination of male patriarchal and heterosexual dominance essentially describing the severe sex and gender bias prevalent in society (Torres, \& Pertusa, 2003).

\section{Heterosexism}

The assumption that everyone is heterosexual, and the belief that those who are heterosexual are inherently better than those of other orientations. "The societal/cultural, institutional, and individual beliefs and practices that assume that heterosexuality is the only natural, normal, acceptable sexual orientation” (Wall \& Evans, 2000, p.169).

\section{Homophobia}

Practices that support hostility and discrimination towards sexual minorities (Queen et. al, 2004). Negative feelings or attitudes towards non-heterosexual behavior, identity, relationships and community, can lead to homophobic behavior and is the root of the discrimination experienced by many lesbian, gay, bisexual and transgender (LGBT) people. "Fear of homosexuality; the fear of feelings of love for members of one's own sex and therefore the hatred of those feelings in others" (Sanlo, 1998, p. 414). 


\section{Internalized Homophobia}

The stigma, shame, or self-hatred experienced by an individual in response to the individual's own feelings of attraction towards individuals of the same sex (Herek, 2004).

\section{Intersectionality}

The study of overlapping or intersecting social identities and related systems of oppression, domination, or discrimination. Intersectionality holds that the classical conceptualizations of oppression within society, (i.e., racism, sexism, classism, ableism, homophobia, transphobia, xenophobia and belief-based bigotry) do not act independently of each other. Instead, these forms of oppression interrelate, creating a system of oppression that reflects the "intersection" of multiple forms of discrimination (Knudsen, 2006).

\section{Latina Lesbian}

Latina lesbian is a complex cultural and political identity for women who share historical commonalities, ethnic and sexual identity, and who face discrimination as women, Latinas, and lesbians (Pickett, 2013).

\section{Marianismo}

A traditional gender code of behavior for Latinas, rooted in Catholicism. According to this code, the female gender ideal is embodied by the Virgin Mary and encompasses sacred duty to family, beautiful, subordination to men, subservience, selflessness, self-renouncement, self-sacrifice, chastity before marriage, sexual passivity after marriage, and erotic repression (Jezzini, Guzman, \& Grayshield, 2008, p.4). 


\section{Machismo}

A strong sense of masculinity within the Latino culture which places value on paternalism, aggression, systematic subordination of women, fetishism of women's bodies, and idolization of their reproductive and nurturing capacities, coupled with a rejection of homosexuality (Sternberg, 2000, p.91).

\section{Pansexual}

Someone who is attracted to females, males, and individuals of other genders (Kumashiro, 2001, p.3).

\section{Sexual Identity}

One's personal sense of one's sexual orientation. The names individuals use to refer to their sexual orientation. I.e. a male who is sexual attracted to another male might use the term gay to define their sexual identity. (Queen et. al., 2004, p.187).

\section{Sexual Identity Development}

Defined as the process by which an individual encounters an awareness and acceptance of the individual's sexual orientation (McEwen, 2003).

\section{Sexual Minority}

A subset of the population that experiences prejudice, social oppression, and discrimination based on sexual orientation or gender expression. Sexual minority encompasses all non-heterosexual individuals a subset that generally includes lesbian, gay, bisexual, transgender, transsexual and queer individuals, which is also defined using the acronyms LGBT or LGBTQ (Chung, 2001; Rocco \& Gallagher, 2006; Rocco, Landorf, \& Delgado, 2009). 


\section{Sexual Orientation}

"The desire for intimate emotional and sexual relationships with people of the same gender (lesbian or gay), the other gender (heterosexual) or either gender (bisexual)" (Wall \& Evans, 2000, p. 169).

\section{Stereotype}

Stereotypes are individual beliefs and attitudes that are established and perpetuated based on secondhand information (Sue \& Sue, 2003).

\section{Summary}

In this chapter the researcher introduced the study including the background to the study, the problem statement, the research questions, conceptual framework, significance of the study, delimitations, and definition of terms. In Chapter 2, a review of the literature relevant to Latina lesbians in higher education is shared. In Chapter 3 the design and procedures that were implemented in the study are described. Both Chapters 4 and 5 present the data analysis and the findings of the study. Chapter 6 provides conclusions and recommendations for future practice and research. 


\section{CHAPTER II}

\section{REVIEW OF THE LITERATURE}

The purpose of this study is to gather insights into the experiences of Latina lesbian students and their sexual identity development at a predominantly HispanicServing Institution (HSI). This chapter is based on the background to the study identified in Chapter 1 and is an overview of the literature that informed this study. It outlines the current research and literature on sexual identity development models in higher education, heteronormativity and the issues sexual minorities face today, heteronormativity in higher education, Latino homophobia and Latina lesbians. This chapter provides the reader with the context and language used in this study.

Knowledge regarding sexual identity development models within higher education is shared, followed by an overview on heteronormativity and the issues sexual minorities face systemically and within the Latino community today is shared including: (a) insufficient legal protection, (b) religious oppression, (c) family rejection, (d) social micro-aggressions and (e) the effects of heteronormativity. Information on Latino homophobia, and Latina lesbians is also shared. Finally, heteronormativity in higher education is reviewed looking specifically at the discriminatory practices, oppressive policies and heteronormativity in Hispanic-serving institutions.

\section{Sexual Identity Development Models}

The literature in this section includes foundational knowledge regarding sexual identity development models within higher education. Sexual identity development is defined as the process in which a person encounters an awareness and acceptance of their 
sexual orientation (McEwen, 2003; Meyer \& Schwitzer, 1999; Morgan, 2013). This section discusses sexual identity development using the three types of models most prevalent within Higher Education: stage models, life span models and diversity models. An overview and critique of each model is presented. Lastly, major themes prevalent in the literature on various models are shared as a conceptual framework for this study.

Higher education professionals have adopted sexual identity development models in an effort to better meet the needs and serve sexual minority students on campus (Bilodeau \& Renn, 2004; Sanlo, 2004). Psychosocial identity development models have been utilized in higher education for more than 30 years and focus on helping sexual minorities resolve the internal conflict experienced as it relates to their sexual identity formation The perspective in these models range from stage linear theories, diversity perspectives, to life-span theories that rely on one's social context and personal experiences (Marine, 2011; Evans et al., 2010).

\section{Stage Models}

Stage models such as those by Troiden, Fassinger, and Savin-Williams, were among the first models created to examine the identity development of sexual minorities. These earlier models focus on a linear advancement moving from sexual orientation awareness, to immersion and finally sexual orientation integration (Bilodeau \& Renn, 2005). Among these stage models, Vivian Cass's (1979) Homosexual Identity Formation model provided a foundation for sexual minorities' identity development models today. Cass's model includes both a cognitive component, reflecting how an individual views themselves and an affective component, indicating how they feel about their own and other's perceptions (Evans et al. 2010). The homosexual identity formation model 
(Cass, 1979) is based on the framework of interpersonal congruence theory and has been utilized mostly within higher education and sexual minority identity development research.

Cass's model proposes that individuals transition thorough a series of six stages, beginning with identity confusion about their sexuality and ending with identity integration. In this model individuals are seeking congruence between their behaviors and their perception of themselves and their perceptions of others. Movement through these stages is achieved when the incongruence between behaviors and current sense of identity is repaired, resulting in the reassignment of one's sexual identity over stages. Progress through these stages can be stopped at any stage through a condition labeled "identity foreclosure," where the incongruence is rectified by retreat from identity growth, denying identity or further progress within the development. Foreclosure of these stages can lead to individuals minimizing or hiding their feelings which can have a negative effect on their emotional and mental health. All six stages and their unique attributes are adapted from Evans, Student Development in College: theory, research and practice (2010) in Table 1 below:

Table 1

Cass Homosexual Identity Formation Model

\begin{tabular}{lll}
$\begin{array}{l}\text { Specific } \\
\text { Stage }\end{array}$ & Attributes of Stage & Focus of Stage \\
\hline Pre-stage & $\begin{array}{l}\text { Individuals perceive themselves as } \\
\text { heterosexual. }\end{array}$ & $\begin{array}{l}\text { Recognize this is the } \\
\text { preferred state of being in } \\
\text { a heteronormative society. }\end{array}$
\end{tabular}




\begin{tabular}{|c|c|c|}
\hline $\begin{array}{l}\text { Specific } \\
\text { Stage }\end{array}$ & Attributes of Stage & Focus of Stage \\
\hline $\begin{array}{l}\text { Identity } \\
\text { Confusion }\end{array}$ & $\begin{array}{l}\text { Individual first aware that their } \\
\text { behavior or feeling could be labeled as } \\
\text { gay or lesbian. Confusion, curiosity and } \\
\text { anxiety accompany this stage. }\end{array}$ & $\begin{array}{l}\text { Reducing discomfort. } \\
\text { Accepts the possibility } \\
\text { they are gay or lesbian. }\end{array}$ \\
\hline $\begin{array}{l}\text { Identity } \\
\text { Comparison }\end{array}$ & $\begin{array}{l}\text { Determine how to manage the social } \\
\text { alienation that accompanies a non- } \\
\text { heterosexual identity. Reactions range } \\
\text { from intense feelings of pain and } \\
\text { ostracism to relief that previously } \\
\text { unexplained feelings of difference are } \\
\text { now clear. }\end{array}$ & $\begin{array}{l}\text { Have accepted the } \\
\text { possibility they might be } \\
\text { gay or lesbian. }\end{array}$ \\
\hline $\begin{array}{l}\text { Identity } \\
\text { Tolerance }\end{array}$ & $\begin{array}{l}\text { Seek out other gay and lesbians to } \\
\text { reduce their feeling of isolation. Nature } \\
\text { of this contact can determine how } \\
\text { individuals feel about themselves and } \\
\text { their new identity. }\end{array}$ & $\begin{array}{l}\text { Develops a more } \\
\text { favorable sense of self and } \\
\text { a greater commitment to a } \\
\text { sexual minority self- } \\
\text { identity. }\end{array}$ \\
\hline $\begin{array}{l}\text { Identity } \\
\text { Acceptance }\end{array}$ & $\begin{array}{l}\text { Increased contact with other gay and/or } \\
\text { lesbian people evolving into } \\
\text { friendships. Lesbian and gay people are } \\
\text { evaluated more positively and are } \\
\text { accepted rather than tolerated. }\end{array}$ & $\begin{array}{l}\text { Questions of "Who am I?" } \\
\text { and "Where do I belong?" } \\
\text { have been answered. }\end{array}$ \\
\hline $\begin{array}{l}\text { Identity } \\
\text { Pride }\end{array}$ & $\begin{array}{l}\text { The individual develops an awareness } \\
\text { of the incongruity that exists between } \\
\text { the person's increasingly positive } \\
\text { concept of self as lesbian or gay and an } \\
\text { awareness of society's rejection of this } \\
\text { orientation. }\end{array}$ & $\begin{array}{l}\text { Exhibit intense anger at } \\
\text { heterosexuals. } \\
\text { Discloses identity to more } \\
\text { individuals and is } \\
\text { immersed in the gay or } \\
\text { lesbian subculture. }\end{array}$ \\
\hline $\begin{array}{l}\text { Identity } \\
\text { Synthesis }\end{array}$ & $\begin{array}{l}\text { Still maintains a deep sense of pride but } \\
\text { now perceive less of a dichotomy } \\
\text { between the heterosexual and gay and } \\
\text { lesbian communities. }\end{array}$ & $\begin{array}{l}\text { A lesbian or gay identity } \\
\text { becomes an integral and } \\
\text { integrated aspect of the } \\
\text { individual's complete } \\
\text { personality structure. }\end{array}$ \\
\hline
\end{tabular}

Stage models have been criticized for not describing the full development of individuals. They are limited in both gender and race and do not represent all sexual 
minority individuals. Much of the research collected in these models has been limited to White males. The linear framework has been criticized given that individuals may not move along the expected linear route to reach a desired outcome or endpoint. These models imply that identity is achieved, rather than something that is constantly negotiated and reconstructed. It is worth noting that although stage models may not adequately represent the intricacy of all sexual minorities' identity development, their prevalence in the literature suggests there is some overall relevancy making them useful in understanding the development of sexual minorities. These stage models have been easily understood and have been applied on university campuses (Bilodeau \& Renn, 2004; Sanlo, 2004).

\section{Life Span and Other Nonlinear Models}

Another type of model within the genre of sexual orientation identity development are life span or nonlinear models introduced by such theorists as D'Augelli (1994), Fox (2000) and Rhoads (1995). These models base sexual orientation identity development on different processes that occur over one's life regardless of stage or time. These processes generally take environmental and various social cultural behaviors into account (D’Augelli, 1994; Fox, 2003; Roads 1994). Nonlinear models have been seen as being more fluid and broad than stage models, with the processes occurring at any time and sometimes simultaneously.

D'Augelli's model illustrates a lifespan approach with six independent processes that are not in any particular order or stage. The processes include: Exiting heterosexuality, developing a personal sexual minority identity, developing a sexual minority social identity, becoming a sexual minority offspring, developing a sexual 
minority intimacy status and entering a sexual minority community. The model has been adapted from Evans et al., Student Development in College: Theory, Research and Practice (2010). (See table 2).

Table 2

D’Augelli's Model of Lesbian, Gay, and Bisexual Identity Development

\begin{tabular}{|c|c|}
\hline Specific Process & Attributes of Process \\
\hline $\begin{array}{l}\text { Exiting heterosexual } \\
\text { identity }\end{array}$ & $\begin{array}{l}\text { Recognition that one's feelings and attractions are not } \\
\text { consistent with the sexual majority and disclosing to others } \\
\text { that one is a sexual minority. }\end{array}$ \\
\hline $\begin{array}{l}\text { Developing a } \\
\text { personal } \\
\text { lesbian/gay/bisexual } \\
\text { identity status }\end{array}$ & $\begin{array}{l}\text { One challenges internalized myths and stereotypes about } \\
\text { what it means to be a sexual minority. Developing a } \\
\text { personal identity status is done in relationship with others } \\
\text { who can confirm ideas about what it means to be a sexual } \\
\text { minority. }\end{array}$ \\
\hline $\begin{array}{l}\text { Developing a } \\
\text { lesbian/gay/bisexual } \\
\text { social identity }\end{array}$ & $\begin{array}{l}\text { Developing a network of people who know and accept } \\
\text { one's sexual orientation. Individuals' reactions may change } \\
\text { over time and with changing circumstances. }\end{array}$ \\
\hline $\begin{array}{l}\text { Becoming a } \\
\text { lesbian/gay/bisexual } \\
\text { offspring }\end{array}$ & $\begin{array}{l}\text { Disclosing one's identity to parents and redefining the } \\
\text { relationship. Establishing a positive relationship with } \\
\text { parents takes time but is possible with education. This } \\
\text { developmental process is particularly troublesome for many } \\
\text { college students who depend on their parents for financial } \\
\text { and emotional support. }\end{array}$ \\
\hline $\begin{array}{l}\text { Developing a } \\
\text { lesbian/gay/bisexual } \\
\text { intimacy status }\end{array}$ & $\begin{array}{l}\text { This is more complex than achieving an intimate } \\
\text { heterosexual relationship because of the invisibility of } \\
\text { sexual minority couples in society. "The lack of cultural } \\
\text { scripts directly applicable to lesbian/gay/bisexual people } \\
\text { leads to ambiguity and uncertainty, but it also forces the } \\
\text { emergence of personal, couple-specific, and } \\
\text { community norms, which should be more personally } \\
\text { adaptive" (D'Augelli, 1994) }\end{array}$ \\
\hline $\begin{array}{l}\text { Entering a } \\
\text { lesbian/gay/bisexual } \\
\text { community }\end{array}$ & $\begin{array}{l}\text { Creating various commitments to social and political } \\
\text { actions. Entering this process can create great risks, such as } \\
\text { losing one's home or employment. Some individuals } \\
\text { choose to not make this commitment. }\end{array}$ \\
\hline
\end{tabular}


One of the major criticisms of these life span models has been that the sample sizes have been limited. Additionally, much of the research has been of an anecdotal nature with very little empirical data. While these models take into consideration environmental and various social cultural behaviors, another criticism is that they have been limited to traditionally White majority institutions.

\section{Diverse Perspectives Models}

The last category of models utilized in the formation of sexual identity, includes those that examine sexual identity development in comparison to other identities such as gender, race and culture. The works of McCarn-Fassinger (1996), Boykin (1996), Clare (1999), Diaz and Kosciw (2009), and Evans and Broido (2002) look at sexual identity development as it relates to the various identities of an individual such as class, spirituality, race, gender, and disability. These models have been instrumental in helping to bring about an understanding of sexual minorities in a multicultural context. McCarnFassinger's model provides an overview of a model that looks at the development of lesbian identity, and has been adapted in the following (see Table 3).

Table 3

Mccarn-Fassinger Lesbian Identity Development Model

\begin{tabular}{lll}
\hline \multicolumn{1}{c}{ Process } & \multicolumn{1}{c}{ Attributes } & \multicolumn{1}{c}{ Example } \\
\hline Awareness & $\begin{array}{l}\text { Individual becomes aware } \\
\text { of feeling or being } \\
\text { different }\end{array}$ & $\begin{array}{l}\text { Lesbian: "Ifeel pulled toward } \\
\text { women in ways that I don't } \\
\text { understand" }\end{array}$ \\
Exploration & $\begin{array}{l}\text { Individual explores } \\
\text { strong, erogenous feelings } \\
\text { towards same sex } \\
\text { individuals (or a particular } \\
\text { person of the same sex) }\end{array}$ & $\begin{array}{l}\text { Lesbian: } \\
\text { makes me think I'd like to be } \\
\text { sexual with a woman" }\end{array}$ \\
\hline
\end{tabular}




\begin{tabular}{lll}
\hline \multicolumn{1}{c}{ Process } & \multicolumn{1}{c}{ Attributes } & \multicolumn{1}{c}{ Example } \\
\hline $\begin{array}{l}\text { Deepening/ } \\
\text { Commitment }\end{array}$ & $\begin{array}{l}\text { Individual commits to } \\
\text { self-knowledge and self- } \\
\text { fulfillment as a sexual } \\
\text { minority. }\end{array}$ & $\begin{array}{l}\text { Lesbian: "I clearly feel more } \\
\text { intimate sexually and } \\
\text { emotionally with women than } \\
\text { with a man." }\end{array}$ \\
$\begin{array}{lll}\text { Internalization/ } \\
\text { Synthesis }\end{array}$ & $\begin{array}{l}\text { Individual Synthesis of } \\
\text { love for women or men, } \\
\text { sexual choices, into } \\
\text { overall identity. }\end{array}$ & $\begin{array}{l}\text { Lesbian } \text { "I alfilled by my relationships } \\
\text { with women." }\end{array}$ \\
& & \\
\hline
\end{tabular}

The criticism of these models is that they have fixed notions of the various social constructs. The assumption that there is a universal experience for sexual minorities within the various categories is limiting. An individual's experiences are not bound by their race, gender, class or any other personal identifier (Bilodeau \& Renn, 2004).

\section{Shared Themes Across Models}

While not one sexual identity development model may be applicable to all individuals, there are some factors that are consistent across the spectrum of all sexual identity development models. These themes tend to occur over a number of growth points and include: (a) alienation, (b) social exclusion, (c) disclosure to others, and (d) self-acceptance (Henrickson 2013; Henrickson \& Neville, 2012). Although there is no specific model being used in this study due to the various criticisms and limitations of the various types of models, a conceptual framework using these four factors will guide this study.

\section{Heteronormative Issues Faced Systemically and in the Latino Community}

In this section, a review of the literature on heteronormativity is provided as well as the issues sexual minorities face systemically and within the Latino community. The 
systemic issues include: insufficient legal protections, religious oppression, family rejection, and social micro-aggressions. Also shared are the effects of heteronormativity on sexual minorities including homelessness and alcohol and drug abuse.

\section{Social Heteronormativity}

In US society, heteronormativity is the prevailing view that heterosexuality is the most common and normal form of sexuality. Heteronormativity is the belief that human beings fall into two distinct categories, male and female, with specific roles that are reinforced within institutions and society. A heteronormative society typically has visible and hidden norms, which are viewed as normal only for males and others normal only for females (Queen et. al., 2004). Heterosexuality is the predominant paradigm which is constantly reinforced in society through laws, religion, images, and language.

Heteronormativity leads to the marginalization and isolation of sexual minorities.

Heteronormativity is the powerful social force that governs gender and sexuality and consistently perpetuates the inequality of sexual minorities (Human Rights Campaign, 2009; Grant et al., 2011).

\section{Insufficient Legal Protections}

While laws are changing for sexual minorities in the United States, the statistics regarding the discrimination and violence this group experiences daily illustrates how the current laws still provide insufficient protection for this population. In the 2012, Federal Bureau of Investigations Hate Crimes Report, $19.6 \%$ of the 5,790 reported hate crimes resulted from an individual's perceived sexual orientation. Sexual orientation bias incidents were the second most common hate crime in 2012 (U.S. Department of Justice, 2012). 
In 2009, the Mathew Shepard and James Byrd, Jr. Hate Crimes Prevention Act (HPCA) Public Law No. 111- 84, was made law (Human Rights Campaign, 2009). The HCPA gives the Department of Justice the power to investigate and prosecute biasmotivated violent crimes where someone has been targeted because of their actual or perceived race, color, religion, national origin, gender, sexual orientation, gender identity or disability.

There have been significant strides in the federal government laws for sexual minorities over the last six years. In September 2011, the 17-year-old law prohibiting gay and lesbian people from serving openly in the military known as Don't Ask, Don't Tell (DADT) was officially repealed. In summer 2013, the United States Supreme Court struck down the Defense of Marriage Act (DOMA) (NGLTF, 2014), which was followed by enacting marriage equality as the law of the land in the summer of 2015 .

Despite these strides there are still daily occurrences of discrimination and harassment happening across the nation towards sexual minorities (Grant et al., 2011; Rothman, Exner, \& Baughman, 2001). Currently in the United States only 21 states have laws that ban discrimination on the basis of sexual orientation and/or gender identity (NGLTF, 2014). While workplace fairness has been recognized as a fundam ental right protected under federal law, currently sexual orientation or gender identity and gender expression are not protected classes under the federal law (HRC, 2014). As a result, many sexual minorities are fired, denied job opportunities, denied promotions and experience harassment on the job. In the 2014 South Florida LGBTQ Community Assessment Study, As I See It, illustrated how employment discrimination and health care/insurance were shown to still be two major issues faced by the LGBT community. 
The study consisted of 476 participants who were from Miami-Dade, Broward and Palm Beach Counties and identified as LGBTQ. The combined results indicated that nearly one third of all respondents did experience some type of discrimination and that at least 73.3\% had heard a derogatory comment or joke targeting LGBTQA people within their place of employment, or in restaurants and public venues (Draft, 2014).

\section{Religious Oppression}

In the United States $76 \%$ of the American adult population identified themselves as Christians, with $51 \%$ attending a variety of churches including but not limited to: Protestant, Evangelical or unaffiliated, and 25\% identified as Catholic and $4 \%$ collectively make up other religions such as Buddhism, Judaism, or Islam (Kosmin \& Keysar, 2009). Much of the research on the intersection of religion and attitudes towards homosexuality has focused primarily on the religious tradition or denomination, the literal views of religious texts, attendance rates, and images of God. Attitudes towards sexual minorities are strongly associated with religious beliefs, behaviors, and affiliations (Loftus, 2001; Olson et al., 2006). While there are progressive groups among Christians denominations such as mainline Protestants, (Olson et. al., 2002) Christian groups on average are more negative in their views towards sexual minorities compared to Jews and those reporting no religious preference (Loftus, 2001; Woodford, Levy, \& Walls, 2013).

Another important factor concerning attitudes towards sexual minorities is the actual perceived source of one's sexual orientation, whether it is a choice or biological. When individuals believe sexual orientation is a choice there is less support or tolerance for homosexuality (Unnever, Cullen, \& Applegate, 2005). 
Religious Oppression in the Latino Community. In the U.S., three out of five Latinos identify as Catholic. It is estimated that approximately $56 \%$ of church teachings and most church leaders oppose same-sex marriage (Branton, Wenzel, \& Wrinkle, 2014). Religion is an integral part of the Latino culture. The traditional views and value not only reject the notion of homosexuality but also actually condemn and denounce sexual minorities (Ellison et al., 2011; McKenzie \& Rouse, 2013).

While Catholicism had been the major religious affiliation shared by many Latinos, with its conservative values and non-accepting views of homosexuality, we now see a new series of denominations become prominent among Latinos such as, Evangelicals, Mormons, and Jehovah's Witnesses (Branton et al., 2014; McKenzie \& Rouse, 2013). These groups have become a strong force in Latino America which raises concerns given these affiliations are significantly less tolerant toward homosexuals than Catholics (Chaturvedi, 2014; Ellison et al., 2011).

In many Latin American countries, and across Central America, these conservative Christian denominations are growing (Akerlund \& Cheung, 2000; Encarnación, 2011). Given the influx of these new ultraconservative denominations, levels of intolerance towards sexual minorities remain high. The religious oppression demonstrated by these conservative denominations makes it difficult for sexual minorities of faith to embrace their identity when religion and faith are still points of conflict.

\section{Family Rejection}

One of the most devastating issues sexual minorities face, is the rejection by family. The connection between family rejection or acceptance and the health of sexual minorities is substantial (Ryan, et al., 2009; Birden 2005). A family's acceptance or 
rejection of a sexual minority can have lifelong effects. Research has linked family rejection among sexual minorities with increased depression, substance abuse, suicidal behavior, and unsafe sexual behaviors (Birden, 2005; Gedro, 2013; Goldberg, Strutz, Herring, \& Halpern, 2013). Sexual minorities who lack the support of their family are eight times more likely to attempt suicide, nearly six times more likely to experience high levels of depression, and are more than three times more likely to engage in unsafe sex or use illegal substances (Ryan et al., 2009; Grant et al., 2011; Cray, 2013).

Sexual minority young adults who reported higher levels of family rejection during adolescence were 8.4 times more likely to report having attempted suicide, 5.9 times more likely to report high levels of depression, 3.4 times more likely to use illegal drugs, and 3.4 times more likely to report having engaged in unprotected sexual intercourse compared with peers from families that reported no or low levels of family rejection (Birden, 2005; Flores, Mansergh, Marks, Guzman, \& Colfax, 2009). Latino men reported the highest number of negative family reactions to their sexual orientation in adolescence (Ryan et. al, 2009; Zea, Reisen, \& Díaz, 2003).

A national survey of 6,450 transgender and gender non-conforming participants also illustrated the growing problem with family rejection. Nineteen percent of all respondents experienced domestic violence at the hands of a family member because of their transgender identity or gender non-conformity. Higher rates of domestic violence were reported for American Indian 45\%, Asian 36\%, Black 35\% and Latino/a 35\% respondents (Grant et al., 2011).

Family Rejection in the Latino Community. Within the Latino community, the family is considered to be the most important unit of society. The values placed on the family 
unit, which is framed with the heteronormative binary model, consists of one man, one woman and children, and oppress sexual minorities who are marginalized group (Agronick et al. 2004; Morales, Corbin-Gutierrez, \& Wang, 2013; Ryan et al., 2009). The current literature points out that homosexuality is stigmatized among U.S. residents of Mexican descent and, more generally, in Latino communities in the United States (Diaz, 2013; Morales, 1992; Peña-Talamanters, 2013; Ryan et al., 2009; Sandfort et al., 2007).

\section{Social Microaggressions}

Microaggressions are the insults, slurs, indignities and affronts individuals might experience in their everyday interactions with others (Solorzano, Ceja, \& Yosso, 2000; Nadal, Rivera, \& Corpus, 2010; Sue, 2010). These insults can be verbal or non-verbal and are either intentional or non-intentional. Macroagressions are the obvious and blatant actions and insults that denigrate sexual minorities in society (Nadal et al., 2010, Woodford, Howell, Kulick, \& Silverschanz, 2013). For sexual minorities, anti-gay language such as "that's so gay," and behaviors such as having only gender specific bathrooms, are ways through which heterosexism and homophobia are enacted in society. These words and behaviors communicate hostility and contribute to creating unwelcoming and unsafe environments and are examples of the microagressions and macroagressions sexual minorities experience in society (Platt \& Lenzen, 2013).

When microaggressions and macroagressions are experienced consistently no matter how minor, they have an influence on an individual's ability to cope. Statements such as, "that's so gay" are used in the pejorative to define something that is negative or distasteful. Microagressions and macroaggressions build up and eventually have a 
negative effect on sexual minorities' ability to feel accepted in their environment and impact their physical well-being (Platt \& Lenzen, 2013; Sue, 2010; Walls, 2008;

Woodford et al., 2013).

\section{Effects of Social Heteronormativity}

Sexual minorities experience issues such as social oppression, discrimination and stigmatization based on their sexual orientation and gender expression on a daily basis (Lewis, Derlega, Berndt, Morris, \& Rose, 2002; Rose \& Mechanic, 2002; Rothman et al., 2011; Tyre, 2009). The marginalization and discrimination sexual minorities experience in society have proven to be detrimental to their physical and psychosocial well-being. These experiences lead to fear, isolation and alienation that can result in an imbalance in their psychosocial well-being, also referred to as gay-related stress (Almeida, Johnson, Corliss, Molnar, \& Azrael, 2009; DiFluvio, 2011; Lewis, Derlega, Clarke, \& Kuang, 2006; Rose \& Mechanic, 2002; Ryan et al., 2009; Tyre, 2009). Psychosocial health is made up of three main components: happiness, overall satisfaction with life, and emotional and psychological wellbeing. Gay related stress is the contributing factor in the increasing rates of homelessness, mental health issues, alcoholism, drug abuse and suicide among sexual minority youth (Biegel, \& Kuehl, 2010; Newcomb, Birkett, Corliss, \& Mustanski, 2014). Homelessness, depression, chronic stress, substance abuse and eating disorders are some of the most alarming outcomes that sexual minorities experience (Balsam, Beauchaine, Mickey \& Rothblum, 2005; Collins, Rocco, \& Bryant, 2014; Lewis et al., 2006; Marshall, 2008; Tyre, 2009; Sullivan, 2013). Reconciliation for sexual minorities who are estranged from their family members is critical. Family 
acceptance and support has a protective effect against adverse health outcomes for sexual minorities (Grant et al., 2011).

\section{Homelessness among Sexual Minority Youth}

Sexual minorities are vastly over represented in the homeless population in the United States. Approximately one out of every four LGBTQ youth who come out to their parents are kicked out of their home (Corliss, Goodenow, Nichols, \& Austin, 2011). In 2011, The Williams Institute surveyed over 354 U.S. agencies with the National Homeless Youth Provider Survey to assess the experience of homeless youth. 94\% of agencies reported working with LGBT homeless and runaway youth in the past year. Over the past 10 years, the percentage of homeless sexual minority youth clients has increased from $82 \%$ to $94 \%$ for all homeless youth providers. Nearly seven in ten (68\%) respondents indicated that family rejection was a major factor contributing to youth homelessness among sexual minorities, making it the most cited factor. Fifty-four percent of the respondents indicated family abuse also contributed to LGBTQ homelessness (Durso \& Gates, 2012).

\section{Alcoholism and Drug Abuse}

Another major problem facing sexual minorities is the increased use of alcohol and drugs within this population (Cray, 2013; Newcomb, et al., 2014). It is estimated that sexual minorities use alcohol and drugs seven times more frequently than heterosexuals (Cochran, Stewart, Ginzler, \& Cauce, 2002; Collins, Rocco, \& Bryant, 2014; Gedro, 2014; Woodford et al., 2012). Having a drug or alcohol abuse disorder among sexual minorities has been closely associated to the negative experiences and climate they are exposed to (Weber, 2008). 
Marshal's (2008) meta-analysis of sexual minority youth use and abuse of drugs showed a significant relationship between sexual identity and their preponderance to use and abuse drugs. Sexual minority youth were $190 \%$ more likely to use substances than their heterosexual counterparts. Bisexual youth were $340 \%$ more likely and lesbians were $400 \%$ more likely to use substances than their heterosexual counterparts. Increased substance use and addiction among sexual minorities is often times the result of the unique stressors they face. These include losing their jobs, being harassed and receiving negative messages from their religious organizations because of their sexual orientation (Lee, 2015).

\section{Latino Homophobia}

It is estimated that 1.4 million Latinos in the United States consider themselves to be LGBT (Gates \& Kastanis, 2013). Of these 1.4 million Latinos in the US roughly 146,000 Latinos live in same-sex couple households. Many of these individuals reside in states such as Texas, Nevada, California, Arizona, Wyoming Florida, Colorado, New Jersey. and New York. With the increasing number of Latinos who identify as sexual minorities one could make a case that homophobia within Latino communities today is less prevalent than it has been in the past.

In 2012 the Pew Research Center conducted the National Survey of Latinos (NSL). The 2012 survey focused on Latino's identities, behaviors and views about social issues among other areas. The survey was conducted in all 50 states and the District of Columbia. A randomly selected sample of 1,220 participants was used. The survey asked participants should homosexuality be accepted and should same-sex marriage be allowed. Sixty-four percent of participants agreed that homosexuality should be accepted. The 
2012 results was the first time, since the survey started in 2004, that more Latinos favored (52\%) same-sex marriage than those who opposed it (34\%). The strongest opposition to same-sex marriage however came from individuals who identify as Evangelical Latinos and those who were 65 and older. The study indicated that for these subgroups little has changed from prior years.

While the 2012 NSL study shows a shift in Latinos perceptions of sexual minorities in the United States we are still encountering a significant number of homophobic incidents. For example, despite a large number of Latino LGBT individuals living in Florida and Texas, these are two states that currently have few legal protections for LGBT individuals (NGLTF, 2014). In pop-culture today, incidents of Latino homophobia are becoming more common. In 2012 the Cuban major league baseball player Yunel Escobar, displayed a homophobic slur on his black eye tape stating, " $t u$ eres maricon" which translates to "you are a faggot" while playing the Boston Red Sox. Despite the offensive remark and the intense scrutiny, the incident received, Yunel defended his statement as, it was only a joke, and showed little if no remorse (Bury, 2015; Hernandez, 2014).

Incidents of homophobia in the Latino culture are not only evident in the United States but are also a growing problem among Latin American countries. The breadth of the problem can be seen in the 2008 Americas Barometer survey on "tolerance towards homosexuality in Latin America" conducted by the Latin American Public Opinion Project (LAPOP). LAPOP is the leading national consortium that works in partnership with various academic and non-governmental institutions throughout North America and 
Latin America, focusing primarily on governance, research and democracy in Latin America. Figure 1 below provides an overview of 23 countries in North, Central and South America and the Caribbean and their tolerance towards homosexuality. Only two of the Latin American countries surveyed—Argentina and Uruguay—have a tolerance for sexual minorities above $50 \%$.

Figure 1

Tolerance Towards Homosexuality in the Americas Percentage of Survey Respondents Demonstrating "High Tolerance" of Homosexuality

\begin{tabular}{|c|c|c|c|c|c|}
\hline Above $50 \%$ & $50-41 \%$ & $40-31 \%$ & $30-21 \%$ & $20-11 \%$ & $10-0 \%$ \\
\hline Argentina & Brazil & Colombia & Bolivia & El Salvador & Haiti \\
\hline \multirow[t]{2}{*}{ Canada } & & Costa Rica & Dominican & Guatemala & Jamaica \\
\hline & & & Republic & & \\
\hline United States & & Mexico & Ecuador & Guyana & \\
\hline \multirow[t]{3}{*}{ Uruguay } & & Nicaragua & Paraguay & Honduras & \\
\hline & & Venezuela & Panama & Trinidad \& & \\
\hline & & & Peru & Tabago & \\
\hline
\end{tabular}

The Gay and Lesbian Alliance Against Defamation (GLAAD), demonstrates another example of the prevalence of homophobia in Latin American. During the 2014 World Cup games in Brazil, homophobic chants and anti-gay slurs were shouted and heard in the stadium. According to GLADD, this behavior is commonplace among the International Federation of Football, (A.K.A. FIFA) which currently has over 200 affiliates world-wide. The Alliance is strongly advocating for something to be done to address this issue but nothing has been done to date. (Bury, 2015; Murray, 2014). 
The magnitude of the problem of homophobia in Latin America is also evident in a report from the Inter-American Commission on Human Right (IACHR). In 2013, 594 anti-LGBT deaths occurred in the Western hemisphere between the months of January and March. Of 594 deaths more than half occurred in Brazil, 61 in Columbia and 29 in Honduras (Lavers, 2014). In November of 2013 Joel Molero, a 19 year-old openly gay man from Peru, was brutally murdered, dismembered and burned in the city of Chachapoyas (Chase, 2013; Tegel, 2013). While these incidents may be disturbing and the numbers staggering, it is important to note that the Intern-American Commission on Human rights expressed further concerns that many of the crimes against LGBT individuals go unreported in Latin America (IACHR, 2015).

\section{Latina Lesbians}

Within Latino families Latina lesbians face discrimination, abuse, and even rejection from their loved ones when attempting to integrate who they are culturally with their identity as lesbians (Espín, 2012; García, \& Torres, 2009; Peña-Talamantes, 2013). Latina lesbian is a complex cultural and political identity for women who share historical commonalities, ethnic and sexual identity, and who face discrimination as women, Latinas, and lesbians (Pickett, 2013).

Latina lesbians are so heavily stigmatized within the Latino community that one of the prevalent stereotypes is that they are traitors who have forsaken their culture and roots (Torres, 2002; \& Torres, \& Pertusa, 2003). An example of this was seen in an article after New York passed gay marriage in 2011 at the Gay Pride festival. The article detailed the accounts of a young Latina lesbian mother who was being ridiculed for publically showing affection to her partner. She was being mocked in Spanish and met 
with much hostility. The couple was told, "you have the devil inside of you and should be ashamed for leaving your husband for this!" (Ramos, 2011). Latina women refuse to use the term Lesbian because of its stigma within the Latino community and out of fear of the harsh consequences in their communities. In addition to stigmas and stereotypes, lesbians are also invisible or non-existent among many Latino communities (Kumashiro, 2001). The lack of lesbian visibility in Latin American countries has been well documented.

During 1991-1994 the Latina lesbian publication, Esto No Tiene Nombre, which translates to, This has no Name, was one of the first publications created to give voice to the experiences of Latina lesbians in the United States (De La Tierra, 2004). The title represented the rejection, obscurity and often negative perceptions the Latino community exhibited towards Latina lesbians (Danielson, 2009). Although short-lived, the publication allowed Latina lesbians to discuss their personal struggles, and cultural challenges in a supportive context. There were over 68 Latina lesbians across the world who published in the publication during its short existence. The stories and articles shared the multiple issues involved in being a minority that was marginalized on multiple levels. One contributor discussed how her family believed that if you were Latina then you definitely could not be a Lesbian, because there was no such thing as a Latina lesbian. The publication allowed Latina lesbians who were often distanced from their families because of their sexuality, to create a safe space where they could freely express their sexuality (De La Tierra, 2004).

The discrimination and harassment Latina lesbians often experienced within the Latino culture has been well documented and stems from the constructs of marianismo, 
familismo, and machismo (Bermudez et al., 2010; Byers, 2010; Galanti, 2003; Jezzini, Guzman, \& Grayshield, 2008; Sternberg, 2000). It is important to understand these three constructs and their place in Latin culture to understand the levels and ways in which Latina Lesbians are discriminated.

\section{Marianismo}

The traditional gender code of behavior for Latinas referred to as Marianismo is heavily rooted in Catholicism. The gender ideal is embodied by La Virgen Maria, the Virgin Mary, which encompasses the following attributes: obligation to family, selfsacrificing, subservience to men, abstinence until marriage and sexual passivity after marriage. (Hernandez \& Curiel, 2012; Lopez, Corona, \& Halfond, 2013; Jezzini, Guzman, \& Grayshield, 2008) These individuals are generally viewed as devout religious women and are held at a higher regard if they have children and are perceived to be caring mothers. This constructed gender role is shared across various Latino communities both in the United States and abroad and any deviation from the expected norms is perceived as being non-Latina. (Villegas, Lemanski, \& Valdez, 2010). One of the challenges this concept presents for Latina lesbians is that they do not fit the Marianismo paradigm, which creates an impediment when attempting to develop a Latina lesbian identity.

\section{Familismo}

Within Latino cultures the concept of family has been recognized as a core value, often times referred to as Familismo (Ayon \& Aisenberg, 2010; Toro-Morn, 2012). The importance of Familismo has been well documented in the literature and usually consists of traits that include: developing close bonds with both the immediate and extended 
family members, being a contributing member, maintaining harmony, being protective with the family, and caring for one another (Ayon \& Aisenberg, 2010; Young, 2009). Loyalty to the family is expected above all else, sometimes at the expense of one's selfpreservation (Toro-Morn, 2012).

As part of the expectations under Familismo, individuals are expected to marry, expand the family, and have children. The importance of large extended family allows for additional support and stability within the family units. An example of this is the role that grandmothers sometime play. Abuela's, Spanish for grandmother, play a strong role in the upbringing of grandchildren by often providing hands on support and care (Young, 2009). As with Marianismo, Familismo can also produce a myriad of challenges for Latina lesbians who may be trying to integrate their lesbian identity with their Latina identity and cultural expectations.

\section{Machismo}

Within Latino cultures, the construct of machismo plays a significant role. The word Machismo is a derived from the Spanish word "macho" meaning male (Mayo, 1997). The term often incites disputes and controversy among individuals because of its complexity and varying perspectives. For the purposes of this study it has been defined as a "strong sense of masculinity within the Latino culture which places value on paternalism, aggression, systematic subordination of women, fetishism of women's bodies, and idolization of their reproductive and nurturing capacities, coupled with a rejection of homosexuality" (Sternberg, 2000, p.91).

One way Machismo is manifested in Latino communities is through the acceptance of a patriarchal family system (Estrada, Rigali-Oiler, Arciniega, \& Tracey, 
2011). Within this system the father is the head of the household, holds a position of power and authority over the rest of the family, and specific gender roles are assigned and followed accordingly (Ingoldsby, 1991; Villegas, Lemanski, \& Valdez, 2010). Within Latino culture the construct of Machismo complements the construct of Marianismo. These limiting concepts of masculinity and gender that frame Machismo within the Latino culture can be detrimental to a Latin lesbian's sexual identity development and will be carefully examined.

\section{Paucity of Research on Latina Lesbian}

Currently Latinas account for one in five women in the U.S. and it has been estimated that by the year 2060 Latinas will make up almost one third of the female population in the United States (Gándara, 2015; Humes, Jones, \& Ramirez, 2011). Despite the growing number nearly one-fourth of Latinas live below the poverty line and more than half are living in near-poverty. Latinas are the least like of any group of women to have access to health care (Gándara, 2015). In 2011, 37 percent of Latinas were uninsured compared to 14 percent of white women. Poor health leads to chronic conditions that often times impacts a Latinas ability to attend work or school (Humes, Jones, \& Ramirez, 2011).

Educational attainment is another factors which impacts Latina women. While Latinas are attending colleges and universities in record numbers, they are less likely to complete a college degree in comparison to all other groups (Gándara, 2015). In 2013, almost 19 percent of Latinas between the ages of 25-29 had completed a college degree compared to 23 percent of African American women, 44 percent of white women, and 64 
percent of Asian women (Gándara, 2015; Hispanic Association of College \& Universities, 2016).

For Latina lesbians aside from the challenges mentioned above, as lesbians they also face the marginalization, homophobia, and heterosexism that exist within the Latino community. Latina lesbians also fall into a segment of the population, which has not been examined closely within the context of higher education (Abes \& Jones, 2004; Espín 1993; Peña-Talamantes, 2013; Torres, \& Pertusa, 2003).

With the increasing Latina population nationally, the growing number of Latino students attending colleges and universities, and the marginalization faced by Latina Lesbians, it is critical to understand the experiences of Latina lesbian students in Hispanic-serving institutions to inform best practices in both student affairs and in academic affairs. Documenting their experiences can provide a lens to begin examining the challenges or success these women are experiencing today.

\section{Heteronormativity within Higher Education}

This section reviews the issues sexual minorities face in heteronormative institutions of higher education. A review of the literature on heteronormativity within higher education is sectioned by: (a) discriminatory policies (b) oppressive practices and (c) issues within Hispanic-serving institutions.

In addition to the struggles sexual minorities face in society when coming to terms with and developing coping mechanisms for their sexual identity, they also deal with unresponsive higher education institutions. The indifference from unresponsive (Wall \& Evans, 2000; Sanlo, 2004). 
It is well documented that institutional factors such as faculty and peer support, inclusive institutional policies, and classroom environments can have a positive effect on retention and student success (Cramer, 2014; Rankin, et al., 2010; Sanlo, 2004). The empirical literature pertaining to strategies that have positively impacted the retention of African American, American Indian, and Latino students have included mentorship programs, financial aid assistance, special interest groups and clubs for minority students, summer pre-college academic programs, multicultural centers and an inclusive and meaningful curriculum (Bennett \& Okinaka, 1990; Hu \& John, 2001). Specific attention has been placed on student integration and enhancing the availability of institutional support services (Bennett \& Okinaka, 1990; Hu, \& John, 2001). While campuses have addressed issues of diversity and developing an extensive body of research on successful retention efforts for various student minority groups such as African American and Latinos, retention and success efforts among sexual minorities remains absent in the literature (Wall \& Evans, 2000; Sanlo, 2004).

While literature exists in regards to microagressions among sexual minorities (Solorzano, Ceja, \& Yosso, 2000; Nadal, Rivera, \& Corpus, 2010; Sue, 2010), research within higher education is limited. Looking at issues of microaggressions within the context of higher education could add to this critical body of research.

\section{Discriminatory Policies}

Heteronormativity is what guides many of the institutional policies and practices in higher education. Sexual minority students perceived less support and guidance regarding their academic and career decisions than their heterosexual counterparts (Nauta, Saucier, \& Woodard 2001; Tomlinson \& Fassinger, 2003). 
Among institutions of higher education, there are no federal requirements for colleges and universities to have policies that protect their sexual minority students from harassment on campus. To date, the only piece of legislation at the Federal level that would specifically address any type of harassment towards sexual minority college students is the "Tyler Clementi Higher Education Anti-Harassment Act of 2013". This legislation would require colleges and universities receiving federal student aid funding to enact an anti-harassment policy, specifically prohibiting the harassment of enrolled students by other students, faculty, and staff because of actual or perceived race, color, national origin, sex, disability, sexual orientation, gender identity or religion. It explicitly prohibits behavior often referred to as cyberbullying. The bill was reintroduced in the 114th Congress in the House by Rep. Mark Pocan (D-WA) and Tammy Baldwin (D-WI) on March 18, 2015 as "HR 1421 Tyler Clementi Higher Education Anti-Harassment Act of 2015". Currently the bill has been moved to the Subcommittee on Higher Education and Workforce Training for Committee Consideration.

Institutional heteronormativity and homophobia is prevalent even prior to students arriving to college through their application and indoctrination process (Cramer, 2014; Koschoreck, 2003). Indoctrination teaches an individual or group to accept a set of beliefs, opinions and values uncritically and to not consider other ideas or beliefs. (Merriam-Webster, 2005). One of the earliest examples of this is when students complete their demographics information on their college applications. The majority of these applications ask for demographics of students such as race/ethnicity, age, marital status, specific sex, either male or female. These demographics do not take into account gender variant students nor do they collect data on student's sexual orientation. When 
publications and marketing materials are sent home, often times they fail to mention or include services or programs offered to sexual minority students on campus (Badgett, 2009). These processes further isolate and intimidate Latina lesbians who are already marginalized on campus.

Heteronormativity implements a binary model and approach for institutions, which is evident on a macro level through the reinforcement of gender specific bathrooms, non-inclusive LGBTQ curriculum, non-inclusive policies, lack of an inclusive indoctrination process, and limited support services (Rankin 2005; Rankin, Sanlo, \& Schoenberg, 2002; Reason \& Rankin, 2006). The injustices and inequities of a heteronormative institution also constrain LGBTQ professors and administrators, encouraging and rewarding professors and administrators when they construct and promote versions of the world that seek to marginalize and obscure knowledge regarding sexual minorities (Surtees \& Gunn, 2010). The inequity in heteronormative institutions is evident when administrators who support and encourage Greek organizations on campus are rewarded and acknowledged for their work with these groups, despite the fact that Greek organizations have historically been hostile towards sexual minorities and perpetuate heteronormative behaviors among students. On the other hand, administrators who work with non-Greek or Gay Straight Alliance type organizations go virtually unrecognized or supported (Case, Hesp, \& Eberly, 2005; Fine, 2011). Heteronormative policies that discriminate against LGBTQ faculty are also evident. Examples include: faculty who find it difficult to gain support from departments or other faculty when their scholarship includes LGBTQ issues, non-discrimination policies that exclude sexual orientation that are neither challenged nor questioned, or when health benefits are only 
offered to married couples (D'Emilio, 1990; Cramer, 2014). In the State of Higher Education for LGBT Report, $42 \%$ of the 498 LGBTQ faculty and $32 \%$ of the 1,071 LGBTQ staff surveyed have considered leaving an academic institution based on the campus climate. The campus climate issues that affect faculty and staff include: homophobia, discrimination, threat to physical safety, and the lack of value of LGBT scholarship (i.e., LGBT course development, general education requirements, research), and lack of institutional support to LGBTQ individuals (i.e., promotions, tenure, risk losing their position if outed, etc.; Cramer, 2014). Thirty-five percent of faculty and $32 \%$ of staff avoided disclosure of their sexual identity for fear of these negative consequences (Rankin et al., 2010; Tetreault et al., 2013).

\section{Oppressive Practices}

Although research supports the pedagogical value of a diverse student body and faculty on enhancing learning outcomes on campus (Hale 2004; Harper \& Quaye, 2004; Harper \& Hurtado, 2007) very little is done in colleges to create awareness or education regarding sexual minorities. Heterosexism and homophobia are prevalent in the general campus climate (Rankin 2005; Evans \& Rankin, 1998).

Campus climates influence both curricular and co-curricular activities. Curricular activities generally contribute to the development of cognitive skills and fall within the area of academic affairs within higher education. According to the United Nations Educational, Scientific and Cultural (2016) Curricular activities consist of class curriculum, faculty, program of study, the planned interaction between students and the instructional content, materials and resources applied in the context of the students. Cocurricular activities are those that complement, but are not a part of the regular academic 
curriculum. These generally fall within the area of student affairs and include activities such as student organizations, student services, peer interactions, employment, residences halls, and out of class involvement with faculty and staff (King, \& Anderson, 2014). Discriminatory curricular and co-curricular climates on campus have a negative effect on student learning (Cabrera, Nora, Terenzini, Pascarella, \& Hagedron, 1999; Feagin, Vera, \& Imani, 1996; Pascarella \& Terrenzini, 2005; Teman \& Lahman, 2010; Windmeyer, Humphrey, \& Barker, 2013).

According to Campus Pride less than $8 \%$ of colleges and universities provide any institutional support for sexual minorities on campus. Institutional support is defined by ACPA College Students Educators International as a part-time or full-time staff position whose job description includes LGBTQ issues and concerns. There are no known standards or practices being used to track retention or matriculation of sexual minority college students. By not allowing sexual minorities the opportunity to self-identify at the point of admission makes them invisible upon enrollment. Institutional decisions to not track retention rates for sexual minorities is alarming and concerning given that this population faces high levels of harassment (Windmeyer, Humphrey, \& Barker, 2013). Heterosexism and homophobia is also prevalent in the residence halls (Evans \& Broido, 2002). Students have been required to complete housing agreements which are non-inclusive, reinforce the binary model and given housing options which are limited and gender specific. Factors that discouraged students from disclosing their sexual orientation included a lack of a visible community in the residence hall, hostility experienced by sexual minorities in the residence halls and the lack of supportive individuals and services (Wickens \& Sandlin, 2010) 
These heteronormative and heterosexist oppressive systems in higher education, result in sexual minorities becoming victims of violence or having diminished opportunities (Rocco \& Gallagher, 2006; Rankin \& Reason, 2008; Teman \& Lahman, 2010). Heteronormativity attempts to constrict and hide the notion of alternative sexual identities from the minds of students and hinders their development.

Heteronormative practices are also evident in the selective tracking and treatment of other at-risk groups on campus. While most other minority groups are identified, tracked and assisted from the start of their college experience; tracking, empirical data and research is virtually non-existent among sexual minority students (Wall \& Evans, 2000; Sanlo 2004; Windmeyer, Humphrey, \& Barker, 2013). There currently are no consistent measures to track, include or support this marginalized group at a college level in their academic progress.

The research and data collected on campus for other minority groups has been abundant compared to sexual minorities. The current literature on sexual minorities has been limited to issues of safety on campus, specifically harassment and victimization (Rankin et al., 2010; Renn, 2010; Wall \& Evans 2000). The current research suggests that sexual minorities on campus are generally victims of verbal harassment, physical assault, intimidation, discrimination, bullying and marginalization in the university environment. Sexual minorities generally do not experience a sense of support and security on campus (D'Augelli, 1992; Sanlo 2004; Wall \& Evans 2000). While sexual minority students encounter campus adjustment difficulties similar to other minority students, there have not yet been any studies that address the strategies and retention needs of sexual minority students (Sanlo, 2004; Bilodeau \& Renn, 2004). Among college 
students the use of microagressions can negatively affect a sexual minority student's wellbeing to the point that it interferes with their learning and personal growth (Nadal et. al., 2010; Platt, \& Lenzen, 2013). The negativity from microagressions is manifested in sexual minority students by experiencing trouble sleeping, feelings of isolation, digestive issues and frequent headaches (Croteau, Lidderdale \& Chung, 2005; Sue, 2010).

Research posits that environments where microagressions are used commonly, creates a hostile environment where sexual minorities are unwelcomed and experience marginalization and isolation.

While heteronormativity and institutionalized heterosexism are two prevalent factors inhibiting the retention of sexual minorities in college, research in these particular areas is insufficient (Evans \& Rankin, 1998; Rankin 2005; Sanlo, 2004; Rocco, \& Gallagher, 2006; Windmeyer, Humphrey, \& Barker, 2013).

\section{Heteronormativity at Hispanic-Serving Institutions}

The growing political strength and cultural influence of Latinos is changing the landscape of the nation and institutions of higher education. HSI enroll more than 1.8 million students and account for $6 \%$ of all college and university students (Hispanic Association of College \& Universities, 2016). However, given these statistics along with the stigmatization and discrimination Latina lesbians face within the Latino community, it will be important to understand the experience of Latina lesbian students in higher education, specifically at Hispanic-serving institutions. While there is some literature documenting the experiences of sexual minorities at non-White serving institutions, this work has been done primarily at historically Black colleges and universities (Tyre, 2009; Patton, 2011; Carter, 2013; Means \& Jaeger, 2013). Research regarding sexual 
minorities at a Hispanic-Serving Institution is currently void in the literature and this study would make a significant contribution to the literature and the field.

\section{Summary}

In Chapter 2, the existing literature relating to the study was reviewed. The literature review included the various sexual identity development models within higher education; an overview on heteronormativity, the issues sexual minorities face today and the effects of heteronormativity; heteronormativity in higher education and its discriminatory practices, oppressive policies, and heteronormativity in Hispanic-serving institutions.

Chapter 3 discusses the research methods and procedures used. Chapter 4 discusses the inductive analysis, the information acquired during the study and pertinent findings. Chapter 5 discusses the deductive and comparative analysis, and pertinent findings. Chapter 6 contains a summary of the study, its findings, along with recommendations and implications for practitioners in a higher education setting. 


\section{CHAPTER III}

\section{METHODS}

Chapter 3 begins with the purpose of the study and the research questions found in Chapter 1. The researcher's autobiography, assumptions and journal process is discussed, followed by the phenomenological framework. Next, the procedures utilized in this study are described including: sample, data collection, data analysis and data management for this study. Finally, integrity measures are discussed along with delimitations of the study.

\section{Purpose of the Study}

The purpose of this phenomenological study was to gather insights into the experiences of Latina lesbian students and their sexual identity development at a predominately Hispanic-Serving Institution.

\section{Research Questions}

The phenomenon of interest was the unique experiences of Latina lesbian students at a Hispanic-serving institution, their experiences and perceived identity development. The primary research question which guided this study was: How do Latina lesbian students describe their experiences and their perceived sexual identity development at a Hispanic-serving institution?

Secondary questions included:

1. From the perspectives of these students, which college experiences have been related to their perceived sexual identity development? 
2. From the perspectives of these students, what cultural factors have influenced their sexual identity development?

3. From the perspectives of these students, what college factors have influenced their sexual identity development?

4. From the perspective of these students, what would make the LGBTQ experience at an HSI better for Latina lesbians?

\section{Researcher's Autobiography, Assumptions and Journal Process}

"I searched for information and support groups on campus that would be able to help me through the feelings I was experiencing. Finding none I began to consider leaving school."

\section{-A Latina Lesbian Student}

An important starting point in phenomenology is for the researcher to set aside any preconceived notions, understandings or judgments, of the phenomenon and to observe the experience as something new (Moustakas, 1994; Van Manen, 1990). This process is known as epoche and is achieved by having the researcher be aware of her/his own biases, previous judgments or notions and setting them aside.

This section begins with the researcher's autobiography, which describes her lived experience and her decisions to engage in this line of inquiry. The researcher then discussed the assumption that college and university campuses are heteronormative in nature, and have the potential to positively or negatively impact the experiences and identity development of Latina lesbian students. Finally, the researcher outlines the rationale and process of journaling throughout the study. 


\section{Autobiography}

Growing up in a traditional Latin home, there were certain rules you always followed. One was to do your chores, respect your elders, obey your parents and never discuss the topic of sexuality, specifically sexual orientation. When sexual orientation was discussed, it carried a negative connotation. One of my earliest recollections regarding sexual orientation revolved around a conversation my mother and aunt had regarding lesbians. The conversation clearly conveyed that this topic was met within my family with much hostility and disapproval. The initial conversation was of no interest to me until I heard my aunt state in Spanish to my mother that she would prefer her daughter be "una prostituta" a prostitute rather than "una lesbiana" a lesbian. The conversation served as an affirmation of my own family's beliefs and values and proved to be very confusing and scary, mainly because I knew I was attracted to women. Growing up I suppressed my feelings towards other women, playing the role of a straight female and attempting to live a heteronormative life.

Once I began college, my whole world changed. During my first two years, I joined a sorority, the cheerleading team, and became an involved member of the campus community. I continued in my role in the heteronormative world, all the while knowing that a part of me was unfulfilled and struggling with the feelings of attraction I was experiencing towards women. It was during my second year in college that I stopped repressing these feelings towards women and fell in love for the first time. The relationship remained hidden, as we were both scared to share what we were feeling with anyone. 
As the relationship continued, we began to experience hostility from others, because of their assumptions of our relationship. In my junior year I was selected as a housing Resident Assistant (RA) and decided to move on campus, much against my parents' wishes. Within my Latino culture it was expected that women would stay at home with their parents until they were married off to their husbands and moved into their own home. By accepting the RA position and moving on to campus, I thought I would be able to further explore my new sexual orientation and independence. During this time, my life began to change rapidly. As we began the rush period for new sorority members, so did the harassment I experienced for being a lesbian. During the first week of rush, derogatory posters were posted throughout campus accusing my sorority of being the "DYKES" Sorority, and the poster had my name listed as the president and main "home girl DYKE". When I became aware of the posters I immediately became scared, confused and felt threatened. I began to isolate myself from friends, sorority sisters, and stopped attending work, classes and all extra-curricular activities. The harassment increased with 3:00 am phone calls from male callers who accused me of being a "Dyke" stating they would "find me" and "change me back and that all I really needed was a good fuck from a real man." The bigotry, discrimination and hatred I experienced began to impact all aspects of my life. My academics began to suffer; I became depressed, left my circle of heterosexual friends, resigned from my position as president of the sorority, quit cheerleading, and completely isolated myself. Through my training as an RA, I was aware that I needed some support and assistance. I searched for information and support groups on campus to help me understand the feelings I was experiencing. Finding none, I began to consider leaving school. It was not until my sorority sisters and my supervisor 
at the time, the Vice Chancellor for Student Affairs, had interceded, that I began to feel a sense of support on campus. Both had become aware of my situation and felt compelled to help me succeed. Although their support and assistance was well-intended, I did not find anyone else like me, a Latina lesbian, and I still felt alone and isolated on campus. It was not until I was connected with a lesbian staff mentor on campus, the Associate Director of Housing, that I was finally able to receive the support I needed. The lesbian staff mentor connected me to "Horizons," an off-campus young adult's facility for gays and lesbians, that assisted me in working through my sexual identity development and empowered me to face the challenges I was experiencing. Fortunately, I was able to find these critical supports that made it possible for me to remain in college and achieve my academic goals.

Unfortunately, 30 years later, sexual minority students are still experiencing the same discrimination and crises on campus. Several years ago, I attended a Sneak Preview day with my step-daughter at a small private school in the southeast United States. During the preview event we were given statistics of the institution that included male and female gender statistics as well as racial and national breakdowns. We met with offices and programs ranging from Disability Services, the Women's Center, the Freshman Year Program, to the Hispanic Student Association. Yet nothing was ever mentioned regarding sexual minority student statistics or any academic or social support groups for them. Needless to say the visit further intrigued my interest in understanding how heteronormative institutions might dismiss or ignore sexual minority students on campus. 
Many campuses today, aside from not having social outlets on campus, have very limited, if any inclusion, of the LGBTQ culture or history in the curriculum on the most basic levels. One example of this is a recent conversation on my own campus with a student who shared a painful interaction she had with a professor. She had asked her professor if she could write her final class paper on family values among same sex parents; the professor quickly responded that it was not a valid topic so she would not accept it. The course was an elective entitled, "Marriage and Family."

As the Associate Director for the Lesbian, Gay, Bisexual, Transgender, Queer, Questioning, Asexual and Ally (LGBTQA) Initiatives program at Florida International University, the only full-time professional hired to work with this population on campus, I have gained insights into the current struggles Latina lesbians students are experiencing. Currently, there are no uniform measures to track, include or support this marginalized group at the college level in their academic progress. As the Associate Director for this program, I encounter students who are struggling with "coming out" to family and loved ones. In some cases, students are thrown out of their homes by their parents and left to fend for themselves having no support or resources. Within the first two weeks of the Spring 2015 semester, I became aware of three Latina lesbian students who had become homeless since the new year started after disclosing to their parents that they were lesbians. While there have been some initiatives established through the LGBTQA Initiatives Office on campus, much of these have focused on creating awareness and education on issues the LGBTQA population face. A mentorship program was developed that connects LGBTQA students with LGBTQA faculty and staff on campus, and two LGBTQA academic achievement recognition programs LGBTQA Lavender 
Graduation and the Excellence Awards have been initiated. The office currently consists of one full-time staff member and two part-time graduate assistants. These individuals, along with a small group of volunteers, provide LGBTQA services for the more than 54,000 students, who currently attend the institution.

The research in higher education involving sexual minorities has been limited to four main areas including: campus climate issues, emerging sexual minority identity models, issues related to intersectional identities, and student affairs practices in working with LGBTQ students. Upon reviewing the literature regarding Latina lesbian students' academic success or experiences at Hispanic-serving institutions with academic affairs I have found it to be nonexistent. Given my passion and experiences in working with sexual minorities and specifically Latina lesbians, a relevant question is how do we begin to transform colleges and universities into more accepting, supportive and affirming places for Latina lesbian students from both a student affairs and academic affairs perspective?

\section{Assumptions}

The researcher's passion in working with this particular group is both professional and personal. The researcher is interested in the study partially because of her experience of oppression and marginalization in college as a Latina lesbian. Additionally, seeing the ongoing oppression of Latina lesbian students further fuels the investigator's interest and serves as the main rationale for delving into this area of research. The researcher's autobiography revealed her conviction that college and university campuses are heteronormative in nature, and have the potential to positively or negatively impact the experiences and identity development of Latina lesbian students. The researcher was 
open to the experiences of other Latina lesbian students on campus and how their experiences positively or negatively impact their identity development and overall experience. As the Associate Director for LGBTQA Initiatives on campus, a greater level of trust and rapport was established with the participants, allowing them to be more candid when discussing their experiences. As a result of my current position at the university, maintaining subjectivity was critical and it was achieved throughout the process by utilizing all the integrity measures outlined in this chapter.

\section{Journal Process}

I kept a journal to record my thoughts, reactions and observations that emerged during the study. Any points of interest, concerns or feelings that arose during the interviews were entered into the researcher's journal. By maintaining a journal, I kept a record of any assumptions and biases that arose that I was aware of, in addition to any notes and emergent themes related to the study. Journal entries served as a medium for the researcher to explore any thoughts or presumptions and were not included as data.

\section{Phenomenological Framework}

Phenomenological research is the study of things in their natural setting (Moustakas, 1994). In a phenomenological study, the researcher attempts to make sense of, or interpret a phenomenon in terms of the meanings that are brought to them by the individual (Creswell, 2009; Moustakas, 1994). A phenomenological study investigates the meaning of a group's lived experience through in-depth interviews in order to capture the essence of their collective lived experience (Van Manen, 1990). A phenomenological approach was useful in further exploring and describing the experience of Latina lesbians at an HSI to inform future professional practices in higher education. This study has 
allowed the researcher to understand the experiences that Latina lesbian students encounter at an HSI and has begun to address the current void in the literature.

\section{Sampling}

Study participants attended a Hispanic-serving institution (HSI) located in Miami Florida, Florida International University (FIU). FIU is an HSI with an enrollment of nearly 55,000 students. It has a diverse student body that is $61 \%$ Hispanic, $15 \%$ White Non-Hispanic, 13\% Black, 4\% Asian or Pacific Islander and 7\% other minority groups. FIU ranks first in the nation in awarding bachelors and master's degrees to Hispanic students and is the fourth largest public university by enrollment in the United States (Florida International University 2015).

The sample for this study consisted of 15 participants. This sample size falls within the middle range of the typical sizes found in qualitative research. Sample sizes can typically range from as few as six participants to as many as 25 participants (Creswell, 1998; Miller, Neil, \& Salkind, 2002; Teddlie \& Tashakkori, 2011). Since the goal in phenomenology is to understand the essence of the participant's experience (Moustakas, 1994), this sample size allowed the researcher to obtain an in-depth exploration of the phenomenon while accommodating for any challenges that may arise in the data collection process.

Participants were purposefully selected using criteria and convenience sampling and provided the researcher with in-depth, rich information that offered the best insights into the phenomenon (Creswell 2009).

In criterion sampling, all participants meet a predetermined set of characteristics (Patton, 2002). To meet the criteria for this study, all participants met the following 
criteria: (a) identified as Latina lesbian students, (b) currently pursuing a bachelor's degree at a Hispanic-Serving Institution and (c) were between 18 to 24 years of age. Having this age group was significant in that it captured the traditional age for undergraduate college students.

In convenience sampling, participants were selected based on their availability (Castillo, 2009). The researcher utilized LGBTQ email listservs and other social media sites available through the Multicultural Programs and Services (MPAS) LGBTQA Initiatives office to send out an invitation to participate in the study (see Appendix A). LGBTQA student organizations including the Stonewall Pride Alliance (SPA), the Delta Lambda Phi National Fraternity, and the Gay Straight Alliance at Florida International University were contacted using various social media outlets and by attending their regularly scheduled meetings. As the Associate Director for MPAS LGBTQA Initiatives, access to the on campus LGBTQ population was readily available. In order to maintain a high level of confidentiality each participant was given the opportunity to create an alias under which to be identified (Seidman, 1991). Selection of several of the aliases was interesting as it provided insights to the participant's self-awareness and knowledge of the LGBT community. Hickock was derived from the name Lorena Hickock, an out lesbian who was Eleanor Roosevelt's life-long friend and believed to be her romantic companion. Pat was used as a name that seemed more androgynous given the stereotypes and gender roles one often confronts in the Latino/a culture. Margarita came from an Indian film named "Margarita with a Straw". The participant shared that the film was about a teenage girl named Laila who was living with cerebral palsy, struggling with her daily life and the realization she was bisexual. Margarita shared how the film ends with 
Laila going on a date with herself, which was symbolic of her strength, perseverance and most importantly being able to take care of and love herself, a struggle that Margarita stated she personally related to. These examples share a level of awareness the participants had about LGBTQ knowledge, history, culture and their own self-awareness about their sexual identity.

The first four participants Roxy, Mache, Cathy and Alejandra were recruited during the start of the Fall 2015 semester when I attended the LGBTQA mentors' program kick-off event. Two additional participants Tiffany and Monserrat, heard about the study through the LGBTQA student group Stonewall Pride Alliance. Luna and Margarita heard about the study via emails that were sent by the Women's and Gender Studies program. Nikki heard about the study via one of the social media outlets. Carolina was referred by a previous staff member that worked in university housing who was aware of my research.

Given the institutional setting, I did not anticipate any difficulty in identifying 15 Latina lesbians. After interviewing my tenth participant, I hit a sudden roadblock. The Fall semester had ended and I still needed 5 more participants. I reached out to the Aqua Foundation for Women, a local foundation that awards scholarships to LBT women in South Florida; they sent out the study invitation to their Aqua scholars via email. Participant 11, Conchita, responded to the request and agreed to be in the study. Snowball sampling proved to be a critical strategy in attaining the final participants. Participant number 12, Hickock, was a referral from a trusted colleague who was aware of my study. Hickock then shared the research with participant 13, Lourdes. Conchita shared the study request with her girlfriend, who later became participant number 14, 
Gertrude. I came across Pat, the last participant needed to fulfill the parameters set for this study when I asked another colleague who worked in the Women's Center on campus for assistance.

There had been 13 additional women who had inquired about and were interested in the study, but unfortunately did not meet the criteria. I kept track of these inquires in my journal and their specific interest in the research. Of the 13 individuals, four of these women identified as bisexual, two as pansexual, three as strictly queer Latinas, and 4 of them were outside of the age range parameters. When I met with these women, they openly expressed their interested in wanting to participate in a study that looks at issues of their sexual identity at an HSI. Several of them shared that this type of research was important and that they had not seen anything like this being done before. A number of the 13 women who did not qualify for the study expressed their discomfort with the label of lesbian and further explained that while they knew they loved women, the term lesbian definitely did not define them. Three of these women defined themselves as gender nonconforming queers and were adamant about not being placed in a lesbian box.

Participants were asked to complete a demographic survey in order to capture basic information from each participant (see Appendix B). This information was then organized and presented as a complete list of participants in Table 4.

The sample was composed of eight Seniors, four Juniors, two Sophomores and one Freshman, with an almost equal number of participants being born within the United States totaling eight participants, and those born abroad totaling seven. There were four participants that lived on campus in the residence halls, five that lived at home with their family, and six that lived off campus. All participants spoke two or more languages and 
represent 11 Latin America countries, the most frequently represented were Cuba with five participants, and the Dominican Republic with three participants.

Table 4

Participant Demographics

\begin{tabular}{|c|c|c|c|c|c|}
\hline Pseudonym & Age & Major & Class & Birth Country & Parents Birth Place \\
\hline Monserrat & 18 & $\begin{array}{l}\text { Biomedical } \\
\text { Engineering }\end{array}$ & $\mathrm{Fr}$ & Venezuela & Peru \\
\hline Nikki & 19 & $\begin{array}{l}\text { Political } \\
\text { Science }\end{array}$ & Soph & United States & Cuba \\
\hline Tiffany & 20 & $\begin{array}{l}\text { Elementary } \\
\text { Education }\end{array}$ & $\mathrm{Sr}$ & United States & $\begin{array}{l}\text { United States, } 1^{\text {st }} \text { Gen } \\
\text { Cuban }\end{array}$ \\
\hline Alejandra & 20 & $\begin{array}{l}\text { Exploratory } \\
\text { track for } \\
\text { sciences }\end{array}$ & Soph & Venezuela & Venezuela \\
\hline Hickock & 21 & English & $\mathrm{Jr}$ & United States & $\begin{array}{l}\text { Cuba and United } \\
\text { States }\end{array}$ \\
\hline Conchita & 21 & Business & $\mathrm{Sr}$ & United States & Spain and Chile \\
\hline Gertrude & 21 & Business & $\mathrm{Sr}$ & United States & Cuba \\
\hline Cathy & 22 & $\begin{array}{l}\text { Political } \\
\text { Science }\end{array}$ & $\mathrm{Jr}$ & $\begin{array}{l}\text { Dominican } \\
\text { Republic }\end{array}$ & Dominican Republic \\
\hline Carolina & 22 & $\begin{array}{l}\text { Business \& } \\
\text { Religious } \\
\text { Studies }\end{array}$ & $\mathrm{Sr}$ & Ecuador & Ecuador \\
\hline
\end{tabular}




\begin{tabular}{|c|c|c|c|c|c|}
\hline Pseudonym & Age & Major & Class & Birth Country & Parents Birth Place \\
\hline Lourdes & 23 & Nursing & $\mathrm{Sr}$ & United States & $\begin{array}{l}\text { Cuban and Dominican } \\
\text { Republic }\end{array}$ \\
\hline Margarita & 23 & $\begin{array}{l}\text { Women's \& } \\
\text { Gender } \\
\text { Study, } \\
\text { Psychology }\end{array}$ & $\mathrm{Sr}$ & United States & Colombia and Mexico \\
\hline Pat & 23 & $\begin{array}{l}\text { Political } \\
\text { Science }\end{array}$ & $\mathrm{Sr}$ & United States & $\begin{array}{l}\text { Dominican Republic } \\
\text { and United States }\end{array}$ \\
\hline Luna & 23 & Asian Studies & $\mathrm{Jr}$ & Peru & Peru \\
\hline Roxy & 24 & Business & $\mathrm{Jr}$ & Nicaragua & Nicaragua \\
\hline Mache & 24 & Business & $\mathrm{Sr}$ & Costa Rica & $\begin{array}{l}\text { Costa Rica and } \\
\text { Nicaragua }\end{array}$ \\
\hline
\end{tabular}

\section{Data Collection}

The data were collected through interviews. A semi-structured interview guide contained questions that allowed the researcher to learn about the participants and their experiences as Latina lesbians at an HSI (Bogdan \& Biklen, 2006). This format allowed me to delve deeper into participants' responses with unscheduled probes that provided indepth and content-rich responses regarding their experiences as Latina lesbians (Patton, 2002). The interview protocol and procedure are described below. 


\section{Interview Protocol}

The interview guide contained open-ended questions (See Appendix C). The interview guide allowed the researcher the opportunity to follow a consistent process in uncovering the essence of the phenomenon (Patton, 2002).

The interview guide contained background questions about participants' family, cultural, their perceived sexual identity development, covered in questions $1-8$. It then explored the four basic tenets that are consistent across sexual identity development models covered in questions 9-30. The four tenets covered included: (a) alienation "the experience of seeing oneself as different", (b) social exclusion "not fitting into the heteronormative majority", (c) disclosure, also known as "Coming out" or the need to announce oneself as a sexual minority, and (d) self-acceptance of a non-heterosexual identity ((Bilodeau \& Renn, 2004; Evans et al. 2010; Henrickson, 2013; Sanlo, 2004). The last part of the guide asked questions on self-acceptance and concluding questions 31-35. (See Appendix C). All questions were open-ended and encouraged the participants to engage at length by proving in-depth details regarding their experiences. The guide was reviewed by my dissertation chair, dissertation team and my peer dissertation group. In addition to the dissertation team and peer dissertation group's feedback, I also piloted the instrument with a colleague who identifies as a Latina lesbian. The review process allowed for feedback on the clarity, organization and relevance of the questions to the problem.

\section{Interview Procedure}

The data collection procedures involved direct interaction between myself and the participants. Upon identifying potential participants, I disclosed to them the purpose and 
format of the research as per all established guidelines with the institution, College of Arts, Sciences, and Education, and the Office of Institutional Research, including IRB permission. I further informed interested participants that they would have the opportunity to participate in an individual interview.

Participants were contacted initially via phone, then email and were asked to identify a convenient time to conduct the interview. They were informed the interviews would be approximately 60- 90 minutes in length. The interviews actually took from 60 125 minutes. The researcher checked-in with the participants at 90 minutes to make sure they were fine with continuing beyond the initial time agreed to.

The interviews were scheduled and conducted in the researcher's office with the exception of one interview. Alejandra's interview was conducted off site, at a location selected by her, due to her busy work schedule. The other interviews were conducted as follows: 13 were at the MMC campus and 1 at the BBC campus in the researcher's office space. The location had been identified by both parties as a safe, quiet, private and welcoming location on campus for them to meet at. Interviews were digitally recorded with the consent of each participant.

During the individual interviews the specific requirements were explained and the consent form which had been emailed to each participant prior to arriving for the interview was reviewed. Participants were given the opportunity to once again ask any questions regarding the study or the procedures. Individuals who agreed to participate in the study were asked to complete the FIU Institutional Review Board participants consent form (See Appendix D) prior to proceeding. The consent form explained the purpose of the study, expectations, how research will be used, and the intent to publish the findings. 
The consent form along with ethical reviews and procedures ensured the privacy and anonymity of the participants throughout the process (Creswell, 2009). An explanation of the participants' rights to withhold any part of the interview data they may object to disclosing was shared. All contacts and permission to proceed were established with the institution, College of Education, and the Office of Institutional Research, including IRB permission. Once all questions had been answered, the consent form was signed by the participants, collected and a copy was given to each participant for their personal records.

For each interview, the researcher made field notes describing participants' behaviors, and any other pertinent information that enhanced the researcher's observations (Patton, 2002). Field notes also included basic information about the interview such as date, time and other facts entered in a sequential format.

Following each interview, a journal entry was made to record any thoughts, impressions, and feelings that arose. The journal was also used to record any thoughts, reactions or relationships between the different themes and interpretations. The journal also allowed me to examine assumptions that arose.

\section{Data Analysis}

The data analysis started with a general review of the information collected during interviews, which included: the transcriptions and the researches notes kept during interviews. First I reviewed all of the transcripts checking for accuracy while listening to the recorded interviews. While English was primarily spoken during the interviews, participants would intermittently speak Spanish in order to convey a particular idea, saying, proverb, or childhood experience. These were then translated, shared, and confirmed with participants for accuracy. 
Upon the completion of transcript reviews, all 15 transcripts were uploaded into the NVIVO software program. NVIVO proved to be a valuable program during the entire analysis process not only in uncovering and identifying patterns, assisting with the organization of codes, but also with the managing of the data. Three main types of analysis were used in this process: (a) inductive analysis, (b) deductive analysis, and (c) comparative analyses. These are each explained in detail below.

\section{Inductive Analysis}

Inductive analysis is a method used to discover and search for meaning in the data to see what patterns, categories, and themes, emerge (Patton, 2002). To perform the inductive data analysis, I set aside my own preconceived notions, judgments and knowledge regarding the phenomenon in order to observe the experience as something new (Moustakas, 1994). This process is also known as bracketing. This was done through epoche; journaling which held my personal notes, and thoughts; and in sharing and discussing all of these with colleagues and my major professor.

The data was collected from participants' interviews. I read through the transcripts and made notes on my first impressions. As I re-read and listened to the transcripts again, I began identifying relevant pieces, words, sections, and phrases. I stayed close to the data and made sure all relevant statements, sections, and phrases were highlighted and coded as nodes in NVIVO. Significant statements and patterns were selected from the data that hold equal value and represent a segment of meaning, also known as horizonalization (Merriam, 2009; Moustakas, 1994).

Quotes from participants were used to support the findings. When quotes were

presented to support a finding, participant's pseudonyms, and the line number from the 
transcripts (i.e., Gertrude, lines 150-155) generated through the use of NVIVO software are cited. Next I clustered and created categories by bringing several relevant and significant patterns together. These overarching categories are knowns as themes. These categories were labeled in NVIVO as parent nodes.

Three themes that emerged from the inductive analysis were: (a) the trifecta effect: family, religion and gender, (b) the paradox of being Latina and lesbian and (c) institutional care. This process allowed for a greater understanding of the participants' collective experiences with the phenomenon during the inductive analysis. Each of the themes describe the participants' collective experiences of the phenomenon and are further discussed in Chapter 4.

\section{Deductive Analysis}

In deductive analysis, data is analyzed through the lens of an existing framework (Patton, 2002). In this study a rubric of a priori codes based on the conceptual framework for this study was used. The framework entails the (a) cultural background (b) identity and the four consistent experiences sexual minorities share including: (c) alienation, (d) social exclusion, (e) disclosure, and (f) self-acceptance of a nonheterosexual identity (See Appendix E). I searched the transcripts for data chunks that confirmed or contradicted the a priori codes. The data chunks were coded with the corresponding a priori codes as parent nodes and child nodes in NVIVO (i.e., CB, I, AS, AF, AC, SEF, SECA, SENC, SEP, D, and/or SA). One example is the chunk of transcript data, "I couldn't find any characters to relate to on the television because none of them had the issues that I had or were LGBT, " that was coded as alienation in society $(\mathrm{AS})$. 


\section{Comparative Analysis}

After the two analyses were completed, I moved on to the comparative analysis. In the comparative analysis, the findings from the inductive and deductive analysis were compared for similarities and differences in patterns and used to answer the research questions (Strauss \& Corbin, 1998). The emergent themes from the inductive analysis (a) the trifecta: family, religion and gender, (b) the paradox of being Latina and lesbian, and (c) institutional care were compared and contrasted with the deductive a priori rubric. The comparative analysis between the inductive and deductive analysis revealed that among all 15 participants the inductive themes of (a) the trifecta: family, religion and gender, and (b) the paradox of being Latina and lesbian where present in all segments of the deductive analysis. These are further discussed in Chapter 5.

\section{Data Management}

Data management is critical in assisting the researcher to organize the data in a manner that it is easily retrievable, understandable and manageable (Marshall \& Rossman, 2006). Data sources for this study included semi-structured interviews, digital audio recordings for each interview, interview transcripts, researcher's notes, and emails. All digital recordings were transcribed verbatim and I reviewed them for accuracy and consistency. Once transcripts were completed they were sent them to participants for member checking. Member checking is the process by which the study's participants are asked to comment on the researcher's preliminary interpretation of information collected from them (Merriam, 2009). Close attention was place on the transcripts that had Spanish to English translations, as well as those containing passages that may have been audibly difficult to decipher on the digital 
recorder. Indications were made on each transcripts for participant to review and check closely the translation for accuracy, as well as to clarify areas that were inaudibly. Upon the completion of each transcription the document was sent to the participant asking them to provide feedback within an allotted time frame. Participants received their transcription three to six weeks following their interview via email, and where asked to provide any changes or comments within a two to three-week time period from the date the document was sent.

In four instances it was difficult to receive the participants' responses given their heavy school schedules and other commitments. Three of these participants were sent a follow-up email and received a courtesy call asking them to please provide feedback by a given date. One participant met with the research to share her suggested changes, given she found it difficult to make changes in the sent document. All participants responded to the follow-up requests within the suggested time frame.

Participants were asked to make changes using Microsoft Office Word with the Track Changes application. Once all changes were made and returned, the research proceeded to review and accept all changes submitted. All interviews were finalized then entered into the NVIVO software program for analysis.

All electronic data was collected and kept in accordance with the Florida International University IRB Data Management/Security Guidelines. All digital copies and hard copies were kept in a secure location. Digital recordings were backed-up and stored on an external drive in a safe location. All printed documents were kept in a locked cabinet, in secure location. These documents and data will be kept for three years following the study, after which they will be properly destroyed and disposed of. 


\section{Integrity Measures}

The integrity of a qualitative study is reflected in its trustworthiness and is validated through a rigorous process (Merriam, 2009). It is recommended that a minimum of two procedures be used in a study to verify its integrity (Creswell, 2009). For this study confirmability, dependability, and credibility were used to validate the trustworthiness of this process. These strategies are further outlined below.

\section{Confirmability}

Confirmability is the researcher's ability to demonstrate neutrality in the interpretation of the data and aids in authenticating the results of the study (Lincoln \& Guba, 1985). Audit trails are the transparencies in the study that illustrate the steps taken in the research project from the beginning, through the development, and to reporting the finding. Audit trails in this study included the interview guide and its method of administration, and procedures and decisions made during the study. Another measurement of confirmability was through the audit trails in the inductive, deductive, and comparative analysis. That included the descriptions of the inductive and deductive analysis that described how the categories were derived and the comparative analysis that described the decisions made to determine similar and dissimilar concepts. All of these steps helped in authenticating the findings and maintaining integrity between the results and the data collection.

\section{Dependability}

Dependability refers to the consistent application of data analysis procedures utilized by the researcher that can be repeated (Lincoln \& Guba, 1985). A peer review process was used to reduce the potential for bias and increase dependability of the study. 
Peer review is when the researcher consults with colleagues or professionals to ensure the research is congruent between data collection, findings and interpretation (Creswell, 2009; Merriam, 2009). Peer reviewers consisted of fellow doctoral students in the College of Arts, Sciences, and Education. The students were part of a dissertation group in the area of adult education and human resource development that met regularly to provide feedback on one another's work. In addition to my fellow doctoral students, peer reviewers also included my dissertation committee, two current post doc students and a previous FIU graduate from the doctoral program who I had been paired with by my major professor and chair. I met regularly with my review team for feedback on the consistency and clarity of my work. They also helped me in probing my own assumptions and provided clarification when needed. My major professor also reviewed the emerged themes, the theme classifications and they were revised as needed. Parent and child nodes were also reviewer by my peer review team and discussed for consistency and accuracy. Those were then shared with my major professor for accuracy and revised as needed. These steps and procedures assisted in maintaining the reliability and validity of the study.

\section{Credibility}

A third procedure used to verify integrity is credibility. This is when confidence is established in the validity of the findings. Data collection credibility was enhanced through member checking (Creswell, 2009). Member checking is the process by which the study's participants are asked to comment on the researcher's interpretation of information collected from them (Merriam, 2009). Transcripts that had Spanish to English translations or that containing audio difficulties were sent to the four (Monserrat, 
Roxy, Luna and Tiffany) participants for review. Indications were made on each transcripts for participant to review and check closely the translation for accuracy, as well as to clarify areas that were inaudibly or that needed to be corrected. A final draft copy of the full dissertation was sent to all participant asking them for any feedback regarding the document. My written notes and information, that where maintained in my personal journal also enhanced the credibility of the study. The journal kept me grounded in the work and decreased personal bias by providing a place for me to bracket my experiences through reflections (epoche). Being able to track and realize my own development as a researcher in this process was essential in conducting good research and maintaining integrity. The researcher's journal was also used to record any decisions made during the research process, and can be relied upon as a reference.

\section{Summary}

This chapter introduced the methods of the study including the purpose statement, research questions and the phenomenological framework. The researcher's autobiography, assumptions and journal process were shared. Data procedures were described which included the researcher's sampling methods, data collection, data analysis, and data management. Finally, integrity measures used in the study were discussed. 


\section{CHAPTER IV}

\section{INDUCTIVE FINDINGS}

In this chapter the findings that emerged from an inductive analysis will be presented. The data was collected from participants' interviews. Quotes from participants were used to support the findings. When quotes are presented to support a finding, participant's pseudonyms, and the line number from the transcripts (i.e., Gertrude, lines 150-155) generated through the use of NVIVO software are cited. The themes that emerged from the inductive analysis were: (a) the trifecta effect: family, religion and gender, (b) the paradox of being Latina and lesbian and (c) institutional care. Each of the themes is presented and discussed in-depth below.

\section{The Trifecta: Family, Religion and Gender Roles}

A trifecta describes a situation where three elements or qualities of great importance come together at the same time (Macmillan, 2016). For the participants in this study a trifecta was formed by the concepts of family, religion, and gender. Throughout the participants' interviews I became aware of the importance of these three concepts, their reoccurrence, and the interconnections with one another. Each of these are integral to the participants' experiences as Latina lesbians and are discussed further below.

\section{Family}

Family within the Latino culture, known as Familismo is defined as having a strong bond where loyalty, closeness, respect, and the ability to contribute to the wellbeing of the nuclear and extended family is central (Ayón et al., 2010). Particiants' immediate family members also include extended members such as grandparents, aunts, 
uncles and cousins. Hierarchy within the family structure also plays a significant role. The father is perceived as the authority figure in the home, while the mother is seen as being submissive. We also find a generational hierarchy where grandparents and elders are integral and revered. Participants shared experiences involving different family member's roles and their importance when it came to navigating their lesbian identity.

Among Latinos, Familismo is described positively when it is a source of support for the individuals, and negatively when expectations are not met (Hackethal et al., 2013). For Latina lesbians the possibility that they might lose an important support system by disclosing their lesbian identity to their families is daunting and has been a major issue when deciding to disclose the lesbian identity. While many of the participants initially hoped for acceptance of their lesbian identity from their family members, many were met with hostility and disappointment. Luna experienced this when she disclosed her sexual orientation to her mother, "In the beginning my mom was not accepting at all. I was 17 when she found out and it was really bad. She insulted me, it was a really harsh few months and I ended up moving out" (Luna, lines 35-36). The negative effects that their lesbian identity has had with their family has been shared by others. Roxy explains how being a Latina lesbian has been the impetus of everything negative in her life with her family:

My family has conservative values, their take on it is pretty much that if there are same sex couple marriages, then what is going to stop gays from having sex with animals. That is pretty much their thoughts on it and it's extremely sad. Ultimately everything that goes wrong in your life, they blame everything on the fact that you are gay, so [pause] yeah. I realized that I was an outsider in my family when, I came home and initially came out to my mom. She began to cry as though I was dying or something completely terrible has happened to me, my mother is a very strong person and I have never seen her cry. So she began to cry 
for that and asking questions like why, how did this happen? (Roxy, lines 81-84 \&114-118)

The emotional impact of recalling these painful experiences with her family became evident during Roxy's interview. She was so dismayed by what she had shared that we stopped the interview momentarily until she regained her composure.

For these Latina lesbians the thoughts of losing loved ones as a result of disclosing their lesbian identity is an ongoing struggle. Conchita shared the critical role her grandmother played as her primary caretaker while growing up. Although she sees her grandmother as one of the most important persons in her life, Conchita does not foresee sharing her lesbian identity with her, given her grandmother's negativity toward lesbians. Another participant, Mache shared her family's disapproval of lesbians and the extent they would go to in order to stop her from being a lesbian.

So they heard a rumor that I was a lesbian and that I was dating my best friend. So they stopped, no prohibited me from going out with her, and hanging out alone with girls. They would say, "that it was very wrong and people were going to say this and that about me". I have a gay friend who is here at school with me, and they didn't want me hanging out with him because they worried people will think I am a lesbian. Everything starts in the family. Oh my God if my own family thinks I am a lesbian and they talk about lesbians the way they do, now imagine how everyone else outside of the family will be, (Mache, lines 120-127)

Mache will be returning home to Costa Rica to be with her family at the end of the semester. She is already experiencing increased levels of anxiety and stress. She goes on to explain, "While here (in the United States) I'm free, but in two weeks I'm going home, uff. This is the first time I realized that I accepted myself the way I am, but I am now apprehensive about going home" (Mache, lines 133-136).

The most alarming concerns for these Latinas regarding their lesbian identity and their family has been the amount of violence and abuse they have experienced. Hickock 
shared she was having a conversation with her father regarding her lesbian identity. Here she gives us a glimpse into the verbal abuse and hostility she experienced, "We were talking about a friend of mine that my dad found out was gay. He looks at me and says, 'Well, if I ever find out that you're a lesbian, I'm going to sew your vagina lips shut!' I took a step back and was like what? Initially I couldn't say anything I was in shock (Hickock, lines 209-212).” The level of anger and vulgarity her father had exhibited was overwhelming for her. Aside from psychological damage these participants experienced from family members as a result of their lesbian identities, others experienced physical injuries as well. Tiffany recalls the most violent beating she received from her parents when she was 16 ,

One of my girlfriends and I dated in $10^{\text {th }}$ grade, nothing to serious, didn't last more than 2 or 3 weeks but it drew a lot of attention at school. The director of the school she held a PTA meeting. Invited all the parents, to discuss the relationship between me and my girlfriend and that's the only way that my parents found out about us. So mom came. They were describing the two people involved, with no names. The other parents knew who they were talking about because the kids in the school would tell them, 'Oh, they're these lesbians at my school', but my parents didn't know. So they were just listening, and they were trying to figure it out. Then they asked me who are the students that their talking about? Oh it's these two people, me and my partner. I couldn't recall a more severe beating when I got at home. As if the beating wasn't enough, immediately after that I got switched from schools. It was I think the worst thing that ever happened to me. (Tiffany, lines 216-229)

The levels of hostility and abuse these Latinas experienced from their family as a result of their lesbian identity was shocking.

Aside from the aggression and resentment experienced by participants, the families also exhibited disapproval by either being dismissive or completely ignoring their lesbian identity altogether. Alejandra and Margarita shared how even though they had disclosed their lesbian identity to their family, their parents either ignored or were so embarrassed 
by their daughter's sexuality that they were dismissive of it. These participants shared uncomfortable family gatherings where they were asked by extended family members about their boyfriends, and how their parents quickly respond by either changing the topic of conversation or redirecting the question to another sibling or family member.

Despite these experiences, many of these women have found it imperative to maintain their family ties. All are currently in communication with their family members to some degree.

\section{Religion}

Religion has been defined as an individual's institutionalized or personal system of beliefs, attitudes and practices concerning the cause, nature, and purpose of the universe, especially when considered as the creation of a God(s) or supernatural agency, and often containing a moral code governing the conduct of human affairs (MerriamWebster, 2005). Religious affiliations and beliefs continue to be a strong cultural ideology in the Latino community (Braton et al., 2014; Ecarnacion, 2011; McKenzie \& Rouse, 2013). Among Latinos, many of the traditional religious views and values reject homosexuality (Chaturvedi, 2014; Ellison et al., 2011; McKenzie \& Rouse, 2013). The rejection and condemnation that Latino sexual minorities experience today can be seen among the experiences of the participants in this study.

There were six different religious affiliations mentioned in this study by participants including: Catholicism, Jehovah Witness, Born Again Christians, Baptist, Mormon, and the United Church of Christ. The effect that religion has had on many of these participants has been overwhelming when attempting to develop their lesbian identity. Negative religious messages regarding their sexuality were received from 
different sources including their church, school, and peers. Alejandra shares an on-

campus encounter with a student who condemns all gays based on his religious views.

We were canvassing on campus for work. So me and one of my co-workers go up to a student and we started talking to him about gay issues. He just got into an argument right away saying that being gay is a choice, and he started bringing up the Bible, he was like just another Bible thumper. I went to Catholic and Christian schools my entire life so I know the Bible. He's there and brings out the bible story of Sodom, the town that got burned, Sodom and Gomorrah. He brings up that story and I'm like okay, but if you do a little bit more research you'd figure out that yeah the acts that were committed they were homosexual, but there's also rape. It didn't matter if they were homosexuals or heterosexual raped, it was rape. That's why God burned down the town not because it was gay rape it was just because there were strippers and prostitution and drugs and all those sort of stuff and if all you're looking for is that one message, then you would think its homosexuality. Of course you're gonna think that. So he still basically said, "religion is against gays so then you go to hell". That was a horrible experience, he finally ended up walking away and just mumbled something like whatever. (Alejandra, lines 246-259)

Conchita who works on campus shared how religion has been influential in her decision not to share her lesbian identity with her supervisor and co-workers. She further explained how she is surrounded by extremely religious co-workers who were always asking her to go to their church, and was most bothered with her supervisor's repeated suggestions that she attend her church where her husband was a pastor, which based on previous conversations Conchita perceived to be ultra-conservative. She goes on to share,

I never went, and to this day I still haven't, but my point is that I was surrounded by very religious co-workers. I took the liberty to NEVER come out to them, any of them. I didn't want them to treat me any differently, nor did I want to risk ending my employment with the department. I hated hearing them make comments about FIU employees in other departments who were LGBT, like "Soand-so -oh he's gay, you know!" I hated hearing that (Conchita, lines 280-286).

In addition to peers, co-workers, supervisors and other students, these participants 
also encountered religious issues among their family members. The intersection of religion and their family values was described as a barrier by most of the participants that has inhibited their families as well as their own acceptance of their lesbian identity. For Gertrude, her parent's non-acceptance of LGBT individuals is directly related to their religious beliefs and has stopped Gertrude from disclosing her lesbian identity to her parents. She is certain that if she were to disclose her sexual orientation to them, it would be viewed as negative, and she would be viewed as needing psychiatric help. She went on to share how growing up in a homophobic family environment, with ultra conservative religious beliefs, affected her ability to accept her own lesbian identity (Gertrude, lines $105-110)$.

The idea that a religious indoctrination process could save these women was also evident in several of the accounts shared. In the passage below, Tiffany recalls a traumatic childhood experience which stemmed from her lesbian identity and a religious encounter with her family.

I got a lot of messages such as, "Oh, you're gonna go to hell and it was against religion. You're gonna regret your decisions because you could choose to do something different you don't have to do this. You could suppress those feelings and then move on with your life." Like, how could they ask me to pretend I'm something I'm not? Am I just gonna live alone for the rest of my life? No. I remember at some point my dad didn't let me visit my mom's side of the family and he kept me at his house every weekend. When my brother would go visit my grandmother, my aunts, and everyone else and I would get sent to my step grandparents' house, and it was like Bible study every single week. It was always about, "God loves you," and it would be so overwhelming because they would be crying for me. They really felt in their hearts because of religion that something really bad would happen to me if I kept going down this path. I knew what their intentions were, but it was really damaging for me for a long time. I'm still in therapy. (Tiffany, lines 60-74 \& 395-402) 
Gertrude's parents are spiritual leaders within their very strict religious denomination, where being homosexual is not allowed. This has made her very sensitive to the intersections between religion and her lesbian identity. Growing up, her parents have used various tactics to proselytized and send negating messages about homosexuality. While Gertrude knew she was a lesbian since ninth grade she refused to accept it. Below is an account of her struggle with her parents.

I was going to church every weekend, and the common notion was that that type of lifestyle was not allowed or going to be welcomed in that church. I knew that if I wanted to pursue that type of lifestyle I couldn't do it in that religion. So my parents realized I was very close with this friend of mine in high school. My parents always kind of felt that I was inclined in that way, so they banned me from talking to her. They even spoke to the counselors to make sure that we didn't have any classes together at least for my sophomore year. At that point I knew I was a lesbian and throughout high school they kind of brainwashed me with religion and afterwards said that it was my friend that was like that and not me. They said that I wasn't like that because I was Christian. They made me believe that I was a good Christian and that it wasn't the life for me. They would say, "como que eso se me hiba pegar", translated means, that I was going to catch that. I kind of got brainwashed through that process and so I didn't want to be gay because of all the implications it would have for my religion, I wouldn't be accepted, or go to paradise. (Gertrude, lines 29-36, \& 84-92)

Participants clearly understand that when it comes to their family's religious position and their family values regarding their sexual identity. Monserrat's explains how her extended family in Peru are mostly Catholic, and even though she doesn't see them as being religious fundamentalists, she is aware that they will probably not react well if they were to find out she is a lesbian (Monserrat, lines 160-170).

Participants also articulated that despite the fact that their families used religion to prevent their lesbian identity development, the participants still love and have a strong sense of loyalty to their family members. Love and loyalty are a main focus of familismo and Cathy shares an interesting account between her grandmother, mother, and religion. 
"When my mom found out I had a girlfriend, after the whole burn-in-hell part, because that's always the genesis (no pun intended) she just kept trying to get me to change and my grandmother while not being against it never spoke up for it either to support me. Yes, yes religion was a big part. I wasn't gay. It was the devil in me. It's what it was, she still loved me though. My mom said that to me. She is a very loving woman except for that. I don't even resent her because it's just the way she was raised and what the religion taught her. (Cathy, lines 240-245)

While her mother and grandmother are religious and see homosexuality as wrong, Cathy knows they still love her and sees them to be extremely important and irreplaceable in her life.

Out of all the participants' religious experiences, only Roxy shared a positive experience with her religious denomination. This came after many unsuccessful searches for a church that was welcoming and affirming. She was able to find a religious denomination that she encountered at a gay event, Miami’s Gay Pride Parade, that had an immediate impact on her awareness and acceptance of her lesbian identity.

The value of religion in the Latino community is important and many of these women, despite their religious experiences, shared that they still viewed themselves as spiritual individuals. While many of them do not agree with their denominations' religious views about their sexual orientation and homosexuality, there are universal teachings among their religions that they did agree with such as loving your neighbor, doing no harm to others and honoring your parents. It is important to point out that aside from Roxy's positive interaction with religion, the majority of these women's experiences with their denominations were negative and had a damaging impact on their sexual identity development. 


\section{Gender Roles}

Gender is a social construct which generally refers to the state of being male or female with reference to social and cultural differences (Fausto-Sterling, 2000). Within the Latino culture, gender roles are distinctly defined as marianismo for women, and machismo for men (Galanti, 2003; Jezzini, Guzmán, \& Grayshield, 2008; Villegas, Lemanski, \& Valdéz, 2010). Women are expected to be pious, beautiful, feminine, exceptional mothers and wives who are subservient to their husbands. Men are expected to be domineering, protectors and are seen as the decision-makers. These roles promote and maintain a heteropatriarchy, (Hernandez \& Curiel, 2012; Lopez, Corona, \& Halfond, 2013; Torres, \& Pertusa, 2003) that has proven to be challenging for these Latinas when trying to develop their lesbian identity. A factor that influences their lesbian identity development is their gender expression or presentation. Gender expression or presentation is the physical manifestation of one's gender identity, usually expressed through clothing and mannerisms (Fausto-Sterling, 2000). The challenges and issues shared by these Latinas regarding gender roles expressed in college and among peers, in the intersection with families, and the intersections with families and religion.

Gender roles in college and among peers. For participants whose gender expression is gender non-conforming, their experiences in college among peers and in the classroom have been challenging. A gender non-conforming individual is someone whose behavior or appearance does not conform to prevailing cultural and social expectations about what is acceptable or appropriate to their gender role (Yes Institute, 2015). For gender non-conforming lesbians who do not ascribe to the expected Latina gender role, they often find it challenging with their Latina identity. Cathy shared how 
she has experienced homophobic remarks from Latino and Latina students on campus. She perceives their homophobia is the result of them being threatened by her lesbian identity. Cathy recalls an incident with a Latino male student at an event on campus where she was teaching individuals how to merengue, "So I was dancing with the students and some guy didn't know how to dance. So I offered, Alright. I'm going to teach you but you have to let me lead, and his response was, Oh, you want to lead because you're gay. I'm not going to let you do that. It's because you're gay, so stop. Stop trying', I was shocked". Cathy went on to share how others heard him but no one did anything because people are so comfortable with their heteronormative roles. As a gender nonconforming Latina lesbian, Cathy has had experiences with other Latinas who have judged her and questioned her Latinaness. She attributes their close-mindedness to being traditionally raised, especially in Miami where almost everyone is Latino (Cathy, lines 583-600).

For Latina lesbians who present as gender conforming or cisgender, their experiences have also been challenging. Gender conforming or cisgender is when one's gender presentation conforms to both their biological gender at birth and societal norms (Yes Institute, 2015). For these Latina women who identify mostly with their Latina gender role, the challenge for them is when navigating their lesbian identity. Lourdes points out that although she is cisgender, the biggest challenge for her as a Latina lesbian is the societal messages and cues she has received about the expected gender presentation for lesbians.

An issue that I find myself struggling with is that I'm very feminine. A lot of times gay women are told by society that if they dress a certain way and act a certain way, they'll probably accept you more. So they'll get it more, hence 
they'll treat you better. Um because of my culture, one, I don't want to dress that way, and two I don't want to identify that way, it would be worst for me to identify and dress in a manner that is not feminine. I am also okay with the way I dress and the way I like to dress. Um but that in itself has made me struggle, because it's made other people understand me less. Which confuses me because I am a woman who feels like a woman, who likes women. And yet I am less understood. If you're female you have to be with men, and if you are female-ish or you have a large amount of femininity then you have to look this way, otherwise they don't get you, and they don't accept you. I find it a struggle. I get things like "oh I didn't know, or I would have never expected you". Okay what so what does gay look like? Because if I we're being truthful our generation doesn't know what gay looks like, and I'm hoping the next generation has no perceived "look" for being gay. That's where I want to get to the point, you know where I don't think there is a look for gay. I think for people who identify with dressing a little more male-ish, it's completely their choice 100\% (Lourdes, lines 813-826).

Conchita shares her experience of being gender conforming and how it has made her experience as a Latina lesbian less difficult.

The initial judgment that someone might make about me is that I'm straight or that I don't come off as gay to them. I guess that has made my experience as a Latina lesbian easier. I haven't experienced as much confrontation as others because I have a couple factors working for me though. I am I guess you would say gender conforming or cisgender (Conchita, lines 412-416).

Conchita's ability to pass as a heterosexual Latina woman based on her gender presentation has provided less conflict. Despite gender being a socially constructed concept (Fausto-Sterling, 2014), we see examples of how expected gender roles have affected the participants' development of both their Latina and lesbian identities.

Gender roles and the intersection with families. The intersection of family and gender has also proven challenging to these women in various instances. From a very early age, Alejandra found it difficult to conform to her family's gender expectations of her. She shared how while growing up all she saw at home were extremely feminine women, who enjoyed wearing dresses, make-up, talking about boys and being what she defined as "girly". Gender roles were extremely confusing to her then and still are one of 
the hardest things to accept (Alejandra, lines 454-463). Monserrat discusses how as a child she enjoyed playing football, wearing sports clothes and had behaviors that in her Venezuelan country and Latino culture were usually associated with boys. She recalls how her brother disapproved and how he was constantly picking on her. According to him she was, "acting like a boy". She goes on to share how those gender biased comments would make her feel like an outsider with her family, and she was even momentarily confused about her own gender identity because of the constant ridicule she received (Monserrat, lines, 153-158). For Cathy, the struggle of not fitting into the Latina gender role made it difficult for her to affirm her Latina lesbian identity. When she came out to her mother, her mother attributed Cathy's lesbian identity to Cathy's desire to be a man. She recalls how her mother's misunderstanding of her lesbian identity resulted in an explosive argument about assigned gender roles and family duty.

"Is it because you didn't have a father figure? Are you trying to take his role in the house? Are you trying to be the head of the house because you think we need it or because I've told you how much it establishes order and we don't have it? So did you just think that it's your job to inherit it? ....Stop trying to be a man because nobody is going to want to marry you. God forbid that you're a Latina woman and you don't want to get married and have children to carry the family name". She continued, "Your degree and all of this, what is it worth if you can't have a family?" (Cathy, lines 258-268)

The assumption that Cathy's lesbian identity has prevented her from fulfilling a Latina women's role is a misconception. Her mother's belief that she needs to be with a man in order to be happy or fulfilled, and that she cannot have children or a family, are all beliefs rooted in heteronormativity. These heteronormative beliefs within Latin culture, even in cases where these women are out to their family, create high levels of anxiety as they 
attempt to develop their lesbian identity. Gender roles and the continued importance of them in the Latino culture has been established by the participants in this section.

Gender and the intersections with families and religion. Given that

Marianismo is derived directly from a religious veneration to the Virgin Mary (Bermudez et al., 2010; Galanti, 2003; Jezzini, Guzman, \& Grayshield, 2008), we see how religion intersects with gender and family among these women. The following illustrates how religion, family and gender are all interconnected for Mache. For her, there is an impending feeling of doom if she chooses to come out because she is not following her religion nor the gender expectations. That decision will have a negative effect on her family.

Recently two of my distant cousins "primas lejanas" came out, both of them, and of course my family was like, "OH MY GOD" can you imagine? Their father is destroyed, he is crying all day and night in a room and he has depression and they think he's going to have a heart attack. I was like "Oh my God," if my parents only knew. Their life is over, they are going to hell, because they are not following what God made, one woman and one man. My immediate family believes this too. My father said that gays are promiscuous and that homosexual sex is UNNATURAL, and off course you go straight to HELL. My parents really likes and care about one of my gay friends, but my mother always says "OJALA SE ARREGLE," [translation: hopefully he'll fix himself], she thinks it is something that could be changed. (Mache, lines 80-91)

The troubling intersections of gender, religion and family created negative experiences that led these women to depression and anxiety. The trifecta created by family, gender and religion has been harmful and inhibiting to their self- actualization and lesbian identity development.

\section{The Paradox of Being Latina and Lesbian}

During the inductive analysis, the paradox of being a Latina and a lesbian emerged as a theme. A paradox is a statement or concept that contains conflicting or 
contradicting ideas that seem impossible but are actually true or possible (MariamWebster, 2016). For participants in this study having both a Latina and lesbian identity is seen as a paradox through their cultural lens. Within the Latino culture, Latina has been defined through the Marianismo construct where women are expected to be selfsacrificing, pious, beautiful, feminine, exceptional mothers and wives who are subservient to their husbands, and are committed to caring for their family (Epsin, 2012; Galanti, 2003; Villegas, Lemanski., \& Valdéz, 2010). Lesbians are defined as women whose sexual orientation is toward another woman. Latina lesbian is a complex cultural and political identity for women who share historical commonalities, ethnic and sexual identity, and who face discrimination as women, Latinas, and lesbians (Pickett, 2013). Some Latina women refuse to use the term Lesbian because of its stigma within the Latino community and out of fear of the harsh consequences in their communities. I found this to be the case in trying to identify 15 Latina lesbians for this study. In looking at the paradox, I first observed how participants viewed their Latina identity and lesbian identity in opposition to one another, then how they personally navigated these identities, followed by how these identities intersected with one another.

\section{The Paradox Between Identities}

Among Latinos, the topic of lesbian is perceived to be taboo, and is not seen as acceptable. A Latina who deviates from the rigid heteronormative Latina role within the community and finds herself involved in a loving sexual relationship with another woman, becomes the target of oppression, exclusion and discrimination (PeñaTalamantes, 2013; Torres, \& Pertusa, 2003). These Latinas are seen as either being sick, immoral or as women who desire to be men (Espín, 2012; García, \& Torres, 2009). By 
identifying as Latina lesbians, they risk losing their home, family, and in some cases even their lives. The shame, guilt and possible losses they may encounter make it almost impossible for their Latina identity and lesbian identity to co-exist, thus the paradox Among some Latino communities, in addition to the many negative stigmas and stereotypes, lesbians are also invisible or non-existent (Kumashiro, 2001). Mache shared how while living in Ecuador she experienced and observed a very hostile and homophobic climate toward gay men and shared that speaking about lesbians is taboo. While she lived in Nicaragua, she learned that gay people were considered the lowest class of all people, she was specifically referring to gay men. She shared that the perception is there are no such things as lesbians in Nicaragua. She recalls living there 10 years and never seeing or encountered, as far as she was aware, another lesbian during that time. She was shocked to find that many of her experiences with her Ecuadorian and Nicaraguan friends here in Miami have been similar. She recently attended a picnic where she attempted to share with a close Nicaraguan friend that she was a lesbian and they responded, “don't even joke about something like that, someone here might hear you!" (Mache, lines 101-112).

Participants noted that their on-campus interactions reinforced the contradictions they received about being Latina and lesbian. Experiences with their peers at their HSI sent negative messages about their identity as a Latina and a lesbian. The judgmental negative perceptions about being Latina and being lesbian are reflected in Cathy's account below:

Other Latinas, they see me and they're like, "Okay." She knows how her culture works. She knows that this is what's expected of us as women. And then when they see or find out that I'm a lesbian, it's like, "How dare you. How dare you be 
raised as you were and say that-- how dare you be proud and say that you are a Latina?" Because again, we're also traditionally raised, especially in this area. In our cultures, people give off this attitude as if I'm destroying the foundation of being a Latina woman. "How dare you try to say you're Latina when you are this, when you are a lesbian? You do not stand for what we stand for." And if I try to bring anything up like, "Well, I can have kids. There's many different ways."

They're like, "No, but that's not the way it's supposed to happen. That's not what happened with our parents. (Cathy, lines 571-581)

It is important to note that among the on-campus experiences participants had involving their conflicting identities, the individuals involved were all perceived as Latinos. This demonstrates the paradox of their experiences among members in their Latino culture.

These women experience the paradox of being Latina and lesbian by feeling the need to be several different people at the same time. The troubling intersection of gender, ethnicity, and sexual orientation makes it impossible for them to have a sense of being whole. By diverging from their expected heteronormative culture, they have experienced different forms of oppression. They have face issues such as sexism and heterosexism and as a result are constantly trying to redefine themselves in order to create communities that embrace them for who they are.

The contradicting messages these women received about being lesbians and Latina and how they have experienced being a Latina lesbian has created a paradox for these women. In the following, we see how they attempt to resolve this difficult puzzle by navigating and intersecting their identities.

\section{Navigating the Identities}

For these women attempting navigation between their Latina identity and lesbian identity is an ongoing and arduous process. Learning how to navigate their identities have included developing different strategies. One way the participants have chosen to 
navigate their Latina lesbian identity is by being selective with whom they choose to disclose or not disclose their lesbian identity. Gertrude shared how exhausting it was to keep her lesbian identity from her parents specifically, but until she is financially secure and emotionally ready to disclose this is her way to best navigate this paradox.

For others, leaving their families to go away for school, dating men and denying their lesbian identity have been ways they have tried to navigate their Latina lesbian identity. They see navigating both identities as being difficult but necessary in order to be who they are. Some women used other labels such as bisexual or queer that seemed to be more acceptable. Margarita explained her rationale for using a different label, "Since it has such a negative stigma to it, at first I didn't even want to say that I was a lesbian. I would say that I was a queer or bi because I didn't really want to say I was a lesbian. So I was hiding behind those other labels, so I wouldn't have to say it. I'm more than okay with it obviously now and it's been a long difficult journey (Margarita, lines 288-291).”

Cathy, Roxy, Hickock, Tiffany and Conchita all had boyfriends as a way to navigate their lesbian identity. Participants were under the notion that if they dated men they could give the appearance of being straight among their family and friends, although each mentioned how they knew they were really lesbians. Cathy shared her experience with dating men.

So I started dating guys and worse than that I just starting sleeping around, which is horrendous for a 15-year-old and not healthy whatsoever especially in Miami and they were way older. I felt dirty every time I slept with a man. It just didn't make sense. Everybody's like, "It's just the first time sucks," so I let it go but then the second time I said that again, and then in the third, and the fourth, and so on and so on, and so eventually I would just have boyfriends for the sake of my mom. "See, she's dating "she'd say ecstatic. Or for the people at school because, again, I've always been quiet in my house and my mom never knew much, but 
people in school, if I'd go a year without dating anybody, they would ask, "So what's going on?" I hated everything dating guys entailed but I did it to, keep up the image of being straight (Cathy, lines 100-112).

Lourdes shares an interesting example of how she tried to navigate her Latina and lesbian identities. Even though she is currently out to her family, and she perceives them to be okay with it, she still finds it challenging to navigate what being Latina and lesbian means for her, given the cues and messages she received from the Latino culture. This example illustrates her own internal struggle in navigating her Latina and lesbian identities.

[Begins in the middle of the sentence] and so I'm out, my whole family knows and everyone's okay with it. I still struggle with that thought because the wedding is just gonna look different you know, and in a Latin family, you know a lot of times that's not acceptable or that's not what we're taught and I don't know, yeah being a Latina lesbian those two words just don't seem to match even though that's clearly what I [pause] I don't think, I know and I quote, "living in a generation that is going to be able to define that. But $\mathrm{Im}$ still coming from somewhere that possibly there is no definition for it (Lourdes, lines 97-104).

For these participants, making the decision on how to best navigate this paradox was not easy. For some, attempting to navigate these identities was painful, humiliating, and embarrassing.

\section{Intersections of Identities}

Reaching a point where the participants' Latina identities and lesbian identities come together and intersect has proven to be equally challenging. In order for these identities to intersect, Latina lesbians learned to confront and manage the heterosexist and homophobic oppressions they experienced within their Latino communities and family.

Most participants have chosen to come out to family and friends. Margarita has integrated her identities into being an out and open Latina lesbian. She recently overcame 
what she called her final hurdle which was to disclose her identity to her father. She

knows that it is not wrong to be who she is. She shared in her interview,

It's important because I want people to know. I want to be able get married. I want to be able to love who I love. It's really important to identify as a Latina lesbian, to me at least. Because it just is you know. My journey; there has been ups and downs of course. I think it's more like when I didn't want to come out with myself. That coming out to yourself process is very hard or it was very hard. Now I'm very happy where I am. I am very happy with my college experience, just everything in general. In terms of my father that's not accepting it, I'm fine with that. I've come to terms with that now. It's only been a short time, but I'm okay with it. I understand, we're not all going to have the same view and it's okay for him not to be okay with it (Margarita, lines $101-103$ \& 285).

Since this interview, Margarita has taken another major step in further integrating her two identities. She recently informed me that she married her long-term girlfriend.

The Latina lesbian paradox was felt and shared by all the participants. The personal battle over fitting into their Latina identity and lesbian identity was a source of angst among them. While there has been some research on the different kinds of oppression Latina lesbians experience (Saavadra, 2001), this dissertation has begun to look at the intersection of these two identities and how it impacts Latina lesbians at an HSI.

\section{Institutional Care}

Institutional care stems from the ethic of care model where educators have a moral obligation to do what is right to meet the fundamental needs of the students (Noddings, 2013). A student's level of university comfort and support are positively connected with their persistence in college (Gloria, Castellanos, Lopez, \& Rosales, 2005). College students who are marginalized look for institutional cues as to whether or not they belong or are welcomed in their academic setting (Walton, \& Cohen, 2007). The importance of finding, having, or witnessing institutional support and care was noted as 
being valuable by the participants during the interviews. Institutional care was identified through their interactions with their peers, faculty, staff or observations they made regarding the overall campus experience. The key concepts discussed in this section include visibility on campus and support systems from both an academic and student affairs stand point.

\section{Visibility on Campus}

One theme that was shared by all the participants was the importance of visibility on campus. Visibility on campus has been seen as an important issue in changing societal perceptions towards LGBTQA people as well as a mechanism for sexual minorities to meet other members of an often invisible community (Rhoads,1997). The invisibility of LGBTQA issues on campus has been closely associated with perpetuating negative stereotypes about sexual minorities, oftentimes forcing them to stay in the closet and inhibiting their sexual identity development (Rankin et al. 2010; Renn, 2009; Wall \& Evans 2000). The issue of visibility was something the participants noticed on campus in several different instances.

The visibility of the LGTBQA community on campus for some was a deciding factor in whether or not to attend this HSI. Roxy, for example, shared how having an LGBTQA component was a deciding factor and described its impact on her.

Well the big thing was the fact that there was an LGBT program here. I think that was what really sold me to this HSI and I think in general FIU is kind of getting a little name for itself within the city of Miami, so I just felt that it was like the next step. Oh man, well from the beginning getting the resources of the LGBTQ program was extremely important. I was very much in a place where I didn't know of any LGBT resources and maybe because I was just so confined, and I was not aware of any other organizations that were LGBTQ and had a big Hispanic population. So for me, it was extremely important to have and feel 
welcomed by this institution that had a program, and had a lot of queer Hispanics to relate to. (Roxy, lines 48-51, 186-190)

Having a visible LGBTQA component at the start of the students' college experiences mattered. Alejandra talks about her first day on campus and seeing the LGBTQA office. She mentioned how important it was for her to be able to observe something LGBTQA related during her orientation to the institution.

I was walking around orientation and there was a booth for LGBTQ and I think that she knew I was gay which I don't know how could that happen, it's a joke by the way. And she called me over and I filled out the paperwork and stuff. I went to religious schools most of my life so I'd never seen anything like that allowed in the schools, I thought that was really cool. (Alejandra, lines 121-126)

Alejandra's appreciation for the LGBTQA presences on campus is further expanded upon in her next quote. Here she implies a sense of inclusion and normalcy on campus which has been echoed by other participants.

I thought it was really cool that a school was accepting of having clubs for LGBTQ individuals and having events where there's more of like a limelight or more exposure to that social location so that people can gain knowledge and be like we're not freaks, we're people just like you. Like the coming out thing that they had. That was really cool and that's why I joined GSA because I've never been a part of that before. (Alejandra, lines 191-196)

Some participants indicated that although they did not get involved directly with any LGBTQA initiatives on campus, they were still very conscious of the visible LGBTQA presence. This theme of visibility and being on an open and welcoming campus was shared by several participants. Lourdes for example shared the impact of one campus LGBTQA visibility strategy she is aware of and its impression on her at the individual level.

I, I pinpoint that pride pin anywhere on campus, I notice the person that wears it, I don't say anything to them but I never forget, If I know them especially I 
never forget that they wore that and something as small as that affects me. Imagine that on a bigger scale, university wide. (Lourdes, lines 788-790)

The pride pins on campus have also been noticed by and left an impression on Conchita,

I was a freshman and you walked up to the booth where I was sitting, back when I worked for the department on campus. You were wearing your rainbow pin, and I asked you what your pin symbolized? You introduced yourself and what the pin represents. I responded "Wow, I didn't know we had that here or that an association of that sort even existed. (Conchita, lines $274-278$ )

Monserrat adds the following regarding visibility:

I think the Writing Center has certain offices where they have the pink triangle on their doors. I noticed there are pink triangles throughout campus as well, even though in very small amounts, but it makes me feel better. Also, when I attend tutoring at the tutoring center in the library, I feel very safe because I know I will not be discriminated. People also seem to care less about someone else's sexual orientation because more attention is concentrated on the students' need and requirements to graduate successfully. (Monserrat, lines 129-134)

For participants, the visibility level of LGBTQA on campus was a common theme they all shared. Other than two instances of marginalization due to the Latina lesbians' decision to wear a pride pin, all other instances of LGBTQA visibility shared were positive and assisted in the development of their Latina lesbian identity.

\section{Support Systems}

Support systems are defined as a network of people that provide an individual with practical or emotional support (Mariam-Webster, 2016). Campus support systems can help a sexual minority feel connected to their institution and possibly aid them as they maneuver through their sexual identity development process (Bilodeau, \& Renn, 2005; Evans, Forney, Guido, Patton, \& Renn, 2010). Having a support system on campus was something participants experienced and were able to talk about openly. 
Mache, Alejandra, Monserrat, Cathy and Roxy are all involved with the

LGBTQA Mentors Program at their institution. They have discussed in depth how this

program has provided them with support while navigating their sexual identity

development. Mache begins by sharing her gratitude for the program.

It is extremely important, I had a weight on my shoulders but now it's off. Now that I am involved in the mentors program I am more free. I felt welcomed in the mentor mentee program. I have this incredible mentor, he got me involved in the events the office was having. I noticed when I went to the first event how proud the people that are there are of themselves and I was like oh my god they are speaking and doing something and I'm not doing anything for this. It makes me realize how they are doing something for people who can't speak for themselves. This is why I love FIU, it has given me something I thought I would never get. It has opened the doors so I can be me. (Mache, lines 132-133, 174-180)

For Alejandra, the level of support received was critical in order for her to

continue attending college. She had been kicked out of her home during her freshman year, and reflects on how instrumental the LGBTQA services on campus were in her being able to continue to attend school.

So a few days after I got kicked out, after a lot of thinking, I decided that I did have to end up dropping out, and usually students who drop out, they have such a hard time getting back in because you obviously have to reapply, you have to go through the process, it's just such a huge deal, so everybody around me was scared that if I did drop out, that I wouldn't be...like coming back, not because I didn't want to, just because it would be so hard to get back. Thankfully, I went to go see the LGBTQA person on campus as soon as everything happened and I explained to her what was going on, and she pointed me in the direction of this other advisor that works at FIU, I believe her name was... Her name was Ana, and I saw her recently actually, she recognized me and everything, and her and I talked and she was like, are you sure this is the best thing you could do and I was like, honestly where my head is right now, I can't continue this semester, which was true and I wouldn't have succeeded it. Since it was something that was out of my control, I was kind of like, okay I have a house, I have a car, I have ways to get to school, and now I don't have any of that. It was not something that was my fault, it wasn't like I was dropping school because I wanted to go and hang out with my friends or travel across the country. So there is something, at school that's called a medical leave I believe it is. What we did is that, we petitioned for 
my leave to be something that was considered medical which I guess... yes, you can totally say it was (Alejandra, lines 338-355)

Alejandra was experiencing what is referred to as minority stress. Minority stress refers to the chronic levels of stress someone who is part of a marginalized group faces (Goldbach, Tanner-Smith, Bagwell, \& Dunlap, 2014; Marshall et al., 2011). The depression, anxiety, and stress she was experiencing was a result of being a lesbian. The stress that Alejandra exhibited is experienced among many sexual minorities and has been well documented in the literature (Matthews et al., 2014; Meyer \& Frost, 2013).

I felt I was facing like a lot minority stress, I guess, I just... I knew that my head wasn't where it was supposed to be, so I wasn't going to successfully finish the semester, it was just, it wasn't going to happen for me. I... I'm not good with a lot of change at the same time and between having to deal with now being completely out in the open to everybody that I knew, to also living alone, to also going to school, to also going to work, it was just something that was not doable for me so... Thankfully I was able to get that withdrawal from school to be under a medical reason and that was the only reason I was able to get back into school that same summer. I was back in school by summer end... in no time. (Alejandra, lines 356-364)

The support participants have received has assisted them in getting involved with other LGBTQA opportunities. Margarita discussed how a positive LGBTQA experience in a classroom setting, eventually encouraged her to get involved at an extra-curricular level on campus, by joining the Gay Straight Alliance, a student based group on campus. Eventually, that involvement led to a state level of engagement as she decided to become part of the planning committee for the Redefining Queer: Making Lavender Connections Conference for LGBTQA students. She has found her experiences on campus gratifying and as a result has, "never been made to feel like a minority" (Margarita, line 169).

The themes of visibility on campus and support systems available were shared by all participants. Regardless of the amount of interaction they had, there was an overall 
perception that their HSI was a supportive institution. Much was attributed to the level of inclusion they experienced with the LGBT services offered. An interesting point is that despite the short existence of the LGBTQA Office on campus, its perceived reach has been significant among these Latina lesbians.

\section{Summary}

This chapter presented the findings from the inductive data analysis. The three themes that emerged during the inductive analysis were: (a) the trifecta: family, religion and gender, (b) the paradox of being Latina and lesbian and (c) institutional care. These themes capture the experiences of Latina lesbians and their perceived sexual identity development at an HSI. In Chapter 5, the deductive and comparative findings are discussed. 


\section{CHAPTER V}

\section{DEDUCTIVE AND COMPARATIVE FINDINGS}

In this chapter the descriptive findings from the deductive and comparative analysis based on the data collected during the participant's interviews are presented. This chapter (a) shares the descriptive findings from the deductive analysis, and then (b) compares the findings from the inductive and deductive analysis.

\section{Deductive Analysis}

The purpose of the deductive analysis was to explore the participants' experience as Latina lesbians at an HSI, and their perceived sexual identity development. The deductive analysis was done using the following a priori codes: (a) cultural background (b) perceived identity, (c) alienation, (d) social exclusion, (e) disclosure, and (f) selfacceptance of a non-heterosexual identity (See Appendix E).

The first two a priori codes are cultural background and perceived identity which helps us frame the participant's experiences with their family, culture and views about their sexual identity. Perceived identity helps us understand participants' personal views about their identities in relation to their family and culture. The other four a priori codes come from the various sexual identity development models (Bilodeau, \& Renn, 2005; Henrickson, 2013; Henrickson, \& Neville, 2012). This framework helps illustrate the complexities of an individual's lived experiences as they attempt to develop a Latina lesbian sexual identity.

\section{Culture Background}

Cultural background helps us understand the values and beliefs conveyed to participants by family and their Latino culture as well as the factors that influenced their 
decision to attend an HSI. In understanding the participants' cultural backgrounds, we gain a deeper understanding of the experiences that have shaped their lives as Latina lesbians. In cultural background, participants were asked to describe their culture, and what being Latina meant to them; their family and the values they taught them; and what influenced their decision to attend an HSI.

Participant's culture and what being Latina means to them. The Latin culture is defined as a group of people who share a common language, formal and informal customary practices, and religion (Morals, 1992, Rosario, Schrimshaw, \& Hunter, 2004). When describing their culture, participants shared their particular music, foods, and various traditions. Religion was also mentioned frequently by participants as a cultural norm, but also ones that participants have struggled with extensively based on the non-acceptance of lesbians and gays in their religion. Lourdes shares her experiences with the Catholic religion and those she encounters from her Cuban and Dominican culture below:

Catholic Christian religion is what I'm really referring to but you know other religions state the same thing umm... that someone like me is sinning, is sinning outside the bedroom, inside the bedroom that our minds are clouded, that we're unsure of ourselves and we're making people around us unsure, and that we're a negative force in the society and we need to be saved. So that is the view, "that we need to fix them and save them from whatever demon is inside of them". So that's kind of the view of how a Cuban, Dominican, or any Hispanic in their country will probably be (Lourdes, 149-154).

Several of the other cultural norms, expectations, and characteristics participants shared when describing their culture will be discussed in the following, along with their perceptions of being Latina. 
According to Villegas, Lemanski, and Valdéz (2010) being Latina embodies the cultural value of Marianismo; that Latina women should be family oriented, subservient to men and follow the patriarchal order. This notion of Marianismo was discussed widely among the participants. Mache, Monserrat, Pat, Tiffany and Roxy all commented on the dominating role of machismo and patriarchy in the Latino family. Monserrat shared that based on her experience, Latina women usually live in patriarchal societies, and how she received this message from family and peers both in the United States and in Venezuela, where she believes the message is even more prevalent (Monserrat, lines 49$51)$.

Marianismo was further confirmed by participants as they shared their experience of how Latinas are expected to conform to certain standards of sexuality, femininity and a prescribed gender role. Cathy shares an example of how Latinas within her Dominican culture are expected to conform to their typical gender roles and are expected to dress in certain colors and in particular ways (i.e., heels, dresses, and skirts), and they should be very pretty and good cooks. (Cathy, lines 173-177). These expectations of femininity and sexuality cause much angst for Cathy as she has never seen herself as being feminine; to her, she prefers the word "handsome". She knows that for a Latina to be labeled handsome is not accepted in her culture. The expectation of Latinas being soft, feminine and beautiful had been shared by multiple participants, and is supported in the literature (Lopez, Corna, \& Halfond, 2013). Another example of the culture's hyper-feminization of Latinas was shared by Alejandra,

the way that society sees a Latina is like this bombshell, tall, light skinned, very elegant, very dressed up and very flamboyantly feminine..., almost every woman in my family is extremely feminine, loves wearing makeup. My mom and my 
sister are both like those ultra fem girls that love their purses and their shoes and all that (Alejandra, lines 43-45).

Growing up in an environment where gender roles and expectations were very ridged made it extremely difficult for Alejandra to accept her Latina lesbian identity.

Participants also shared the following attributes: importance of family, traditions, being hard working, sense of pride, aspirations, and strength as being components that made up their Latina identity and culture. The significance of family and traditions in the Latina identity and culture were shared by all 15 participants and can be seen in the following example by Pat,

Being Latina to me just means being a part of a very specific community. It's a very diverse community but it also represents a lot of tradition not that I subscribe to any of it though but I have been raised by it. I mean if we get to the specifics of it, it means a lot of festivities, family bonding, and support, um I don't know it's very specific very particular (Pat, lines 16-20).

For Tiffany, the sense of family, openness, and affection she shared has been validated by other participants, "I just know that it's very, very family-oriented. Everyone is everyone's family. You go say 'hi' to somebody. It's a kiss on the cheek or a hug. It's very open and welcoming"' (Tiffany, lines 13-17).

Roxy, Carolina, Alejandra and Gertrude discussed how being Latina and their culture encompassed the characteristics of strength, community, ambition, and resilience. For Roxy, being Latina, "is to be strong, to be different, to have culture and not be shy about it... as well as eating really good tasting food, [laugh]" (Roxy, 18-19). Carolina views being Latina as, "having a little more spunk. We're a little more sassy, and a little more honest. I think we communicate better. I just think Hispanic people are better way of communicating and expressing themselves" (Carolina, lines 15-20). Alejandra shared 
how her mother as a Latina showed courage, strength, and ambition by leaving Venezuela, in the hopes of find a better life and future for her family. She also sees that same strengths, courage and resilience in herself as a Latina as she faces the stigma created by society about her own sexuality (Alejandra, lines 13-18). For Gertrude being Latina was not only about being proud and strong, it was also about the importance of being connected to a community (Gertrude, line 22-23).

For these participants their culture and being Latina encompassed various attributes such as: the importance of family, defined gender roles, pride, and strength. All participants have received messages that played an integral part as to how they have made meaning of their Latin culture and Latina identity.

Describe their family and the values they taught them. In describing their families, participants shared information that included their family networks, their siblings, extended family, and their relationships. Their family make-up consisted of single or two parent homes, being an only child to having younger or older siblings, and being raised by grandparents and extended family members such as aunts, uncles or cousins.

Values are a person's or community's ideals, beliefs, standards, and behaviors that are deemed acceptable and unacceptable. Each participant shared approximately two to five major family values. These included: caring for others, having a strong work ethic, being self-sufficient, being religious, the importance of family, being strong women, and the value of education. The most commonly shared values among participants were: importance of family, caring for others, education, hard work, and religion. 
In discussing the importance of family, several participants used their parents' decision to come to the United States as an example of this value. Monserrat shared how her parents made the decision to come to the U.S. as political refugees from Venezuela for their family's safety and to create a better life for them (Monserrate, lines 15-17). Alejandra also shared her mother desire to provide her and her siblings with more opportunities and a better life by moving to the U.S.

Education was an important value for Carolina, Margarita, Gertrude, Nikki, and Lourdes. Carolina explained how education was the number one value her mother taught her, and that regardless of what happens in life, a good education can sustain her and never be taken away. Mache was sent to study here in the U.S. on her own, because her father wanted the give her the best education possible.

Among values shared, several have proven to be troublesome for these women include: religious beliefs and heteronormative expectations from their family members such as marrying a man, having children, and conforming to the stereotypical gender roles. The family value of masculinity and machismo, which highlights the patriarchy and the systematic subordination of women (Bermudez et al., 2010; Byers, 2010; Guzman, \& Grayshield, 2008; Sternberg, 2000) is demonstrated in Hickock's understanding of her family values:

My family is pretty stereotypically Cuban despite how young my parents are, where it's expected for women to turn their cheek. Whatever the man is doing, as long as the woman isn't embarrassed and respect is kept, and the man continues to give her, her place in society as the wife, the woman of the household, he can sort of do whatever he wants. In my family, my grandmothers, both my grandparents, are always in the shadow of a man, always. The man has the last say. The man makes the decisions. The man is the breadwinner. It's a patriarchal society completely. It's "Machista" a macho mentality where you see, "Here I am the star 
and you're just the accessory. I hope you look good because there's people watching," (Hickock, lines 95-105).

Hickock also shared that although her family never tried to instill these values directly, it was something she grew up watching and experienced with both her parents and grandparents.

Family religious values shared by the participants' provided ample evidence supporting the disapproval and rejection exhibited towards sexual minorities found in the literature (Chaturvedi, 2014; McKenzie, \& Rouse, 2013). Gertrude shared how growing up in a strict religious home the most important value was to be a morally good person. Being morally good included: being nice to your neighbor, doing no harm, no sex before marriage, and not engaging in homosexuality. What trouble Gertrude the most were all the negative messages she received about homosexuality, that it was a major sin, that all homosexuals are going to hell, that it is immoral, sick and not accepted. This value was also shared by Roxy, Tiffany, and Alejandra.

Much of what was shared in this section highlighted the participants' families and the values they were taught. Many of these women commented how these values were not only expressed verbally but were lived on a daily basis among family. The next section will look at what influenced their decision to attend an HSI

\section{What influenced their decision to attend an HSI. The Department of} Education defines an HSI or Hispanic serving institution is a not-for-profit institution of higher learning with a full-time equivalent (FTE) undergraduate student enrollment that is at least $25 \%$ Hispanic. In choosing to attend an HSI, each participant shared approximately two to three responses. These included: proximity to family, the dominant 
Latino population, financial support and scholarship opportunities, parent's expectation, the school's reputation in their home countries to move away from home, the diversity present, and the LGBTQA support services available.

The most frequent response among participants was the desire to remain close to family, illustrating the importance of Familismo (Ayón et. al., 2010) within the Latino culture. Lourdes decision to remain home is centered on the importance of family. In her interview, she shared the desire to be close to home because her first niece was about to be born. She feels a sense of loyalty and responsibility to be around for her niece's birth and upbringing. She went on to share,

I couldn't bear the thought of not being here. I'm particularly close to my brother who was having the child. You know they say the first four years of a child`s life is essential and I'm not going to be around for $90 \%$ of the year? No way. It's not her fault or my fault and it's not a bad choice to not go away, but I don't know that I could make that choice (Lourdes, lines $65-78$ ).

She knew her decision to stay close to home stemmed back to the importance of family in her culture despite having had the opportunity to go away.

Cathy's reason for attending an HSI stemmed from her attempt to manage her Latina identity and lesbian identities. For her, attending an HSI represented a comfortable space, one where she could hide her Lesbian identity by hyperbolizing her Latina identity. For her, being in a Latin environment would allow her to be just like everyone else, she knew how to be Latina, speak the language and could easily hide her lesbian identity. Going to a non-Hispanic serving institution, she believes, would have proven to be much more challenging in trying to manage both her Latina and lesbian identities (Cathy, lines 60-73). The importance of attending an institution where she fits in and does not feel ostracized as a Latina was very important. For Cathy being able to 
connect with her Latina identity became a coping strategy in dealing with her lesbian identity.

In the a priori codes of cultural background and family an understanding of the issues and challenges these women face as Latina lesbians has been presented. Their understanding of their cultural norms, values, and beliefs were shared. Responses confirmed the values and shared beliefs introduced in Chapter 2 including: the importance of family, religion, gender roles, and the prevalence of homophobia in the Latino community.

\section{Perceived Identity}

Identity concerns an individual's personal beliefs about themselves in relation to their various social groups (Evans, Forney, Guido, Patton, \& Renn, 2010). Individuals use the dominant beliefs in society that inform cultural norms and expectations to help them make meaning of their own identities (Sanlo, 1998; Torres, Jones, \& Renn, 2009). In understanding the participants' perceptions of their sexual identity development, they each described their sexual orientation and when they realized they were not heterosexual, what being a Latina lesbian meant to them, how their family viewed lesbians and gays and the messages they received, and their ethnic cultural views on lesbians and gays and the messages received.

\section{Sexual orientation and when they realized they were not heterosexual.}

Sexual orientation is defined as a person's sexual identity in relation to the gender they are emotionally and sexually attracted to (Wall \& Evans 2000). Bayly (2007) defines a lesbian as, "a woman who seeks and or experiences physical, emotional and/or spiritual 
intimacy with another woman" (p. 19). In this study, while all participants identified their sexual orientation as being lesbian, the point at which they realized they were not heterosexual varied.

Participants realized they were not attracted to members of the opposite sex, or heterosexual as early as early as 3 years old (Monserrat) to as late as 19 years old (Nikki). Most participants realized they were not heterosexual either between the ages of six to eight or 12 to 14 , an earlier range than the typical 13 to 21-year-old range for lesbians based on the 2013 Pew Research Centers survey on LGBT Americans. Several shared that despite the fact they realized it at a very young age, they did not actually act upon those feelings until they were older for fear of rejection or being punished by their family (Gertrude, Alejandra and Roxy).

Although Pat and Roxy prefer to use the label queer, they also identify as lesbian. An interesting observation from the participants' responses in sharing their sexual orientation, was that many had shared that they at some point chose to identify as bisexual, not because they felt they were bisexual but rather that they felt they would be more accept by using that label.

Being a Latina lesbian means. Latina lesbian is defined as women who share historical commonalities, an ethnic and sexual identity, and who face discrimination as women, Latinas, and lesbians (Pickett, 2013). Based on the responses of the participants, their perceived Latina lesbian identity development has been complex and challenging on various levels. While all participants identify as Latina lesbians, when initially asked to share their insights on being a Latina lesbian, they all exhibited some angst in formulating a response. They commented on the negative stigmas and stereotypes 
associated with these words, specifically when discussing their cultural, family, and peer

perceptions. There was a strong sense of invisibility, alienation, discrimination and isolation when discussing being a Latina lesbian, which is supported in the literature (Espín, 2012; Peña-Talamantes, 2013; Kawahara \& Espín, 2013). In the following, Mache and Roxy share examples of the stigma they associate with being a Latina lesbian:

It's hard because you face a lot of discrimination or stereotypes because they think all lesbians are butch or promiscuous. Sometimes I feel like I'm not from here, I'm not that girly and I'm not that butch. It's weird sometimes I feel like I don't belong anywhere, I'm alone. Being Latina involved many traditions, not only religious but social, for example it is very common for me to be asked in a social event "y el novio? ", always asking "where's the boyfriend", or the idea of "te va a dejar el tren", meaning "you're going to miss the train", putting pressure to find a man before you get too old. (Mache, lines 70-77)

A Latina lesbian? What does it mean? Oh man, that's a lot of baggage I feel. You have to be extremely brave, you have to get to a point that you completely defy everything that you have grown up thinking, and the roles that you were set to have just to be a Latina lesbian. Within your own family, you are just kind of put aside, you are just sort of outside the norm, it's just difficult to be relate-able with anybody or just have a normal conversation with anybody, without you being considered an outsider. (Roxy 72-77)

These example support the conceptual frameworks tenets of alienation and social exclusion and the harmful impacts it has had on these participants.

Conchita shared that for those growing up embracing and emerging themselves in their Latin culture, it is extremely difficult to be a Latina lesbian, "To be yourself in the streets, on a date in a restaurant, even though you are not ashamed, you don't want others to look down on you, or pass judgment or treat you poorly because of who you are" (Conchita, lines 145-149). 
The participants shared how cultural stigmas and stereotypes about Latina

lesbians made it difficult to affirm to others their Latina lesbian identity. Hickock and

Monserrat provide insights into the challenges of being a Latina and a lesbian.

My initial reaction to that is an image of somebody who listens to a lot of Reggeton, probably wears baggy clothing and wears a lot of gel in their hair. That's just my association with those two words together in my experience in Miami. I know that there's plenty of people who might say, and I'm not shaming them or anything, who might say my sexual orientation doesn't define who I am. I 100\% agree with that statement. However, it is a definitive factor of who I am. It's interesting that they are so different, being a lesbian and being Latina because you'd almost think they can't co-exist but these two huge parts of me, of who I am, they existed inside of me. Interesting where to see when they clash and where they mesh. So it means -- I don't know. Thankfully today it doesn't mean too much but, yeah. I don't know. Being of a minority, such as a Hispanic minority, and I can only speak to my own minority because I'm Hispanic, where custom to - I'm sure it happens across board but especially in a Cuban household where there's already a path for you. You're supposed to go in this direction. Especially being a part of minority where people tend to be extroverted, so opinionated, like I said again, involved. It's interesting to see how I brought the lesbian part of me. It's trickled its way into the Latina aspect of who I am. It's kind of like an impending mixture of [two different] solutions, you know. Well, those two don't go together. Just scratch that idea. (Hickock, lines 176-190)

I think it's like a revolution. It's because you're going against the rules. Latinas are expected to be heterosexual and follow rules that men expect them to follow. Latina women usually live in patriarchal societies. I think being a Latina lesbian is harder because you are expected to follow rules and never go against them. (Montserrat, lines 49-52)

There is an increased level of marginalization Latina lesbians experience as a result of having their varying intersections. The struggle for these women becomes intensified as highlighted by Cathy.

Latina lesbian, I'll put it this way. One counselor called me this term one time and I was offended. She said, "You're a super minority." I don't know how she meant it but yeah, I felt really offended. I responded, "You're telling me I'm extra lesser than other people?" And she's just like "No, you're just a subgroup within a group that's already a minority". She said, "I'm just saying. You're going to have to deal with that." At that point I understood. I know everybody coming out is difficult no matter what your background is, but with Latinas it's like -- everybody when it 
comes to Latinos and Latinas, they have high expectations for an individual to fill their gender role as expected, the man is the macho. He's the head. The woman is the woman, she dresses in certain colors and in particular ways [clarified with participant that she meant in heels, dresses, and skirts] and she's very pretty and she must cook. The difference between women in general and Latina women that I feel nobody ever puts into words is the fact that Latina women are just so active. They are not passive whatsoever. The fact that you are the woman and that you're not the head does not mean in any way that you are not working or that you're not putting in your fair share. The Latina women are so active and are at the forefront of things. And for me that's what makes it harder to be a Latina lesbian, and to define it. How can I be so at the forefront? How can I be fighting for my family and making sure that everything's covered in the way that I know and feel comfortable and still fit that role as a woman? (Cathy 168-184)

The participants' insights have demonstrated the struggles encountered in understanding and reconciling the intersections of these two identities. Currently, nine have fullydisclosed their lesbian identity to their immediate family. Of the remaining six, four have partially disclosed to their immediate family, and two participants have not disclosed their lesbian identity to their immediate family members.

As demonstrated above, negative messages and stereotypes that participants received about these two identities coexisting has caused them unnecessary anxiety. While all participants identified as Lesbians, in sharing their backgrounds, seven of them had indicated that prior to accepting their lesbian identity they had identified as either bisexual or pansexual. Many explained how it was easier for them to just identify as bisexual or pansexual while they attempted to figure out the essence of their sexual identity. It was shared how even though they had been aware of their attraction toward women at a very young age, it wasn't until later in life that they actually acted upon those attractions. 
Strategy used by participants to block or withhold their feeling towards other women included: dating men and absorbing themselves in religion. Mache shared how she tried to use religion to change her sexuality, "I prayed to God for a miracle", and how she had also considered going to therapy (Mache, lines 284-287). What was most interesting in Mache's attempt to change her sexuality was the fact that she was that she did not actually want to change who she was, she shared that she just did not want to destroy her family by having them find out.

Much of their resistance in acknowledging and accepting their identity stemmed from the homophobia present in their environment and the fear of being ostracized or rejected by their family based on the messages and views their family and culture had about lesbian and gays. We see how the tenets of alienation and social exclusion play a significant role in the experiences of these women. The struggles they have experienced in attempting to understand their Latina lesbian identity has been stifling and has made it difficult for them to live open and affirming lives.

Family views of lesbians and gays and the messages they received. In this section, being lesbian and gay was explored by participants through a family lens. Family views of lesbians and gays refers to the particular belief and attitude family members have towards lesbians and gays.

There were many family views and perspectives participants shared that stemmed from a homophobic and negative viewpoint, that have been well documented in the literature (Torres, 2002; \& Torres, \& Pertusa, 2003). Some commonly shared viewpoints included: that LGBT people just need to be fixed, that pretty women cannot be lesbians, lesbians are trying to be men, lesbians and gays are immoral and are going to hell. 
Participants shared that while some family members were more vocals about their contempt towards gays and lesbians, those who chose to be silent still found ways to show their disdain towards gays and lesbians. Even Conchita's mother who identifies as a lesbian shared that she would prefer her daughter not be a lesbian because of the difficult life she would have (Conchita, lines 154-158).

Some of the other views family members have towards gays and lesbians were shared previously under family values. Within Latino communities the family unit is seen as central to the wellbeing of an individual (Ryan, 2010). Despite the importance of family, for these women there is a constant fear of rejection because of how their families view lesbians. Higher rates of family rejection have been associated with poorer health among LGBT individuals (Ryan, 2010; Ryan, Huebner, Diaz, \& Sanchez, 2009).

Additional views of lesbian and gays and message participants received by family have been incorporated into the cultural views below.

Cultural views of lesbians and gays and the messages they received. In this section being lesbian and gay was explored by participants through a lens which stemmed from their own cultural views. Cultural views refer to the particular beliefs and attitudes a group has towards different factors that is race, gender, sexual orientation etc. Many of their responses confirmed stereotypes and homophobic sentiments still prevalent in Latino culture when discussing the term lesbian (Espín, 2012; Pickett, 2013). Derogatory terms such as "dyke" and "Tortillera", a Spanish derogatory term for lesbians, used to marginalize this population have been directed toward several of the participants. Cathy shared her experiences with being called a "dyke", and explained how in her culture it is seen as synonymous with being a man. It was upsetting to her that others would assume 
that she wants to be a man (Cathy, 753-757). Conchita associates being lesbian with negative and heteronormative comments she has often heard from individuals. She shared,

They are very gruesome, like for lesbian they use the term "Tortillera". Basically the messages are negative, that being lesbian is absolutely horrible -to live that way and to be that way, to be with a woman is not right, why would you want that? You should want to be with a man, being with a man is a good thing. That's the best thing, why would you be interested in anything else. (Conchita, line 179184)

Participants shared how lesbians have been associated with either pornography or prostitution. Evidence of this can be seen by conducting a simple search in google by entering the words Latina lesbian in tandem. The first 18 sites that appear are all on Latina lesbian pornography. Lesbians have also been seen as an abomination in the name of religion. Tiffany and Cathy detail their two accounts below.

A lot of them were very, very graphic. I think one of the ones that kind of stuck with me the most was that lesbians only belong in pornography. They don't belong in real life and that was so bizarre to me because I didn't think that. (Tiffany, lines 67-69)

When my stepdad was in the picture, he was fine with it, especially because one of his brothers is gay. But again, whenever I started and I wasn't fitting the mold, they wouldn't say I was gay but they would say, "Stop acting like a lesbian.

You're going to burn in hell. God is not okay with this." (Cathy, lines 231 - 234)

Cultural background and perceived sexual identity revealed that there were many similarities among participants' perceived Latino cultural values and beliefs. They also shared similarities regarding how they perceived their Latina and lesbian identity.

\footnotetext{
Alienation

For sexual minorities, alienation has been described as the experience of seeing oneself as different from those around them, and is often manifested through the lack of
} 
connection, hostility, and indifference (Henrickson, 2013). These experiences of separation and difference have shaped the way in which our participant's' live and view the world they live in. In this section, the participants discuss their experiences with alienations in the context of society, family, and their HSI.

Alienation in society. In alienation in society the experiences of Latina lesbians seeing themselves as different from those around them is examined. Alienation was manifested through the lack of connection participants experienced in an environment. For participants their experiences with alienation in society stemmed primarily from religious beliefs, perception in media, ascribed gender roles, lesbian stereotypes, and school.

Religion was shared by all participants as a strong value within their culture, families, and peers which confirms the current literature (Braton et al., 2014; Ecarnacion, 2011; McKenzie \& Rouse, 2013). Participants also shared that many of these religious views and values reject homosexuality (Chaturvedi, 2014; McKenzie, \& Rouse, 2013). Roxy, Gertrude, Mache, Luna, Cathy, and Monserrat all shared their upbringing and the important role that religion played. Their social conditioning about religions nonacceptance of homosexuality began at a very early age these women. Many attended Catholic or religiously affiliated elementary and secondary schools where they received negative messages about sexual minorities.

Historically, the portrayal of sexual minorities in media has been negative (Lopez, Corna, \& Halfond, 2013). While there are some LGBT characters and positive images in the media today, participants shared the view that there are still not enough. Roxy shared how growing up she felt alienated and found it difficult to relate to images and characters 
on television. "The fact that you're an outsider-- and even watching like regular TV shows before today's age, I couldn't find any character to relate to because none of them had the issues that I had or were LGBT" (Roxy, lines 118-122). The feeling of alienation as a result of the absences of lesbian characters in television was echoed by other participants as well.

For Lourdes and Pat, some of the alienation they experienced was a result of expected gender roles and heteronormative attitudes they encountered in school. Lourdes' example highlights the negativity she encountered by her teammates as a result of her ability to break down the expected gender roles at her schools and in society. Her account of the incident stated below gives us an understanding of how Latino cultural stereotypes about lesbians is used to marginalized people based on perception. At that time, even though Lourdes was not out as a lesbian, the implied lesbian association with being a tomboy and being athletic was used to marginalized and mistreat her.

I started running cross country for the varsity. I played for my high school [pause] Um, I had played very serious sports my whole life. So with being somewhat of a female jock you already kind of get picked on a little, but not picked on because you know... you kinda have to avoid the "I'm gay" or anything that identifies me as gay because you are already a female playing sports. So when I was beating all the boys in whatever sport it was [pause] they called me names. So it's not that they really thought I was gay, it was just at home you know their mom and dad would when they curse they'd say "maricon" [translated this is a derogatory word for gay] or whatever it may be and that's what they were calling me. So that's probably some of the first memories that made me realize that I need to be careful in the way that people view me because if not I'm gonna be a target. (Lourdes, lines 175-190)

Gender presentation or expression has been another factor that has been used to alienate or exclude participants. Pat shared how her gender presentation has made her feel different. 
It wasn't so much my sexual orientation that made me different it was more of my person my demeanor. People become confused when they see me, that's why I identified with the word androgynous so much. I'm not very feminine but I'm not very masculine. I probably seem more masculine than feminine so that's enough to confuse people. I get sir on a daily basis...I don't know exactly when I realized that it would change the way people treated me, but I also don't put myself in environments where I don't think I'm going to be welcomed. I don't like to do that. (Pat, lines 135-139)

Pat considers herself complex when it come to her gender presentation and is aware that it is not within the expect norms of society. As a result, she is accustomed to being alert of her surroundings so she does not find herself in a place where she is vulnerable or alienated.

In the following recollection, Hickock discusses the resentment and isolation she experiences stemming from the negative stigma that stereotypes Latina lesbians as sexual objects or novelties. Sexual objectification has been described as the act of treating a person as an instrument of sexual pleasure or object without any regard to their personality or dignity (Nodelman, Allen, \& Perry, 2003).

There is an extra way in where I feel lesbians are responded to negatively and that's in the sense that lesbians are sort of seen as a novelty act. There is something extremely, sexually arousing about two females to a good amount of the population that you probably won't find people respond in that way to two men. So one moment that I feel like it's been repetitive in my life, I have no shame in my sexual orientation. I'm not scared of admitting that I'm a lesbian. I carry my relationship with a woman the same way I would carry it had I been with a man. A lot of the times I'm in public, people bring out their phones. They start taking pictures. They start taking videos. My initial reaction is, "I'm going to kick your ass." I've physically closed someone's phone and been like, "You have absolutely no respect." Because I'm no longer having an intimate moment with my girlfriend. I'm the laughing stock. I don't know. It feels like being on the other side of the camera lens just makes it seem either wrongfully erotic or like this is the Discovery Channel. I don't know. It's just I'm in a glass. I'm like a monkey performing for an audience when I'm just trying to live my life here. (Hickock, lines 254-267) 
The sexual objectification of Latina lesbians was shared by other participants including Tiffany and Lourdes. Sexual objectification is another way in which these women have been alienated by their community.

While participants shared their experiences of alienation in schools and other public spaces, the majority of their encounters came directly from their family members. Alienation among family members will be shared in the next section.

Alienation with family. Familismo is a critical cultural Latino construct that emphasizes the importance of family roles, acceptance and belonging in the Latino culture (Ayon, \& Aisenberg, 2010). This was implied by all 15 participants as they confirmed that family is one of their most important values. While these women confirmed that family matters, they all experienced some type of rejection based on their Latina lesbian identity.

Beliefs associated with Marianismo and Machismo were present in the interactions participants had with their families. The negative effects of these concepts were readily visibly. As they started to share about the alienation they experienced, their physical demeanor changed to a more somber one and they became increasingly uncomfortable as they continued. Their experiences are outlined below beginning with Margarita.

Starting with my father, I guess he was very, he kind of just told me, "Oh, your screwed up," that kind of thing. He's Mexican so it comes from that Machista views. Like it's completely wrong to be gay and I don't know if it's because he...my dad he just had a really negative take on it. It's also not something that he was exposed too much, growing up. So that might be it. I don't want to make an excuse for it but maybe that's why. And he's not a very open minded person. In terms of my other family, they're very Catholic so I don't think it's something that they necessarily agree with, (Margarita, 45-51). 
Margarita's decision to disclose to her father her sexuality has left her feeling shunned and alienated. She shared how she tries not to bring up anything regarding her sexuality to avoid his hostility and negative comments. Cathy attempted to gauge how her family might react to her being a lesbian by posing a question based on someone else's sexuality.

I started asking my family "So what if there is a gay or lesbian but they don't dress like the other gender?" Their response was "Well, they're on their way to dress like the other gender. They might not be comfortable to do it in public but it's really what they want. Why else would most gay guys be so sissy or why would lesbians tend to be more masculine?" So this is what it always comes down to trying to put them into those two roles. There is no gray area. It's man or woman. And if you don't do what's expected, you're obviously trying to cross into the other side, because it just makes no sense otherwise. (Cathy, lines 326334)

The response Cathy received not only confirmed her families' non-acceptance of lesbians and gays, but also reinforces their expectations of the gender binary and roles. To Cathy's family a gay man must really want to be a woman, and a lesbian must just want to be a man.

The number of experiences shared regarding alienation with family members was shocking. While the participants expressed a deep amount of love for their family, they were challenged with the alienation they encountered from them. It was difficult for them to understand how their families could exhibit such aloofness or hostility toward them. Several were and continue to be challenged with redefining their relationships despite having been rejected and alienated.

Findings in this section included not fitting into the family cultural expectations (i.e., Religion), and strict heteronormative ideology. Even though there were challenges, a strong source of connection for these women included the importance of maintaining a 
strong sense of family despite their sexual orientation. A strong desire to redefining their relationships was prevalent despite the alienation and rejection they encountered.

Alienation in College. Alienation in college refers to the experience of Latina lesbians seeing themselves as different in their college setting. Participants' share their experiences regarding how welcomed or excluded they felt on campus, their interactions with the various offices, departments, students and staff, and they shared insight into what it means to be a Latina lesbian at an HSI. Participants' responses to the level of connection they felt are shared below.

Those who felt connected to their institutions cited the following reasons: Inclusion of LGBT topics in different courses, visibility of LGBTQ on campus and at orientation, LGBTQA support and programs, and student groups on campus. Inclusion of LGBT classes on campus was cited as a way participants felt connected on campus by Pat, Margarita, Monserrat and Cathy. Classes taken on campus which included LGBT content were: Global Learning courses, Women's and Gender studies, and the SLS freshman year life skills courses.

A strong LGBTQA presence on campus through visibility (e.g., Safe zone stickers, rainbow stickers, information on TV prompters and social media marketing) and inclusive student organizations were mentioned by all 15 participants as ways that they felt connected and that they weren't alone on campus. Gertrude, Roxy, Conchita, Alejandra, and Monserrat all shared how an LGBTQA presence during their orientation session and while they conducted their research on the institution made them feel welcomed. All participants indicated having had at least one positive interaction or experience with LGBT visibility on campus. Several of the larger LGBT events on 
campus such as National Coming Out Day and the LGBTQA Mentors Program were also mentioned as welcoming and supportive places. Mache describes her mentor in the following:

I felt welcomed in the mentor mentee program. I have this incredible mentor, he got me involved in the events the office was having. I noticed when I went to the first event how proud the people that are there are of themselves and I was like oh my god they are speaking and doing something and I'm not doing anything for this. It makes me realize how they are doing something for people who can't speak for themselves. This is why I love this school; it has given me something I thought I would never get. It has opened the doors so I can be me. (Mache, lines 174-180)

Student clubs both LGBTQA specific like the Stonewall Pride Alliance and GSA; and non-specific like Hillel, Amnesty International and Slut Walk were identified as support systems.

Feelings of alienation by participants were cited in the following areas: the hostility and or homophobic messages received in the workplace, comments from other students, the lack of Latina lesbian visibility, campus groups, and being at an HSI where cultural norms and negative stereotypes towards Latina lesbians persist.

There were 4 individuals in the study who shared instances where they felt alienated as a result of their job on campus. Conchita, Hickock, Alejandra and Mache all work on campus in various departments. For their privacy, the names of these institutional departments and offices have been removed. Below is Conchita's experience at work:

At the department I was working for at the time, my supervisor was Christian and her husband was a pastor for the church they attended. Another coworker would ask me to come to her church almost every weekend. I never went, and to this day I still haven't, but my point is that I was surrounded by very religious co-workers. I took the liberty to NEVER come out to them, any of them. I didn't want them to treat me any differently, nor did I want to risk ending my employment with the 
department. I hated hearing them make comments about employees in other departments like "So-and-so -oh he's gay, you know!" as if that was the only thing there was to know about him. Therefore, I didn't feel welcomed to be myself while working in that department. (Conchita, lines 278-286)

Mache adds:

.... they are like my family and they are in my life, but they are very old fashioned. I walked into the office and they were all looking at me in a weird way, and then I realized that I had my LGBT pin on, oh my God. They were probably thinking, "what are you doing with that pin on your back? You're a beautiful lady". They think my best friend, who is gay, is my boyfriend. (Mache, 160-165)

Mache, Monserrat, Cathy, and Tiffany all shared experiences with other students and organizations on campus that made them feel ostracized. Cathy shared an experience in the library where she was having an exchange with a peer about heteronormativity and the gender binary, when they were approached by a group of students who had overheard their conversation. These students approached Cathy and her acquaintance in an antagonistic manner and then began to share disparaging and degrading comments. The students shared the reason why gay people are ostracized is because they choose to go against the norm. The excerpt below illustrates their sense of entitled and privilege,

So this one girl says, "We don't understand. It's not that difficult to dress a certain way. If you guys don't want to be picked on, then why do you have to be dressed like that?" My friend JC gets his eyebrows done. So she starts in on him and is like, "See, I can obviously tell you get eyebrows done. So if you don't want to be picked on being gay, you don't have to be so out there about it with your eyebrows. Be a man. Men don't do that."

Cathy went on to share that before the conversation ended there were several students who also join the discussion, making her and the other student feel even more disliked. That experience has given Cathy the perception that the views and beliefs shared by those students are widely accepted on campus, which makes her feel alienated. Monserrat, 
Mache, and Tiffany have all received contentious stares and comments from other

student on campus.

Sometimes when walking to class at FIU, I hear people say, "Is she lesbian? She's so skinny. She's not a girl, she's a guy." I used to be told things like that in high school too, but I'm not transgender, I'm just Monserrat. I identified myself as cisgender, but I have my own way of interpreting the words ''be a woman.' (Monserrat, lines 118-122)

An issue of concern shared was a sense of isolation on campus as a Latina lesbian.

They had an overwhelming sense of being the only one, which seemed improbable given the size and demographics of the institution. Hickock's reflection frames many of the thoughts and reflections shared by Latina lesbians regarding their feeling of isolation at their HSI. She discusses the cultural norms and Latino heteronormativity that still persists in this campus culture.

I felt like we don't exist. I think in Miami again, not the majority but the plurality of us are Hispanic, maybe even just the majority of people in Miami and at FIU are Hispanic. There's that undertone of that is way off from the other end of things that are not acceptable. I feel like a lot of Latina lesbians are in hiding, and it's a joke. I joke with my friends like, "Where the lesbians at?" "I don't know. They don't exist." I can say confidently there's nobody that's targeting that demographic, the Latina lesbian demographic, not just at FIU specifically but in Miami in general, that is majority Hispanics. I feel like we must exist, right? I know I exist and I put myself in another people's shoes and they probably don't know about me and I'm wondering. But because of the fact that we probably all grew up in the same kind of household where that wasn't a good idea to be a lesbian. We're sort of reserved. I don't know... I mean I can probably count 15 myself. So just imagine the ones I don't know about and the ones I haven't met, we for sure exist, but it's almost as if like in our personal lives with our friends in our comfort zone, we're like, "Yes, I'm a lesbian." But once you step out of that, we tap back into that, "That's not acceptable. That's not normal. That's not okay," and we retreat. So we keep to those close circles of close knit friends. Otherwise, I don't identify outwardly and like I said, we can't find each other because we're not real. Like what? It's been like seeing a unicorn or something. That's how I feel. Anytime I see a lesbian or I find out of one, "What? No way. Yes." It's like playing iSpy. (Hickock, lines 465-483) 
In college the challenges of alienation were experienced from peers who reinforced the Latino culture and gender expectations through microagressions and discrimination. The sense of inclusion in college was achieved as a result of LGBTQA materials in academic courses, visibility of LGBTQ community on campus, inclusive indoctrinations processes on campus such as orientation, LGBTQA support and programs, and extracurricular groups and activities on campus.

The findings in this a priori code included: their perceive isolation as a Latina lesbian on campus, hostility from peers, and the continued separation they experienced with their family. While there were experiences in which that participants felt alienated as Latina lesbians on campus, their overall experiences at their HSI indicated a strong sense of involvement and connection.

\section{Social Exclusion}

Social exclusion is the perception of not fitting into the heteronormative majority (Bilodeau, \& Renn, 2005), and involves the process in which sexual minorities are systematically blocked or denied various rights, opportunities, and resources that are available to the heterosexual majority (Queen et. al., 2004). In this section the participants discuss their experiences of social exclusion with family, the institution, and with peers.

Social Exclusion with Family. Social exclusion with family examines how Latina lesbians are marginalized within their immediate and extended family. Negative attitudes towards Latina lesbian women discussed earlier are reinforced in this section.

Participants' experiences with their families left them feeling worthless, invisible, and unimportant. Shame and isolation were used in a variety of ways to marginalize 
these women not only from the family but from friends and their communities. Hickock and Gertrude had to change high schools two to four times, once their parents perceived they were lesbians. Roxy recalls confrontations with both her uncle and mother that made her feel excluded. The homophobic attitudes she encounters within her family were difficult for her to share.

I think when it really hit home was when one of my uncles, I mean my dad still lives in Nicaragua and I grew up with one of my uncles, and that uncle, I pretty much considered a dad. He was the strongest father figure within my life growing up, and when he compared me to someone that would want to have sex with animals, or when my mom said I was an abomination, and compared me to someone that's a Pedophile, that's when I started realizing that. I started questioning whether if I suck as a person, or if they sucked as people. (Roxy, lines 223-229)

Monserrat, Cathy, Caroline, and Margarita shared how their families would avoid discussing their sexual orientation by refusing to acknowledge them in conversation or changing the subject. They also shared how their family became immediately uncomfortable whenever a discussion might come up regarding their sexuality with extended family members.

It's gotten better with my immediate family but my mother doesn't want to speak about it with other family members because I will be seen as the weird one. She doesn't think that they will accept me. Most of my family lives in Peru, and they are mostly Catholics. Even though they are not religious fundamentalists or orthodox, they won't probably react well if they get to know I am lesbian. (Monserrat, lines 163-167)

Discussing this topic was difficult for participants given the intensity of emotions it produced for them. Brief breaks were given during the interviews to allow participants to regain their composure. The extensive amount of social exclusion experienced among family by participants confirms social exclusion is a part of their lesbian epistemology. 
The finding in this section revealed that the social exclusion and marginalization they experienced from family resulted in participants being ashamed of their lesbian identity, feeling worthless, invisible and unimportant. Despite their parents' initial sense of exclusions, some participants perceived their parents desire in maintaining a continued relationship.

Social Exclusion within the Classroom/Academic Setting. Faculty and the academic environment played an important role as to the level of exclusion or inclusion perceived by sexual minorities (Reason \& Rankin, 2006; Teman, \& Lahman, 2010; Wall, \& Evans, 2000). Interview questions regarding social exclusion within the classroom/academic setting examined Latina lesbian experiences of exclusion in classrooms with professors and instructors, courses offered, and their chosen majors. In this section participants shared experiences that made them feel both excluded and included. Examples of both are provide below.

The two primary reasons student felt excluded in the classroom were: their choice of major and their perceived lesbian identity with other student in the classroom. Cathy shared her concerns about how her lesbian identity might negatively affect her career choice in politics, so she fears coming out.

"There's no way in hell that I'll be in government or an elected official." I want to be a diplomat and work in the Middle East. But I'm a woman, a minority woman, Latina. That's already one hurdle to get through. But being that I'm lesbian, once they find out, there's no way in hell I'm getting a government diplomatic job. So I looked for other jobs. (Cathy, lines 664-669) 
Choice of major was also shared by Tiffany as a way she felt excluded. In the following experience Tiffany struggles with feeling excluded not only because of being a lesbian but also because of her gender presentation.

I use to be a business major and I really like business...but I remember walking in a class one day and all I saw were guys. It was me, another girl or maybe two other girls kind of scattered and I'm like "Oh my goodness. I'm the only girl in this class". I remember somebody kind of giving me a funny look cause all these other feminine girls had beautiful long hair and their little dresses, and their little flat shoes and I was in jeans and a T-shirt and they're like "Is she trying to be a guy or something?" I'm like, "ooof..." This is not the major for me. I can't be in the major where I feel disconnected with the people I'm gonna be around. (Tiffany, lines 303-311)

Although these participants struggled with their major, Tiffany changed to Education which she feels included in, and Cathy is starting to have a more positive outlook about her major. An interesting observation regarding choice of major was that for some participants this made them feel included as well.

In this section participants shared more experiences where they were social included rather than excluded within their institution. This is in contrast to the existing literature on campus climate for sexual minorities (Rankin et al., 2010; Tetreault et al., 2013). The reasons students felt included are discussed below.

Participants' experiences that validated a sense of inclusion by faculty and staff were the courses offered and finding connections between their identity and chosen major. There was also an acknowledgement that sexuality didn't seem to matter to their professors. Others pointed out how their experiences in the classroom with instructors and professors made them feel positive, included and validated. Margarita's experiences have all been positive. She recalls how one of her professor's statement of, "you should be able love who you love", made her feel included and part of the community on 
campus. Supportive faculty help them in accepting their identity and their career paths. Monserrat's mentor has helped her with applying for med school and getting into Honors College.

Their choice of major greatly influenced their perceptions of how well they felt connected. Nikki shares how her involvement with LGBT issues positively affected her choice of major. She is now more passionate about making a change in the world and has switched from speech pathology to political science. Monserrat discussed how being a Latina lesbian has made her more excited in medical school because she will be able to influence how that profession looks at LGBT issues. Margarita stated that her Latina lesbian identity helped her change her major because she wants to go into work that will help her community.

The levels of exclusion or inclusion were manifested differently for the participants based on whether they presented more feminine or masculine. One observation made was that while they experienced both inclusion and exclusion, participants experienced less social exclusion in the classroom/academic setting than with their family. Findings revealed that the social exclusion in a classroom /academic setting was experienced in their choice of majors, lack of curriculum and class content in major course. Inclusion in a classroom/academic setting included having visible out faculty and staff, finding connections with their majors selected and the perception of their identity being unimportant to their professors and faculty.

Social Exclusion in Extracurricular non-classroom setting. In this section the participant's experiences in an extracurricular context are examined. These included their experiences with student organizations, staff, administrators and their overall perception 
of the institution. Experiences in these areas had an effect on the level of exclusion or inclusion perceived.

The level of involvement of students clubs, organizations and activities varied among participants. While there were instances of both feeling inclusion and exclusion, all reported experiencing a sense of belonging.

Among those who had experienced incidents of exclusion, it was from either organizations they encountered in passing on campus, that are religious, or Greek affiliated. Mache and Monserrat shared getting dirty looks and hearing disparaging remarks as they would walk past tables in GC from certain religious organizations. Mache experienced this as a result of having her pride flag pins on her backpack and Monserrat because of her gender non-conforming appearance. While most participants felt a sense of inclusion in the organizations they chose to become members of, Carolina felt a disconnect from her sorority which ultimately resulted in her decision to leave.

The visibility and their involvement in LGBTQA functions offered on campus were areas where participants felt included. Tiffany shared that in MPAS LGBTQA her experiences were great, but in some of the office or departments that are predominately Latino they are not open minded, and make assumptions about her. There is an office that every time she walks in, she is asked how's her boyfriend. Monserrat has been involved in the Mentor's program, attended on-campus events, and been involved in three student clubs: one LGBT focused, one focused on her major and one on social justice. Monserrat shared that while she felt included on campus overall and believes most of the time the campus is inclusive, there are still instances where she feels excluded; the main reason being the heteronormativity she encounters (Monserrat, lines 205-210). Despite 
Cathy having many positive interactions and having a strong sense of inclusion outside the classroom, she is hesitant to share her sexual identity with her leadership team at work for fear of losing her job (Cathy, lines 712-716).

Margarita shared how her sense of inclusion with organizations, staff and administrators has not only made her feel a part of her institution but also helped her through the toughest 2 years she has ever had. Margarita found inclusion through her student organization the Gay Straight Alliance, the Mentors programs, and the activities offered on campus.

For these Latina lesbians, a result of the events, clubs, organizations and visibility on campus was to give them an overall sense of belonging. While there were some instances cited of exclusion, they felt overall a sense of connection with the institution. The findings concerning social exclusion in extracurricular non-classroom setting included hearing disparaging and exclusionary comments from other students, different groups, co-workers and supervisors. It was found that participants felt included in campus in this area as a result of the inclusive groups and events, a visible LGBTQA community on campus, and inclusive policies and practices that made them feel welcomed at their HSI.

Social Exclusion with Peers. In this section the participant's experiences with their peers are examined. Experiences with peers created both a sense of inclusion and exclusion for the participants. Outlined below are participants' experiences with each.

Alejandra and Monserrat estimate the student body is evenly split when it comes to making Latina lesbians feeling included. Alejandra's job required her to survey 
student on campus about their perceptions of LGBT individuals. The interactions she has had leads her to estimate that about half of the students are accepting and half are not. Tiffany, Cathy, and Roxy feel excluded among peers on campus as a result of their Latina lesbian identity. Tiffany changing her major because of the heteronormative experiences with peers in class as a business major. (Tiffany, lines 303-318) Roxy a current business major shared,

within my classroom, obviously my assumption is that I'm the only LGBTQ person or the person... I'm the only person that's out. Identify as LGBT, expresses as LGBT. I'm not creating a network base necessarily for something that I might want to do in the future. Like I said I'm... you know, most likely I will lean towards LGBT businesses and kind of see how that can evolve in the future which I think it will and has a great potential to. But, there's nobody within my class that's aware or thinking of that because that's not being taught and nobody's out. So, I guess I'm indifferent towards anybody I meet in my classes. (Roxy, lines 386-391)

Gertrude, Conchita, Nikki, and Hickock all shared how most students think they're straight so it doesn't affect them directly. For those who don't present as cisgender social inclusion has been a concern. Cathy whose gender presentation is perceived as masculine was told by a student on campus, "You're hobbling and that's gross. Walk like a woman, you're walking like a man, stop it!”, (Cathy, line 728-730).

Roxy shared how she does not spend a lot of time on campus but when she does, she perceives a strong heteronormative presence. She notices that there is an unwritten expectation to look and act a certain way, and if one does not conform then they are met with awkward stares or are just not included. She gives the example of how the sororities have a particular way of singling out a particular type of individual they are looking for when they are recruiting at the tables in GC, and Roxy does not fit that look. She mentioned that she has never been stopped or asked to join (Roxy, line 361-387). I had a 
personal experience on campus shortly after Roxy's interview. I recall seeing a large banner for sorority recruitment that was place outside of the student center on the large wall above the entrance to the building. All the women appeared to be wearing shirts that had different Greek letters and colors from sororities, however, once you looked beyond the shirts, they had very similar physical features. They all were fair skinned, had long dark hair, were wearing make-up and had similar poses. This reinforces the heteronormative expectations of the college campus (Rankin, 2005).

Margarita and Pat shared that they have not felt excluded on campus. Margarita went on to share that most of the peers she's encountered have been positive people that have helped her and been very open minded. Tiffany shared that despite what she had gone through on campus, there were far more positive experiences than negative, which gave her an overall sense of belonging at the university. The feeling of inclusion on campus shared by participants is noteworthy and is in direct contrast to the literature on campus climate (Renn, 2010).

Social exclusion was experienced as a result of not being able to identify other Latina lesbians on campus, and the reinforcement of Latino homophobia and gender role expectations they received from peers. While some participants found social inclusion through supportive classmates and friends, most participants indicated based on their experience, less than half of all students on campus would be supportive or affirming of sexual minorities.

\section{Disclosure}

Disclosure is the process through which an individual makes the decision to announce to others publically that their sexual identity is non-heterosexual. This process 
is often referred to as coming out (Cass, 1979; Evans, Forney, Guido, Patton, \& Renn, 2010). This tenet explored the participant's perceptions of coming out to family, peers, and faculty and staff.

Coming out to family. Coming out to family is when the participants announce to their family publically their lesbian identity. In disclosing or coming out to their family, 14 participants had at least one person in their family, immediate or extended, who they had come out to. This included: siblings, cousins, aunts, uncles and parents. In choosing who they disclosed to, it was generally a family member who there was a significant bond or level of attachment to. Of the participants nine have come out to parents, four where outed to their parents and two are not out to their parents. Being outed refers to divulging someone's sexual identity publically without that individuals' consent. For the individuals who were forced to come out, their process was noted as extremely difficult. Gertrude and Mache, who are not out to their parents do not foresee coming out to them anytime in the near future for fear of rejection and being ostracized by them.

Disclosing one's sexual orientation can be a complex and life-long process. In Carolina's account she explains how coming out is an ongoing struggle for her as she comes out her mother.

It was a little bit of a roller coaster... My mom had found something on one of my online profiles which I had apparently forgotten to close, it said, "lesbian" on it. My mom picks me up from school and she's crying, and in that minute I knew, she didn't have to tell me what it was I knew she knew. I was so scared, the way she reacted it was like someone had died. At least the idea of who I was to her had died. All the future plans in her mind had died and then she asked me, "ah do you really know you are lesbian or are you just confused?" in that moment I really thought I'm lesbian but then I looked at how she's reacting, and look at everything I have to face. So I told her I was Bi, no then I told her I was confused. 
I really didn't tell her anything concrete, I just told her I was confused, that I was questioning. Then it just went on from there, the thing with the priest, then the thing in Ecuador then I kind of went back into the closet. But only at home with my family. (Carolina, lines 405-415)

It was four years later when Carolina was confronted once again by her mom about her sexuality. Now in college, armed with what she called, "being put together and her strength", she found the courage to admit she was a lesbian. Of the women who came out to their parents seven has shared how this had been a difficult process for them and could recall previous incidents where there were innuendos made about their sexuality by their parents, but they chose to ignore them. Six out of the nine who chose to come out to their parents have experienced adverse consequences: being asked to move out, having religion used against them, being switched from schools, and limiting the participants' contact with their social group. Several indicated that although their coming out had been difficult initially, they are now working on or have reached a reconciliation point with their parents.

For the four who were outed to their parents, this happened primarily through the use of technology, specifically social media, such as pictures on Facebook, text messages on cellphones or computer emails. Alejandra experiences was among the most extreme encountered. She experienced being outed twice with her parents, first her mother, and then a few years later with her father. The first time she was kicked out of her mother's home, and went to live with her father. While living with her father she vehemently denying her lesbian identity. She was able to stay as long as she agreed to go therapy for her condition. The second time she was confronted by her father in his house about being a lesbian, she did not deny being a lesbian and was given an ultimatum. She had to make 
a decision between her family and her lifestyle. She chose to accept her lesbian identity at this point. An account of her experiences are below:

My dad, would kept coming in and out of my room, kept yelling, "how could you do this type of thing?", like this had to be fixed, and then finally he gave me that ultimatum, "it's either be straight and stay at home, or be gay and go live with those people", ... he associates being gay to being a criminal...It was just like automatically being gay just made me dumber. I told him, "no dad, being gay doesn't make more susceptible to crimes and lower your IQ". Well he gave me the ultimatum, and the next morning I had school, so we agreed that I wasn't going to change, I told him that it was not possible to change...He couldn't understand that, he was like, yes you can, yes you can! So the next morning he told me to leave the car keys, but I had to get to school somehow, so I took the car anyway. That night I drop off the car at my dad's house and went to live in an apartment, and I've been living there ever since.

I dropped out of school, it was like my fifth day into my spring semester. I was working at HRC and I had to take up a full time schedule working eight to seven, Monday through Saturday and I just couldn't fit school into that, I had to make $\$ 900$ dollars for rent, and it was just not possible to come out, go to school, and work enough to make that money, still survive, and buy food...so I had to make a choice. (Alejandra, lines 297-392)

Alejandra's father was adamant that her being a lesbian could be changed. Recently, Alejandra shared that she and her father have begun to reconnect and make progress in trying to reconciling their relationship. She has not however moved back home and their contact is still very limited.

When coming out to family, Margarita and Nikki indicated having had a positive experience. They shared that this was due largely in part to how close they were to the person they came out to and how educated the individual already was regarding LGBT issues. In the next section we will look at participants experiences in coming out to peers.

Coming out to peers. Coming out to peers is when the participants announce to their peers at their HSI publically their lesbian identity. For those who chose to disclose to their peers in college they have received a mixture of both negative and positive 
responses. Some of the negative responses they received included: not fitting the lesbian stereotype, disbelief, and shock. A number of the women discussed the multiple messages they received from peers of how they could not be lesbians because they did not fit the stereotypes. They were perceived to be much to feminine. Hickock's experience shares some insights.

I guess people, but it isn't natural for where we are right now in terms of LGBT issues, most people are shocked. "Oh really? Oh wow. I couldn't tell." That, I hate that one. "I couldn't tell." Really? Do I have to wear on my forehead? Because unfortunately there's a stereotype when people associate they were lesbian, they think of somebody in primarily masculine clothing, something like that. So they see me and I'm quite feminine, at least physically, right? They're like "Oh. I didn't even know that was thing." What do you mean? People I didn't even know people are thing. So many of these conversations that have no relevance, right, and no point to them. But otherwise pretty good. Also, due to the fact that I see myself as an equal with the students for the most part, and this is why I feel more comfortable, more in control of my environment to just be open about my sexuality. (Hickock, line 667-675)

One of the main reason participants chose not to come out to friends or peers was the fear of fear of losing their friendship. Luna shared that she is very careful in whom she chooses to come out to. She is out to her gay friends but among her Japanese friends, she doubts they would be supportive or understanding so she does has not shared her lesbian identity with them (Luna, lines 204-208). Nikki's decision to come out to her friends, made her realize how unaccepting, narrow minded, and unsupportive her friends were. When Nikki decides to come out she began dating a woman who was gender nonconforming. Her best friends, who initially said they were okay with Nikki's sexuality began to share in their circle of friends that she was a lesbian. It became worse when they started judging Nikki and harassing her for whom she chose to date. One of her 
friends said, “oh I didn’t know you liked big fat dykes Nikki!” (Nikki, lines 355-361) leaving Nikki in a state of shock and disbelief.

Margarita, Mache, Alejandra, Pat, and Lourdes have had positive interaction with peers on campus when coming out. The messages they received were supportive and caring. Gertrude, mentioned that while her peers were okay with her being a lesbian, they still could not believe it because she had been so religious. An interesting observation regarding those whose experiences have been positive is that they have normalized their coming out process where they now feel comfortable interjecting the sexual identity into their everyday life.

Coming out to faculty and staff. Coming out to faculty and staff is when the participants announce to faculty and staff at their HSI publically their lesbian identity. Cathy, Monserrat, and others shared that they did not feel it was necessary to come out to faculty or staff, unless it is part of a meeting or event. Margarita, Carolina, and Pat, shared that it seemed that the more educated you are, the more open minded you are, so their experiences with faculty and staff have been all positive.

None of the participants reported any major coming out issues or concern with the faculty or staff at their HSI. None were outed by their faculty and staff at their HSI. This could be an indication that negotiating disclosure with faculty and staff rests within the control of the individual coming out. This concludes the disclosure tenet that explored the participant's perceptions of coming out to family, peers, faculty, and staff.

\section{Self-Acceptance of a Non-Heterosexual Identity}

Self-acceptance of a non-heteronormative identity is when a sexual minority has gone through a process of understanding their own life experiences and accepts their 
sexual identity despite the challenges faced. Attributes of self-acceptance often include: seeking out or increased contact with other sexual minorities or having a supportive network of non-sexual minorities. Self-acceptance is also seen as crucial to the healthy development of sexual minority identity (Cass, 1979; D’ Augelli, 1994).

Self-acceptance is characterized by the participants' journey as a Latina lesbian. In this section the participants' self-acceptance of a Latina lesbian identity while attending an HSI are examined. Their challenges, success, support systems and resilience are shared below.

Challenges. One of the most prevalent challenges still faced by participants include the reconciliation of their lesbian identities with family. Mache is fearful of returning home this summer now that she has begun to fully accept her Latina lesbian identity. She is loving and accepting of herself, but is concerned with going home and possibly hurting or destroying her family.

Pat's family dynamics, while different also poses some challenges. Pat's mother's side of the family is accepting and she understands that her father's side is not and this something she will have to contend with in the future. Gertrude although she said she would never come out to her parents, she is aware and struggling with finding the right time to disclose her lesbian identity. These participants are not sure how they will navigate that situation when the time comes.

Other challenges for these women include: reconciling their Latina and lesbian identities, specifically not fitting into the ascribed Latina heteronormative image, the challenges of feeling isolation and not having any out Latina lesbians with whom they identify. Hickock in her struggle to find other Latina lesbians to identify with calls 
Latina lesbians "a whole different breed," and used the analogy of being "a lone wolf" and stressed her perceptions of isolation and the lack of solidarity.

Successes. The success these women have experienced stems from their resilience in wanting to affirm who they are despite the conflicting experiences with their Latina and lesbian identities. Some of their successes have included: beginning to reconciling their relationship with their families, accepting their sexual identity while maintaining their spirituality, being out on campus and developing strong support systems.

Developing the strength to come out and accepting their Latina lesbian identity is a success that the participants have all shared in varying degrees. Hickock shared how in the face of adversity she found strength, "It was like playing Russian roulette, but I decided to put MY big girl pants on". She stated that she chose to honor herself and not give into the Latina heteronormative expectations that were set for her by her family.

Alejandra, despite being kicked out of her family's home, has made amends with her father and is working on re-establishing their relationship. Pat attributes her family's willingness to accept her identity being in part to her perception that they have accepted or assimilated more to the American culture and have become more open minded. In their assimilation, she has been able to abandon many of the limiting traditional values and norms of her Latina culture. She goes on to state, "I think a lot of the traditional elements in our heritage have been kind of abandoned so it's been easier to grow in that environment." This perception is shared by her mother and her mother's side of the family. This has not been the case with her father and his side of the family. Her father and his family still continues to be a challenge for her. Another success for Pat has been 
accepting her Lesbian identity. Despite her own personal struggles with reconciling her gender and sexuality, she has embrace and accept her lesbian identity.

Roxy has been able to begin reconciling her religion and sexual orientation. She has found a place of worship, which is affirming and has refuted the negative beliefs that were instilled in her at an early age regarding religion and her lesbian identity.

I didn't know that there was a church that allowed LGBTQ people to be welcome. I was actually at Miami Beach Gay Pride and I was kind of looking at the floats and then I realized that there was one that was a church. The float was set up like a wedding cake, with the pastor on the top and then they had a bunch of gay couples and a heterosexual couple in the cake. This was prior to marriage equality. When I saw that I was just in awe. I said, "Churches accept me? What?" It was such an impactful moment for me because all my life I've grown up with, like I said, different religions and none were accepting of LGBT folks. So, religion was a core thing that I grew up in and I missed it. So, I ended up Googling gay friendly churches and sure enough. That same church that had float in the Gay Pride Parade came up on my Google search. That's currently where I go to church. (Roxy, line 502-510).

Another success they have all had was establishing a strong network for themselves on campus. Although Monserrat is only a Freshman her networks and connections on campus have been helpful to establishing her Latina lesbian identity. She states:

Now that I am at FIU, I am able to feel much better and more confident about myself - to the point that I have become one of the LGBTQA+ student leaders on campus and plan to be a positive influence for LGBTQA+ community here (Monserrat, lines 300-303).

Supports. There were a variety of levels of support indicated by the participants. They found support among friends, faculty, staff, and peers. Supportive staff, faculty, supervisors, and mentors on campus were among the most cited reasons. Seven of the participants had indicated there on campus mentors as being extremely supportive and helpful to them. Of these mentors four were from a formalized LGBTQA Mentors 
program on campus, and the other three were professors and advisors on campus. Roxy and Alejandra both shared how their mentors introduced them to a myriad of both on campus and off campus resources, and offered them personal support during what they perceived to be some of their most challenging and difficult experiences. Hickock, Tiffany, and Cathy indicated their teachers and professors being both strong mentors for them.

For Mache, Luna, and Monserrat their best friend were strong supports for them. Mache shared that her best friend of 18 years, who she came out to was also the person who told her about this institution and she has always been supportive. Pat explains how her ex-girlfriend, helped her to look at herself critically through a different lens and accept her Latina lesbian identity. Despite the challenges and difficulties, they have faced as Latina lesbians, they have all developed strategies in order to resolve and positively adapt to their intersecting identities.

Resilience. Resilience addresses the participants' ability or capacity to recover from the challenges and difficulties encountered throughout their experiences (DiFulvio, 2011; Sanlo, 2004). Resilience is a characteristic that has been evident in all 15 participants. Examples of their resilience and strength are seen throughout the interviews but become most evident when discussing their journeys and self-acceptance as Latina lesbians.

Gertrude begins by explaining how she must be brave given the hostility encountered and the importance of being a role model and setting the example.

Being a Latina lesbian to me means being brave, in this day and age, the Latin American culture does not necessarily accept this lifestyle and so being and living in this type of community, and doing as you please, is a very courageous move. There 
will always be hard looks, and judgment, but being a lesbian in a Latin setting is something I am proud of, not ashamed. At this point, I do not care what others think of me, as I represent a group of people who may be scared to be who they really are in fear of what others may think. Being a lesbian for me, means setting the example. (Gertrude, lines 96-102)

Margarita goes on to shares how proud she is of who she is today in college and her responsibility in helping others:

I think I'm very proud of who I am especially now that I've been in college. I feel like I can play a big part especially in the community to help other people come out or embrace their sexuality regardless of what it is. But especially in terms of I guess Latinos there's a lot of stigmas. There is no such thing as being like a lesbian or being gay I guess you can say. It's a bad thing and I don't want to accept that because it's not bad to be who you are, so just embracing that...I think I have a lot of opportunities. Being involved in LGBTQ events is very important also. You do have a lot of opportunities here and I guess because I've been exposed to so many people that have been positive. I've been able to grow from that and actually open up and come out, because I wasn't afraid to come out. I was, but like it's helped. It's been kind of like a support system. (Margarita, lines 36-41/172-176)

Resilience among these woman has been exhibited through their examples of how they faced adverse situation in their lives and the strategies they used to cope. Despite the struggles these women have experienced as they attempted to negotiate the intersection of their identities, they have begun to recover and adjusted to their situations while managing to remain positive.

In the a priori code of self-acceptance there were four main findings. These included: beginning to reconciling their relationship with their families, accepting their sexual identity while maintaining their spirituality, coming out on campus, and developing a strong on campus support systems.

Coming out or disclosure continues to be a challenging and complex process for these women. Their degree of being out various among family, peers, and their campus culture. There was not a significant number that reported coming out directly to their 
professors as a result of: the belief that it did not matter, they were already out when they started college or were concerned about perception, although most mentioned never hearing a disparaging or non-affirming remark from faculty. One interesting finding regarding disclosure was that none of the participant shared having been outed on campus.

\section{Summary}

In the deductive analysis it was revealed that participants still struggled with ways to integrate their lesbian identity with their family, peers, and Latino culture. Despite these challenges, participants had a strong desire in wanting to reconcile their relationships with their family. There was an overall sense of inclusion by participants at their HSI as a result of the services offered. This analysis revealed overall that while participants' experiences in their HSI have included both encouraging and disparaging experiences, their levels of identity development while attending an HSI were determined by the levels of challenge or support they received from family, peers and the overall institution. In the next section the findings from the inductive and deductive analysis are compared.

\section{Comparative Analysis}

Comparative analysis involves comparing and contrasting the findings from the inductive and deductive analysis. During this process the researcher identifies and verifies consistencies in the findings, looks for patterns and answers the research questions. The emergent themes from the inductive analysis were: (a) the paradox of being Latina and lesbian (b) the trifecta: family, religion and gender and (c) institutional care. The deductive findings were analyzed using the a priori codes rubric consisting of 
the participants' (a) cultural background, (b) perceived identity and the four consistent tenets present in all sexual identity development models (Henrickson, 2013; Henrickson, \& Neville, 2012): (c) alienation, (d) social exclusion, (e) disclosure, and (f) selfacceptance of a non-heterosexual identity.

The comparative analysis between the inductive themes and deductive themes revealed the following findings: for all 15 participants the inductive themes of the trifecta: family, religion and gender where present in all a priori codes in the deductive analysis. They were most evident in those a priori codes that were part of the conceptual framework.

\section{The trifecta: family, religion, and gender}

The trifecta: family, religion and gender theme found in the inductive analysis was present in all a priori codes but most noticeably in the conceptual framework tenets including: alienation, social exclusion, disclosure and self-acceptance in the deductive analysis. These are discussed below.

When comparing and contrasting the tenet of alienation to family, religion and gender the following findings were uncovered. Participants encountered isolation, hostility and aggression based on their sexual identity from family (Henrickson, 2013). Family members held rigid negative and hostile attitudes towards gays and lesbians. There is also a strong disconnect between their sexual identity and religion. Their lesbian identity is not accepted in their society (i.e., culture, family, or peers). Participants did not fit into their expected gender role as Latinas lesbians. There was also a sense of disconnect from others because of the sexual objectification they encountered. 
Social exclusion involves the process in which sexual minorities are systematically blocked or denied various rights, opportunities, and resources that are available to the heterosexual majority (Queen et al., 2004). When comparing and contrasting the tenet of social exclusion to family, religion, and gender the following consistent findings were uncovered. Their cultural construct of Familismo and rigid expectations was confirmed. Participants experienced feelings of shame, insignificance, and disconnection with family due to their sexual identity. Participants experienced disconnected from religion based on the prevalent heteronormative attitudes, values and beliefs encountered. Participants experienced heteronormative attitudes and beliefs which further excluding them from their environment based on the gender

When comparing and contrasting the tenet of disclosure to family, religion and gender the following findings were uncovered. Experiences were complex and challenging when choosing to come out to family. They were met with varying degrees of acceptance. Religious doctrine was used negatively against participants after disclosing their sexual identity. Participants Experienced challenges and criticism from family and peers when trying to affirm their gender in the context of their lesbian identity.

Self-acceptance of a non-heteronormative identity is understanding one's life experiences and accepting one's sexual identity despite the challenges faced. Selfacceptance is crucial to the healthy development of a sexual minority's identity (Cass, 1979; D' Augelli, 1994). In comparing and contrasting the tenet of self-acceptance of a non-heterosexual identity to family, religion and gender the following findings were uncovered. Maintaining a strong sense of family remained important to participants. 
Reconciling and redefining their relationships with family was important despite the challenges they had faced. Participants questioned and re-evaluated their religion while finding new ways to reconciling their own sense of spirituality. Participants rejected their ascribed gender roles and expectations from society. They accepted their Latina lesbian identity despite continued feelings of isolation.

Their level of self-accepting and deciding whether they should come out or not, was mostly impacted by their decision to not disappoint or upset family members. Selfacceptance and coming out also had implications for the participants as they attempted to maneuver the various aspects of heteronormativity encountered at their institution, which were also presented in the deductive analysis.

\section{The paradox of being Latina and lesbian}

The paradox of being Latina and lesbian was also present in all a priori codes in

the inductive analysis and was most notable in experiences among family, peers, and students on campus as they struggled with alienations, social exclusion and selfacceptance. The alienation experienced was a result of not fitting into the heteronormative majority on campus and not being able to identify or relate to other Latina lesbians on campus. The reinforcement of the Latino cultural and gender expectations was also prevalent across all tenets in the conceptual framework.

\section{Institutional Care}

Patterns were also seen in comparing the inductive theme of institutional care with the deductive a priori codes of disclosure and self-acceptance. Examples of these included: LGBTQA visibility on campus, out LGBT faculty and staff, inclusive courses 
and events on campus, finding connections with college majors and having a strong support mechanism on campus.

\section{Summary}

This section looked at the comparative analysis comparing and contrasting the inductive and deductive analysis of this study. This completes the comparative analysis section of this study. In the next chapter, the responses to the research questions and implications for research and practice are discussed. 


\section{CHAPTER VI}

\section{DISCUSSION}

Chapter 6 is divided into five separate sections: (a) participants' responses to the research questions, (b) implications for practice, (c) recommendations for future research, (d) limitations of the study, and (e) final summary.

\section{Response to Research Questions}

In this section, responses to the research questions are provided. Answers to the four subsidiary questions are discussed first in order to gain a clear understanding of the participant's full experience, followed by the primary question. Response are provided below.

From the perspectives of these students, which college experiences have been related to their perceived sexual identity development

The participants indicated that experiences with peers, faculty, staff, and the LGBTQA community were all connected to their sexual identity development. Their in class and out of class experiences with peers, shared in the a priori code of alienation and social exclusion, confirmed the challenges Latina lesbians face when trying to affirm their sexuality on campus. Examples of these challenges included: the microagressions and macroagressions conservative student groups exhibited towards the participants as a result of their perceived sexual orientation or gender presentation which made them feel disconnected and unwelcomed (Platt \& Lenzen, 2013; Solorzano, Ceja, \& Yosso, 2000; Nadal, Rivera, \& Corpus, 2010; Sue, 2010).

Their direct involvement and encounters with staff were both supportive and nonsupportive, which was discussed in the a priori code of disclosure and the theme of 
institutional care. This was also evident with their extracurricular experiences that involved different aspects of the LGBTQA community.

\section{From the perspectives of these students, what cultural influences or factors have influenced their sexual identity development}

As seen in the deductive themes, participants identified family relationships, religious beliefs, and ascribed gender roles, as cultural factors that have influenced their sexual identity development. With family there were extensive similarities among the participants which highlighted the discrimination and challenges encountered with family members. Familismo (Ayón, \& Aisenberg, 2010), was often times cited as hindering the participants from disclosing their sexual identity. Their desire to develop a strong bond and sense of belonging with their family has made it very difficult for these women to come out.

Conservative religious values are grounded in the belief that homosexuality is immoral, unacceptable and unnatural (Branton, Wenzel, \& Wrinkle, 2014). This perception was highlighted by the participants as an important factor that negatively affected their perceived sexual identity. For Gertrude her family's negative response (Gertrude, lines 29-30) inhibits her from disclosing her lesbian identity to her family. This resonated with other participants throughout their interviews.

Another cultural factor that has influenced these Latinas' sexual identity development was their expected gender roles (Hernandez \& Curiel, 2012; Lopez, Corona, \& Halfond, 2013). As participants attempted to navigate their sexual identity, they were confronted with the challenge of not conforming to the expected gender role that their culture has placed upon them. 


\section{From the perspectives of these students, what college factors have influenced their sexual identity development}

Participants shared similar college factors that have influenced their sexual identity development including: from an academic standing point, classes, majors, faculty and LGBT classes different office and from a student affairs perspective there were offices, departments, LGBTQA programs, staff and an inclusive orientation process. While some of these factors negatively impacted their sexual identity development, there were more similarities that positively impacted their perceived sexual identity development.

Being at an institution which supported the LGBTQA community was important for participants and influenced their sexual identity development positively as observed in the institutional care theme. For the international students who came here to study, the visibility of the LGBTQA community on campus has been a positive factor for their sexual identity development. Roxy's, Mache's, and Alejandra's desire to find a supportive institution, was an essential part in deciding to attend their HSI. Participants shared with detail the importance of their institutions support during the development process of their sexual identity.

For others, their heteronormative experiences on campus influenced their identity development by creating a sense of disconnect and isolation, negatively impacting their decision to coming out. These experiences produced some anxiety and complications as to whether the participants chose to disclose their sexual identity or not to others. While participants shared both affirming and un-affirming experiences at their HSI, each one was able to described at least one affirming interaction on their sexual identity 
development stemming from either the LGBTQA visibility on campus or the support available.

\section{From the perspective of these students, what would make the LGBTQ experience at an HSI better for Latina lesbians}

Participants articulated multiple factors that would improve their experience.

These were shared in the deductive analysis, under the theme of institutional care. These were broken down into factors from a curricular or academic affairs perspective and those from a co-curricular or student affairs perspective and listed below.

From a curricular/academic affairs perspective

1. Offering core courses that infuse LGBTQA content into different disciplines was suggested. Offering business classes geared towards learning about LGBT issues and developing marketing strategies towards this population (Roxy, 620-621).

2. Offering colloquiums about Latina lesbians in different professional career options. For example, offering a Latina lesbian businesswomen's panel discussion (Gertrude, Lines 427 - 429).

3. Have faculty conduct research on Latina lesbian students.

From a co-curricular/student affairs perspective

1. They shared the importance of increased Latina lesbian visibility for what they perceived to be an invisible community on campus. One way this could happen was to have specific events and activities for Latina lesbians on campus as shared by Luna (line 319).

2. Mentorships program that pairs Latina lesbian students together with Latina lesbian faculty and staff who are out. 
3. Offering specific Latina lesbian events and receptions were Latina lesbian students can meet others on campus who identify as Latina lesbians.

4. Have the counseling and psychological programs and services office on campus offer programs and groups counseling and therapy sessions.

In providing these supports the development of these Latina lesbians' identity could be positively affected and lead to their overall academic and personal success in higher education (Mayhew, Grunwald, \& Dey, 2006; Pascarella \& Terenzini 2005).

Primary Research Question. How do Latina lesbian students describe their experiences and their perceived sexual identity development at a Hispanic-serving

institution. The participants' acknowledge that while they had some challenging experiences at their HSI, overall their experiences made them feel included in relation to their sexual identity. Participants whose experiences and perceived identity development were seen as positive stemmed primarily from the LGBTQA visibility on campus, supportive and inclusive programs on campus, inclusive classes and supportive faculty and staff. Despite their struggles to reconcile these identities, their HSI can be a source of support in their overall well-being and identity development, given there is an institutional LGBT infrastructure established.

\section{Implications for Practice}

This study has implications for student affairs practitioners and academic affairs administrators in higher education who work with Latina lesbian students at an HSI. It contributes to understanding the experiences and perceived identity development of Latina lesbian students. It revealed the complex and challenging experiences Latina lesbians encounter when they navigate their intersections of sexuality, gender, and culture 
in the context of higher education. Implications for academic affairs, student affairs and theoretical implications are shared below.

\section{Implications for Academic Affairs Administrators}

This study inferred that while some strides have been made in class curriculum and materials, many majors and specific courses on campus are not inclusive of LGBTQ issues, and classrooms remain heteronormative in nature. Developing new approaches to teaching and learning is one way campuses can become less heteronormative. Creating new learning approaches that encourage faculty to reconfigure their class by engage students when developing course syllabus, content, and materials can be instrumental in creating change. Cross-cultural teaching that includes Latina lesbians and the issues LGBTQ individuals face will begin to transform the heteronormative classroom environment.

Faculty are in position of powers and have a responsibility in creating a classroom environment that is inclusive and respectful to all students. Training and in-services for faculty members should include diversity awareness and sensitivity training that promotes in class discussion and exploration of different students' interests and needs. This can be beneficial in helping faculty build pathways for student success.

Lastly, committed department heads and chairs have a responsibility in creating change by developing policies and procedures that better equip faculty in addressing the heteronormative climate still present in classrooms. Educational policies and procedures with a strong emphasis on social justice and multicultural education can provide faculty with accurate information and skills. This information can be used to implement equitable practices that can help reduce heteronormativity in the classroom. 


\section{Implications for Student Affairs Practitioners}

The study inferred that while Latina lesbian students have some academic and personal support at their HSI, their home experiences continue to be challenging and difficult when attempting to reconcile their Latina lesbian identity. These findings support the argument that Latina lesbians still face discrimination, abuse, and even rejection from their families (Espín, 2012; García, \& Torres, 2009; Peña-Talamantes, 2013). The results suggest the importance of student affairs practitioners understanding the value and structure of family in the Latino community. This can help practitioners be empathetic to the family dynamics and challenges Latina lesbians face in order to provide better support and guidance.

The findings also demonstrated the importance of Latina lesbians being able to validate their experiences with others through self-awareness. The validation of their Latina lesbian sexual identity had a profound impact on their personal well-being and their ability to feel a connecting to their institution. The findings relating to the participant's self-awareness implied that their level of support and resilience were influential factors in overcoming the challenges they faced when trying to affirm their Latina lesbian sexual identity (Sanlo, 2004). A message received from Cathy shortly after her interview described the cathartic impact the interview had on her. Several other participants upon completing their interviews also shared the sense of relief and validation experienced in sharing their narratives. University counseling centers can be instrumental in providing support for Latina lesbians as they discover who they are.

The argument that campus programs and supportive systems can positively impact a student's identity development and success in higher education is supported in 
the findings (Braxton, 2010; Jones \& Abes, 2013, Mayhew, Grunwald, \& Dey, 2006; Pascarella \& Terenzini 2005; Turner, 2004). When considering institutional policies and practices, these should be revisited frequently to ensure inclusiveness of sexual minorities and gender variant individuals.

Developing strategies that help students connect with other Latina lesbians on campus is strongly recommended. Creating initiatives such as a student group on campus for Latina lesbians, establishing a Latina lesbian network and programs, and developing a mentorship program can help these students connect and build relationships with other Latina lesbians. In offering these types of initiatives student affairs practitioners can help Latina lesbians' address their feelings of isolation and their perception of being the "only one”. Other recommendations that could better support Latina lesbians include: programs focusing on their professional development and on issues of intersectionality. Offering these services would help Latina lesbians make sense of their experiences. Intentional training for student affairs practitioners could also be offered to inform them regarding the intersections of Latina lesbians. Follow-up session could focus on developing coping strategies for Latina lesbian students regarding the cultural stigma they experience.

The overall experiences in college can still be marginalizing to Latina lesbians. It is important for student affairs practitioners and academic affairs administrators in higher education to further research and explore the campus climate in order to create a more welcoming environments. In the next section I will discuss the theoretical implications in this study. 


\section{Theoretical Implications}

This study confirmed that the experiences of these 15 Latina lesbians was consistent with the sexual minority epistemology present in the sexual identity conceptual framework. All participants experienced varying degrees of alienation, social exclusion, disclosure, and self-acceptance (Bilodeau, \& Renn, 2005; Henrickson, 2013; Henrickson, \& Neville, 2012).

While Latina lesbian students struggle to reconcile their Latina and lesbian identities among families and friends, their experiences at a Hispanic-serving institution can be a source of support in their overall well-being and sexual identity development. Through the ethic of care theory (Noddings, 2013) we were able to see institutional cues that instilled a sense of belonging for participants. There is strong evidence of institutions commitment to doing the right things in order to meet the fundamental needs of the students. This gave participants a sense of relief and support which was empowering and uplifting for them, and was consistent with the literature regarding the level of connection, persistence, and fit students feel with their institution (Gloria, Castellanos, Lopez, \& Rosales, 2005).

The findings also supported the argument that environmental factors such as psychological climate, and behavioral climate as well as having campus support systems positively impact Latina lesbian student's sexual identity development and success on campus (Mayhew, Grunwald, \& Dey, 2006; Pascarella \& Terenzini 2005; Turner, 2004). While most campus environmental factors affirmed the participants' sexual identity, there were some psychological and behavioral experiences that perpetuated the campus' heteronormative climate (Rankin, 2005; Rankin \& Reason, 2008). 
The study also reinforced the theories of micro and macroagressions on Latina lesbians (Walls, 2008; Woodford et al., 2013). The microaggressions participants experienced in this study created a hostile environment which left them feeling marginalized and isolated (Croteau, et. al., 2005; Sue, 2010). These micro and macroagressions also had a negative effect on Latina lesbians ability to feel accepted in their environment and affected their sexual identity development (Platt \& Lenzen, 2013; Sue, 2010).

Currently higher education policies and practices do not take into consideration the experiences or sexual identity development of Latina lesbians at an HSI. Theories on Latina lesbians still needs to be developed that can direct future research. Although Latina lesbian sexual identity cannot be explained in terms of a model that applies to all individuals, Figure 2 represents a visual model of the themes and factors that have informed the participants perceived sexual identity development in this study. The model consists of the trifecta formed by the concepts of family, religion, and gender, the paradox, institutional care, and resilience. The Latina lesbian paradox is the concept that the two identities are contradicting and should not exist together, however for these women the two identities do exist and as part of their sexual identity development they have learn to have them co-exist. This theme is an important aspect in the development of their sexual identity. The paradox process consisted of the recognition of the contradictions between their identities, learning to navigate the identities and finally have the identities intersect. Institutional care stems from the ethic of care model and included the visibility on campus and the support systems on campus. These are important factors in helping these women accept their Latina lesbian identity. Lastly the resilience 
addresses the participants' ability or capacity to recover from the challenges and difficulties encountered throughout the Latina lesbians experiences and their levels of self-awareness. In the resilience aspect of this model we see an increase level of confidence, optimism, and positivity among these women as they accept their Latina lesbian identity.

Figure 2

A Visual Model for Latina Lesbian Sexual Identity Development

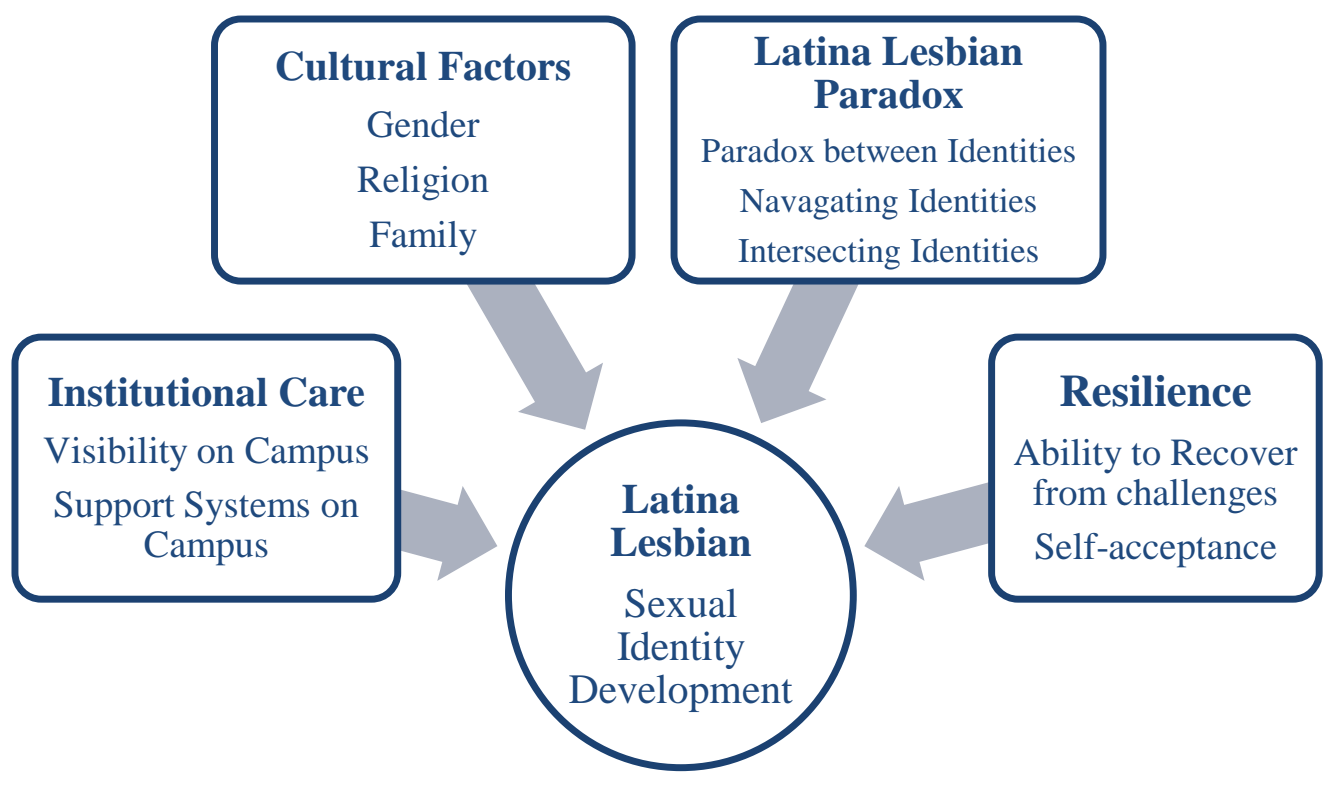

This model can serve as a starting point for higher education practitioners and administrators to begin to understand the factors that influence Latina lesbian's sexual identity development in college. 
In order to best serve this population, institutions should consider establishing measures in higher education to assist Latina lesbians with reconciling their intersecting identities. The findings of this research have implications on future support, programs, and resources offered to ensure the well-being and continued sexual identity development of Latin lesbians on college campuses.

\section{Recommendations for Future Research}

Research studies that focus on the experiences and perceived identity development of Latina lesbians within a Hispanic-serving institution have not been found. The findings from this study have begun to examine the experiences of Latina lesbians at an HSI. Research examining Latina lesbians experiences at an HSI should be expanded upon. Given the various lines of inquiry uncovered in this study, possible future researcher may include the following.

First, to further explore the experiences of Latina lesbian students at other HSIs within the context of the conceptual framework used in this study. The amounts of alienation, social exclusion, disclosure, and self-awareness Latina lesbians experiences at other institutions, while attempting to reconcile their identities could be noteworthy. With 435 Hispanic-Serving Institutions, (Hispanic Association of College \& Universities, 2016) continuing this line of research would further inform best practices in order to meet this growing populations needs.

Secondly, this study has indicated that institutions can be a place of challenge or support when it comes to Latina lesbians' feeling of inclusion on campus. Understanding that there are institutional factors that help students succeed in college (Pascarella \& Terenzini 2005; Renn, 2009), an on campus climate assessment examining the level of 
supports and/or challenges Latina lesbians experience on campus could provide valuable insights into creating more inclusive and welcoming campuses.

Third, the paradox of being Latina and lesbian present many challenges for Latina lesbians while in college. The fear of losing family and friends as a result of disclosing their lesbian identity is on ongoing struggle. Given the importance of the family unit in the culture (Ayon, \& Aisenberg, 2010; Ayón et. al., 2010; Toro-Morn, 2012), an exploration of how practitioners can assist Latina lesbians in reconciling their identities with family could be beneficial. Additionally, how Latinas who have romantic relationships with women and make meaning of their sexuality should to be explored. This could provide valuable information in understand the experiences and needs of Latinas who have romantic relationships with women but do not ascribe to the label of lesbian, looking at the evolving roles and nuances in understanding Latina students' sexual identity.

Final for the participants of this study, despite their personal progress made in reconciling their own identities, various factor of their Latino culture, (i.e. family, religion and gender roles) continue to create conflict for them as Latina lesbians. This study has only begun to uncover Latina lesbians experiences and sexual identity development at an HSI. Much remains to be learned about the identity development of Latinas in general and Latina lesbians in particular. Research that looks specifically at Latina lesbian identity development would add to the current void in the literature.

The findings of this study are not exhaustive, and reflect the experiences and perceived identity development of 15 Latina lesbian students at one Hispanic-serving 
institution. Future research that focus on the experiences of Latina lesbians at an HSI can build upon the findings of this study.

\section{Limitations of Study}

The findings of this study should be considered in the context of certain limitations. These Latina lesbians' experiences on campus varied as a result of the actual amount of time they spend on campus. A significant amount of these participants lived off-campus, the finding might yield different results at a HSI with a significant oncampus population.

Additionally, the participants in this study did not comprise one specific ethnic group within the Latino community. The participants in this study represented 12 different countries including: Cuba, Venezuela, Peru, Dominican Republic, Nicaragua, Ecuador, Columbia, Costa Rica, Spain, Chile, Mexico and the United States. Narrowing the focus to one specific ethnic group may produce different results.

\section{Summary}

Chapter 6 concludes the study with the responses to the research questions, implications practice, and recommendations for future research. This phenomenological study was to gather insights into the experiences of Latina lesbian students and their perceived sexual identity development at a predominately Hispanic-serving institution.

Three themes emerged from the data collected through interviews with the participants. The themes are the trifecta: family, religion and gender, the paradox of being Latina and lesbian, and institutional care. The sexual identity development conceptual framework utilized, provided significant insights into the experiences and perceived sexual identity development of Latina lesbians. For students who struggle to 
reconcile their Latina and lesbian identities among families and friends, their experiences at a Hispanic-serving institution can be a source of support or challenge in their overall well-being and sexual identity development.

The study provided implications for practitioners in higher education which were discussed earlier in the chapter. These included: the need to create affirming and welcoming environments for Latina lesbians on campus, to conduct further research on the experiences of Latina lesbians on campus, and to identify different measures on campus that can assist these students as they struggle in reconciling their Latina lesbian identity. The findings of this study can have implications on future support, research, and resources offered in helping these women affirming their sexual identity on college campuses and with their overall wellness and success. It is recommended that future researchers continue to examine the paradox of students being both Latina and lesbian, in order to inform practitioners to better assist Latina lesbians with their sexual identity development at other HSI. 


\section{REFERENCES}

Abes, E. S. \& Jones, S. R. (2004). Meaning-making capacity and the dynamics of lesbian college students' multiple dimensions of identity. Journal of College Student Development, 45(6), 612-632.

Agronick, G., O'donnell, L., Stueve, A., Doval, A., Duran, R., \& Vargo, S. (2004). Sexual behaviors and risks among bisexually- and gay-identified young Latino men. AIDS and Behavior, 8(2), 185.

Alden, H. L., \& Parker, K. F. (2005). Gender role ideology, homophobia and hate crime: Linking attitudes to macro-level anti-gay and lesbian hate crimes. Deviant Behavior, 26(4), 321-343.

Almeida, J., Johnson, R. M., Corliss, H. L., Molnar, B. E., \& Azrael, D. (2009). Emotional distress among LGBT youth: The influence of perceived discrimination based on sexual orientation. Journal of Youth and Adolescence,

Al-Timimi, N.R. (2003). The effect of identity development and perceived university environment on the college adjustment of gay, lesbian and bisexual college students. Dissertation Abstracts International, 64(11). (UMI No.3112251)

Ayón, C., \& Aisenberg, E. (2010). Negotiating cultural values and expectations within the public child welfare system: A look at familismo and personalismo. Child \& Family Social Work, 15(3), 335-344.

Ayón, C., Marsiglia, F. F., \& Bermudez-Parsai, M. (2010). Latino family mental health: Exploring the role of discrimination and familismo. Journal of Community Psychology, 38(6), 742-756.

Balsam, K., Beauchaine, T., Mickey, R., \& Rothblum, E. (2005). Mental health of lesbian, gay, bisexual and heterosexual siblings: Effects of gender, sexual orientation and family. Journal of Abnormal Psychology, 114(3), 471-476.

Bayly, M. (2007). Creating safe environments for LGBT students: A Catholic schools perspective. New York, NY: Routledge.

Bennett, C., \& Okinaka, A. M. (1990). Factors related to persistence among Asian, Black, Hispanic, and White undergraduates at a predominantly White university. Urban Review, 22, 33-60.

Bermudez, J. M., Kirkpatrick, D. R., Hecker, L., \& Torres-Robles, C. (2010). Describing Latino families and their help-seeking attitudes: Challenging the family therapy literature. Contemporary Family Therapy, 32, 155-172. 
Biegel, S., \& Kuehl, S. (2010). Safe at school addressing the school environment and LGBT safety through policy and legislation. The National Education Policy Center. Retrieved from http://nepc.colorado.edu/publication/safe-at-school

Bilodeau, B., Renn, K. (2005). Analysis of LGBT identity development models and implications for practice. New Direction for Student Services, 111, 25-39.

Birden, S. (2005). Rethinking sexual identity in education. Lanham, MD: Rowman \& Littlefield.

Bogdan, R.C., \& Biklen, S. (2006). Qualitative research for education: An introduction to theories and methods. Fourth Edition. Boston, MA: Allen and Bacon.

Boykin, K. (1996). One more river to cross: Black and gay in America. New York, NY: Doubleday.

Branton, R., Franco, A. B., Wenzel, J., \& Wrinkle, R. D. (2014). Latino Attitudes Toward Abortion and Marriage Equality: Examining the Influence of Religiosity, Acculturation, and Non-Response. Journal of Religion and Society, 2(16), 1-23.

Braxton, J. M., (2010). Catalysts and constraints to college student persistence: Introduction to a special issue other journal of college student retention: Research, theory and practice. Journal of College Student Retention, 11(1), 1-5.

Brown, R. D., Clarke, B., Gortmaker, V., \& Robinson-Keilig, R. (2004). Assessing the campus climate for gay, lesbian, bisexual, and transgender (GLBT) students using a multiple perspectives approach. Journal of College Student Development, 45, 826.

Bury, J. (2015). Non-performing inclusion: A critique of the English Football Association's Action Plan on homophobia in football. International Review for the Sociology of Sport, 50(2), 211-226.

Byers, K. (2010). And the quest for gender equality. (Doctoral dissertation, Saint Mary's University, Halifax).

Case, D. N., Hesp, G. A., \& Eberly, C. G. (2005). An exploratory study of the experiences of gay, lesbian and bisexual fraternity and sorority members revisited. Oracle: The Research Journal of the Association of Fraternity Advisors, 1(1), 15-31.

Cass, V.C. (1979). Homosexual identity formation: A theoretical model. Journal of Homosexuality, 4(3), 219-235. 
Carter, B. A. (2013). "Nothing Better or Worse Than Being Black, Gay, and in the Band" A Qualitative Examination of Gay Undergraduates Participating in Historically Black College or University Marching Bands. Journal of Research in Music Education, 61(1), 26-43.

Castillo, J. (2009). Convenience Sampling-Retrieved from http://explorable.com/convenience-sampling, on June 2014.

Chase, R. (2013).Gay man tortured and killed in Chachapoyas, Peru. Retrieved from: http://www.peruthisweek.com/news-gay-man-tortured-and-killed-inchachapoyas-peru-101671

Chaturvedi, N. S. (2014). The next generation? A reexamination of religious influence on Mexican-American attitudes toward same-sex marriage. Politics, Groups, and Identities, (ahead-of-print), 1-18.

Chung, B. (2001). Work discrimination and coping strategies: Conceptual frameworks for counseling lesbian, gay, and bisexual clients. Career Development Quarterly, 50(1) 33-44.

Chickering, A.W., \& Reisser, L. (1993). Education and identity. Second Edition. San Francisco, CA: Jossey Bass. The Jossey-Bass Higher and Adult Education Series.

Cochran, B.N., Stewart A.J., Ginzler J.A., and Cauce A.M. (2002). Challenges Faced by Homeless Sexual Minorities: Comparison of Gay, Lesbian, Bisexual, and Transgender Homeless Adolescents with Their Heterosexual Counterparts. American Journal of Public Health, 92(5), 773-777.

Collins, J. C., Rocco, T. S., \& Bryant, L. O. (Eds.). (2014). Health and Wellness Concerns for Racial, Ethnic, and Sexual Minorities: New Directions for Adult and Continuing Education, Number 142. John Wiley \& Sons.

Corliss, H. L., Goodenow, C. S., Nichols, L., \& Austin, S. B. (2011). High burden of homelessness among sexual-minority adolescents: findings from a representative Massachusetts high school sample. American journal of public health, 101(9), 1683-1689

Cray, A. (2013). 3 Barriers that Stand Between LGBT Youth and Healthier Futures. Center for American Progress. May 29, 2013. http://www.americanprogress.org/issues/lgbt/news/2013/05/29/64583 /3barriers-that-stand-between-lgbt-youth-and-healthier-futures/

Cramer, E. (2014). Addressing homophobia and heterosexism on college campuses. Routledge. 
Cress, C. M. (1999). The impact of campus climate on students cognitive and affective development. Unpublished doctoral dissertation. University of California, Los Angeles.

Creswell, J. W. (1998). Qualitative inquiry and research design: Choosing among five traditions. Thousand Oaks, CA: Sage.

Creswell, J.W. (2009). Research design: Qualitative, quantitative, and mixed methods approaches $\left(3^{\text {rd }}\right.$ ed.). Thousand Oaks, CA: Sage.

Danielson, M. T. (2009). Homecoming queers: desire and difference in Chicana Latina cultural production. Rutgers University Press.

D’Augelli, A. R. (1990). "Homophobia in a university community: Attitudes and experiences of heterosexual freshman. Journal of College Student Development. 31: 484-491.

D'Augelli, A. R. (1992). Lesbian and gay male undergraduates' experiences of harassment and fear on campus. Journal of Interpersonal Violence, 7, 383-95

D' Augelli, A. (1994). Identity development and sexual orientation: Toward a model of lesbian, gay, bisexual development. In E.J. Trickett, R.Watts, \& D. Birman (Eds.), Human diversity: Perspectives on people in context (pp. 312-333). San Francisco: Jossey-Bass.

De La Tierra, T. (2004). Activist Latina lesbian publishing: Esto no tiene nombre and conmoción. I am Aztldn: The personal essay in Chicano studies, ed. Chon A. Noriega and Wendy Belcher. Los Angeles: UCLA Chicano Studies Research Center Press, 172.

D’Emilio, J. (1990). The Campus Environment for Gay and Lesbian Life. Academe. 6(1): 16-19.

Diaz, E. M. \& Kosciw, J. G. (2009). Shared differences: The experiences of lesbian, gay, bisexual, and transgender students of color in our nation's schools. New York: GLSEN.

Diaz, R. M. (2013). Latino gay men and HIV: Culture, sexuality, and risk behavior. Routledge.

DiFulvio, G. T. (2011). Sexual minority youth, social connection and resilience: From personal struggle to collective identity. Social Science \& Medicine (1982), 72(10), $1611 ; 1611-1617 ; 1617$. 
Dugan, J. P., \& Yurman, L. (2011). Commonalities and differences among lesbian, gay, and bisexual college students: Considerations for research and practice. Journal of College Student Development, 52(2), 201-216.

Durso, L.E., \& Gates, G.J. (2012). Serving our youth: Finding from a national survey of service providers working with Lesbian, Gay, Bisexual and Transgender youth who are the homeless or at risk of becoming homeless. UCLA: the Homeless Institute, Retrieved from: http://escholarship.org/uc/item/80x75033.

Draft, S., (2014). As I see it: 2014 South Florida LGBTQ Community Assessment Study. Commissioned by the Aqua Foundation and Our Fund.

Dreyer, Y., (2008). Hegemony and the internalization of homophobia caused by heteronormativity. HTS Theological Studies/Theologies Studies, 63(1), 1-18.

Ellison, C. G., Acevedo, G. A., \& Ramos-Wada, A. I. (2011). Religion and attitudes toward same-sex marriage among US Latinos. Social Science Quarterly, 92(1), 35-56.

Ennis, S. R., Ríos-Vargas, M., \& Albert, N. G. (2011). The Hispanic population: 2010. US Department of Commerce, Economics and Statistics Administration, US Census Bureau.

Encarnación. (2011). Latin America's gay rights revolution. Journal of Democracy, 22(2), 104-118.

Espín, O. M. (2012). ...“An illness we catch from American women”? The multiple identities of Latina lesbians. Women \& Therapy, 35(1-2), 45-56.

Espín, O. M. (1999). Latina realities: Essays on healing, migration, and sexuality. Boulder, CO: Westview Press.

Estrada, F., Rigali-Oiler, M., Arciniega, G. M., \& Tracey, T. J. (2011). Machismo and Mexican American men: an empirical understanding using a gay sample. Journal of counseling psychology, 58(3), 358.

Evans, N. J., \& Broido, E. M. (2002). The experiences of lesbian and bisexual women in college residence halls: Implications for addressing homophobia and heterosexism. Journal of Lesbian Studies, 6(3-4), 29-42.

Evans, N.J., Forney, D.S., Guido, F.M., Patton, L.D., \& Renn K.A. (2010). Student development in college: Theory, research and practice. San Francisco, CA: Jossey-Bass. 
Evans, N., \& Rankin, S. (1998) "Heterosexism and campus violence.” In A. Hoffman, J. Schuh, and R. Fenske. (eds.). Violence on campus: Defining the problems, strategies for action. Gathersburg, MD: Aspen Publishers.

Fine, L. E. (2011). Minimizing heterosexism and homophobia: constructing meaning of out campus LGB life. Journal of homosexuality, 58(4), 521-546.

Flannery, D. J., Quinn-Leering, K. (2000). Violence on college campuses: Understanding its impact on student well-being. Community College Journal of Research and Practice. 24, 839-855.

Fausto-Sterling, A. (2000). Sexing the body: Gender politics and the construction of sexuality. Basic Books.

Flores, S. A., Mansergh, G., Marks, G., Guzman, R., \& Colfax, G. (2009). Gay identityrelated factors and sexual risk among men who have sex with men in San Francisco. AIDS Education \& Prevention, 21(2), 91-103.

Fox, R. (2000). Bisexuality in perspective. Education, research, and practice in lesbian, gay, bisexual, and transgendered psychology: A resource manual, 161-206.

Fox, R. C. (2003). Bisexual Identities Ronald C. Fox. Psychological perspectives on lesbian, gay, and bisexual experiences, 86.

Galanti, G. (2003). The Hispanic family and male-female relationships: An overview. Journal of Transcultural Nursing, 14(3), 180-185.

Gándara, P. (2015). Fulfilling America's Future: Latinas in the US, 2015. Washington, DC: U.S. Government Printing Office.

Gates, G., \& Kastanis, A., (2013). LGBT Latino/a individuals and Latino/a same-sex couples. UCLA: The Williams Institute. Retrieved from: http://escholarship.org/uc/item/

Gedro, J. (2014). Alcoholism and Lesbians. New Directions for Adult and Continuing Education, 2014(142), 49-62.

Gloria, A. M., Castellanos, J., Lopez, A. G., \& Rosales, R. (2005). An examination of academic nonpersistence decisions of Latino undergraduates. Hispanic Journal of Behavioral Science, 2005(27), 202-223.

Goldbach, J. T., Tanner-Smith, E. E., Bagwell, M., \& Dunlap, S. (2014). Minority stress and substance use in sexual minority adolescents: A meta-analysis. Prevention Science, 15(3), 350-363. 
Goldberg, S., Strutz, K. L., Herring, A. A., \& Halpern, C. T. (2013). Risk of substance abuse and dependence among young adult sexual minority groups using a multidimensional measure of sexual orientation. Public Health Reports, 128(3), 144.

González, C., \& Gándara, P. (2005). Why we like to call ourselves Latinas. Journal of Hispanic Higher Education, 4(4), 392-398.

Grant, J. M., Mottet, L.M., Tanis, J., Harrison J., Herman, J. L., \& Keisling, M. (2011). Injustice at Every Turn: A Report of the National Transgender Discrimination Survey. Washington: National Center for Transgender Equality and National Gay and Lesbian Task Force.

Greene, B. (1994). Ethnic-minority lesbians and gay men: mental health and treatment issues. Journal of consulting and clinical psychology, 62(2), 243.

Hackethal, V., Spiegel, S., Lewis-Fernandez, R., Kealey, E., Salerno, A., \& Finnerty, M. (2013). Towards a cultural adaptation of family psychoeducation: Findings from three Latino focus groups. Community Mental Health Journal, 49, 587-598.

Hale, F. W. (2004). What makes racial diversity work in higher education. Sterling, VA: Stylus.

Harper, S. R., \& Hurtado, S. (2007). Nine themes in campus racial climates and implications for institutional transformation. New Directions for Student Services, 2007(120), 7-24.

Hernandez, A. M., \& Curiel, Y. S. (2012). Entre Nosotros: Exploring Latino Diversity in Family Therapy Literature. Contemporary Family Therapy, 34(4), 516-533.

Hernández, R. (2014). Drawing Offensive/Offensive Drawing: Toward a Theory of Mariconógraphy. MELUS: Multi-Ethnic Literature of the United States, 39(2), $121-152$.

Henrickson, M. (2013, February). Identity satisfaction in sexual minorities: a queer kind of strength. Presentation at 'LGBTTI Wellness and Suicide: What do we need to change?' - a one-day symposium hosted in Auckland, New Zeland, by Auckland DHB, Affinity Services, OUTLine NZ, Rainbow Youth and the Mental Health Foundation.

Henrickson, M. \& Neville, S. (2012). Identity satisfaction over the life course in sexual minorities. Journal of Gay and lesbian Social Services, 24: 80-95.

Herek, G.M. (2004). Beyond "Homophobia": Thinking about sexual prejudice and stigma in the twenty-first century. Sexuality Research and Social Policy. 1(2), 6-24. 
Herek, G. M. (2009). Hate crimes and stigma-related experiences among sexual minority adults in the United States prevalence estimates from a national probability sample. Journal of interpersonal violence, 24(1), 54-74.

Hill, R. J. (Ed.). (2006). Challenging homophobia and heterosexism: Lesbian, gay, bisexual, transgender and queer issues in organizational settings. Jossey-Bass Inc Pub.

Hill, R. J., \& Grace, A. P. (2009). Adult and higher education in queer contexts: Power, politics, and pedagogy. Discovery Association Publishing House.

Hispanic Association of College \& Universities. (2016). 2016 Fact sheet Hispanic higher education and HSIs [Data file]. Retrieved December 29, from http://www.hacu.net/hacu/HSI_Fact_Sheet.asp

Huffington, A. (2013). Huffington post. Retrieved 9, October, from http://www.huffingtonpost.com/news/gay-youth-suicide.

Humes, K., Jones, N. A., \& Ramirez, R. R. (2011). Overview of race and Hispanic origin, 2010. US Department of Commerce, Economics and Statistics Administration, US Census Bureau.

Human Rights Campaign (2009). Issues: Federal Advocacy. http://www.hrc.org/

Hu, S., \& John, E. S. (2001). Student persistence in a public higher education system: understanding racial and ethnic difference. The Journal of Higher Education, 72 (3), 265-286.

Jezzini, A. T. \& Guzmán, C. E., \& Grayshield, L. (2008, March). Examining the gender role concept of marianismo and its relation to acculturation in Mexican-American college women. Presented at ACA Annual Conference, Honolulu, HI. Retrieved June 27, 2008, from http://counselingoutfitters.com/vistas/vistas08/Jezzini.htm

Johnson, T. P., Hughes, T. L., Cho, Y. I., Wilsnack, S. C., Aranda, F., \& Szalacha, L. A. (2013). Hazardous drinking, depression, and anxiety among sexual-minority women: self-medication or impaired functioning? Journal of studies on alcohol and drugs, 74(4), 565.

Jones, S.R. \& Abes, E.S., (2013). Identity development of college students: advancing frameworks for multiple dimensions of identity. San Francisco, CA: Jossey-Bass.

Josselon, R. (1996). Revising herself: The story of women's identity from college to midlife. New York, NY: Oxford University Press.

Kahn, M. (2013). LGBTQ Educators: Global Inequities. MER, 5(1). 
Kawahara, D. M., \& Espín, O. M. (2013). Feminist Therapy with Latina Women:

Personal and Social Voices. New York, NY: Routledge.

King, J. M., \& Anderson, D. M. (2004). A practitioner's guide to a learning-centered cocurricular activities program. College Student Affairs Journal, 24(1), 91.

Knudsen, S. V. (2006). Intersectionality-A theoretical inspiration in the analysis of minority cultures and identities in textbooks. Caught in the Web or Lost in the Textbook, 53(1), 61-76.

Koschoreck, J. W. (2003). Easing the violence: Transgressing heteronormativity in educational administration. Journal of School Leadership, 13(1), 27-50.

Kosmin, B.A., \& Keysar, A. (2009). "American Religious Identification Survey (ARIS). Hartford, Connecticut, USA: Trinity College. Retrieved 2009-04-01.

Kuh, G. D., Kinzie, J., Schuh, J. H., \& Whitt, E. J. (2010). Student success in college: Creating conditions that matter. John Wiley \& Sons.

Kumashiro, K. K. (2001). Queer students of color. In K. K. Kumashiro (Ed.), Troubling intersections of race and sexuality: Queer students of color and anti-oppressive education (pp. 1- 25). Lanham, MD: Rowman \& Littlefield)

Lavers, M.K. (2014). Report: 594 LGBT people murdered in Americas during 15-month period. Retrieved from: http://www.washingtonblade.com/2014/12/20/report594-lgbt-people-murdered-americas-15-month-period/

Lee, S. J. (2015). Addiction and lesbian, gay, bisexual and transgender (LGBT) issues. In Textbook of addiction Treatment: International perspectives (pp. 2139-2164). Springer Milan.

Lewis, R. J., Derlega, V. J., Berndt, A., Morris, L. M., \& Rose, S. (2002). An empirical analysis of stressors for gay men and lesbians. Journal of homosexuality, 42(1), 63-88.

Lewis, R. J., Derlega, V., Clarke, E. G. \& Kuang, J. (2006). Stigma consciousness, social constraints, and lesbian well-being. Journal of Counseling Psychology, 53(1), 4856.

Lincoln, Y. S., \& Guba, E. G. (1985). Naturalistic Inquiry. Newbury Park, CA: Sage Publications.

Loftus, J. (2001). America's Liberalization in Attitudes toward Homosexuality, 1973 to 1998. American Sociological Review 66:762-782. 
Lopez, V., Corna, R., \& Halfond, R. (2013). Effects of gender, media influences, and traditional gender role orientation on disordered eating and appearance concerns among Latino adolescents. Journal of Adolescence, 36, 727-736.

Marine, S. B. (2011). Stonewall's legacy: Bisexual, gay, lesbian, and transgender students in higher education: AEHE (Vol. 152). John Wiley \& Sons.

Marshall, C., \& Rossman, G. B. (2006). Designing qualitative research (4th ed.). Thousand Oaks, CA: Sage.

Marshal, M. P., Bukstein, O. G., Miles, J., Morse, J. Q., \& Freidman, M. Stall, E. (2008). Gay youth reported higher rates of drug and alcohol abuse. Addiction Journal.

Marshal, M. P., Dietz, L. J., Friedman, M. S., Stall, R., Smith, H. A., McGinley, J., \& Brent, D. A. (2011). Suicidality and depression disparities between sexual minority and heterosexual youth: a meta-analytic review. Journal of Adolescent Health, 49(2), 115-123.

Matthews, A., Li, C., Aranda, F., Torres, L., Vargas, M., \& Conrad, M. (2014). The influence of acculturation on substance use behaviors among Latina sexual minority women: The mediating role of discrimination. Journal of Substance Use \& Misuse, 49(14), 1888-1898.

Mayhew, M. J., Grunwald, H. E., \& Dey, E. L. (2006). Breaking the silence: Achieving a positive campus climate for diversity from the staff perspective. Research in Higher Education, 47(1), 63-88.

Mayo, Y., (1997) Machismo, Fatherhood and the Latino family. Journal of Multicultural Social Work, 5(1), 49-61

McCarn, S. R., \& Fassinger, R. E. (1996). Revisioning sexual minority identity formation a new model of lesbian identity and its implications for counseling and research. The Counseling Psychologist, 24(3), 508-534.

McEwen, M.K. (2003). New perspectives of identity development. In S.R. Komives, and D.B. Woodward Jr. (Eds.), Student services: A handbook for the profession, $\left(4^{\text {th }}\right.$ ed.) (pp. 203 -228). San Francisco: Jossey-Bass.

McKenzie, B. D., \& Rouse, S. M. (2013). Shades of faith: Religious foundations of political attitudes among African Americans, Latinos, and Whites. American Journal of Political Science, 57(1), 218-235.

Means, D. R., \& Jaeger, A. J. (2013). Black in the rainbow: "Quaring" the Black gay male student experience at historically Black universities. 
Merriam, S. B. (2009). Qualitative research: A guide to design and implementation. San Francisco, CA: Jossey-Bass.

Merriam-Webster's collegiate dictionary (11th ed.). (2005). Springfield, MA: MerriamWebster.

Meyer, I. H., \& Frost, D. M. (2013). Minority stress and the health of sexual minorities. Handbook of psychology and sexual orientation, 252-266.

Meyer, S. and Schwitzer, A. (1999). Stages of identity development among college students with minority sexual orientations. Journal of College Student Psychotherapy 13(3), 41-65.

Miller, D. C., \& Neil, J. Salkind (2002), Handbook of research design and social measurement.

Misawa, M. (2010). Racist and homophobic bullying in adulthood: Narratives from gay men of color in higher education. New Horizons in Adult Education and Human Resource Development, 24(1), 7-23.

Morgan, E. M. (2013). Contemporary issues in sexual orientation and identity development in emerging adulthood. Emerging Adulthood, 1(1), 52-66.

Moradi, B., Mohr, J. J., Worthington, R. L., \& Fassinger, R. E. (2009). Counseling psychology research on sexual (orientation) minority issues: Conceptual and methodological challenges and opportunities. Journal of Counseling Psychology, 56(1), 5-22.

Morales, E.S. (1992). Counseling Latino gays and Latina lesbians. Counseling Gay Men and Lesbians: Journey to the End of the Rainbow, 125-139.

Morales, A., Corbin-Gutierrez, E. E., \& Wang, S. C. (2013). Latino, immigrant, and gay: A qualitative study about their adaptation and transitions. Journal of LGBT Issues in Counseling, 7(2), 125-142.

Moustakas, C. (1994). Phenomenological research methods. Thousand Oaks, CA: Sage.

Murray, R. (2014). GLAAD and over 25 organizations: FIFA must take action on homophobia in soccer. Retrieved June 2015

from: http://www.glaad.org/blog/glaad-and-over-25-organizations-fifa-must-takeaction-homophobia-soccer

National Gay and Lesbian Task Force (2014). Movement Analysis: The Pathway to Victory, A Review of Supreme Court LGBT Cases By a Task Force Public Policy and Governmental Affairs Law Fellow. http://www.thetaskforce.org/report 
Nadal, K. L., Rivera, D. P., \& Corpus, J. H. (2010). Sexual orientation and transgender microaggressions. Microaggressions and marginality: Manifestation, dynamics, and impact, 217-240.

Nauta, M. M., Saucier, A. M., \& Woodard, L. E. (2001). Interpersonal influences on students' academic and career decisions: The impact of sexual orientation. Career Development Quarterly, 49(4), 352-362.

Newcomb, M. E., Birkett, M., Corliss, H. L., \& Mustanski, B. (2014). Sexual orientation, gender, and racial differences in illicit drug use in a sample of US high school students. American journal of public health, 104(2), 304-310.

Noack, K. W. (2004). An assessment of the campus climate for gay, lesbian, bisexual and transgender persons as perceived by the faculty, staff and administration at Texas $A \& M$ University (Doctoral dissertation, Texas A\&M University).

Noddings, N. (2013). Caring: A relational approach to ethics and moral education. University of California Press.

Nodelman, U., Allen, C., \& Perry, J. (2003). Stanford encyclopedia of philosophy. Stanford, CA: Stanford University.

Nora, A., \& Crisp G. (2009). Hispanics and higher education: An overview of research, theory and practice. Higher Education: Handbook of Theory and Research, 24, $317-353$.

Olson, L. R., \& Cadge, W. (2002). Talking about Homosexuality: The Views of Mainline Protestant Clergy. Journal for the Scientific Study of Religion 41:153-167.

Olson, L. R., Cadge, W., \& Harrison, J. T. (2006). Religion and Public Opinion about Same-Sex Marriage. Social Science Quarterly, 87(2), 340-360.

O'Malley Olsen, E., Kann, L., Vivolo-Kantor, A., Kinchen, S., \& McManus, T. (2014). School Violence and Bullying Among Sexual Minority High School Students, 2009-2011. Journal of Adolescent Health.

Onorato, S. M. (2010). Developing a leadership identity: A case study exploring a select group of hispanic women at a hispanic serving institution. (Ed.D., Florida International University). ProQuest Dissertations and Theses.

Owles, V. (2009). The experiences of Cuban american women attending a hispanic serving institution and the influences on identity development. (Ed.D., Florida International University). ProQuest Dissertations and Theses. 
Pascarella E. \& Terenzini P. (2005). How college affects students: Volume 2 a third decade of research. San Francisco, CA: Jossey-Bass.

Patton, L. D. (2011). Perspectives on identity, disclosure and the campus environment among African American gay and bisexual men at one historically Black college. Journal of College Student Development, 52(1), 77-100.

Patton, M. Q. (2002). Qualitative research and evaluation methods (3 ${ }^{\text {rd }}$ ed.). Thousand Oaks, CA: Sage.

Peña-Talamantes, A. E. (2013). Empowering the Self, Creating Worlds: Lesbian and Gay Latina/o College Students' Identity Negotiation in Figured Worlds. Journal of College Student Development, 54(3), 267-282.

Picket, C,N, (2013). Latinas in the United States: A Historical Encyclopedia. Reference Reviews.

Platt, L. F., \& Lenzen, A. L. (2013). Sexual Orientation Microaggressions and the Experience of Sexual Minorities. Journal of homosexuality, 60(7), 1011-1034.

Pride, C. (2010). LGBT-friendly campus climate index. Charlotte, NC: Author.

Quaye, S. J., \& Harper, S. R. (2004). Taking seriously the evidence regarding the effects of diversity on student learning in the college classroom: A call for faculty accountability. UrbanEd, 2(2), 43-47.

Queen, M., Farrell, K., \& Gupta, N. (2004). Interrupting Heteronormativity: Lesbian, Gay, Bisexual, and Transgender Pedagogy and Responsible Teaching at Syracuse University. Graduate School at Syracuse University, New York.

Ramos, D. (2011). That's gay and Hispanic homophobia. Dry as toast. Retrieved from: http://www.dryastoast.com/2011/10/thats-gay-and-hispanic-homophobia.html

Rankin, S. R. (2003). Campus Climate for Gay, Lesbian, Bisexual, and Transgender People: A National Perspective. New York: The National Gay and Lesbian Task Force Policy Institute.

Rankin, S. R. (2005). Campus climates for sexual minorities. New Directions for Student Services, 2005(111), 17-23.

Rankin, S. R. (2006). LGBTQA students on campus: Is higher education making the grade? Journal of Gay \& Lesbian Issues in Education, 3(2-3), 111-117. 
Rankin, S. R., \& Reason, R. D. (2008). Transformational tapestry model: A comprehensive approach to transforming campus climate. Journal of Diversity in Higher Education, 1(4), 262-274.

Rankin, S., Sanlo, R. and Schoenberg, R. (2002). Assessing the Needs and Proposing Solutions. Our Place on Campus: Lesbian, Gay, Bisexual, Transgender Services and Programs in Higher Education. Greenwood Press. Westport, CT. 13-24.

Rankin, S., Weber, G. N., Blumenfeld, W. J., \& Frazer, S. (2010). 2010 state of higher education for LGBT people. Charlotte, NC: Campus Pride.

Reason, R. D., \& Rankin, S. R. (2006). College students' experiences and perceptions of harassment on campus: An exploration of gender differences. College Student Affairs Journal, 26(1), 7-29.

Renn, K. A. (2007). LGBT student leaders and queer activists: Identities of lesbian, gay, bisexual, transgender, and queer identified college student leaders and activists. Journal of College Student Development, 48(3), 311-330

Renn, K. A. (2010). LGBT and queer research in higher education: The state and status of the field. Educational Researcher, 39(2), 132-141.

Renn, K. A. (2012). Mixed race students in college: The ecology of race, identity, and community on campus. SUNY Press.

Rhoads, R. A. (1994). Coming out in college: The struggle for a queer identity. Greenwood Publishing Group.

Rhoads, R. A. (1995). Learning from the coming-out experiences of college males. Journal of College Student Development, 36, 67-67.

Rhoads, R. A. (1997). Implications of the growing visibility of gay and bisexual male students on campus. NASPA Journal, 34(4), 275-286.

Rocco, T. S., \& Gallagher, S. J. (2006). Straight privilege and moralizing: Issues in career development. New directions for Adult and Continuing education, 2006(112), 2939.

Rocco, T. S., Landorf, H., \& Delgado, A. (2009). Framing the issue/Framing the question: A proposed framework for organizational perspectives on sexual minorities. Advances in Developing Human Resources. 11(1), 7-23.

Rockman, A.L., (2013). "Gay, Lesbian, and Bisexual Students on Community College Campuses: Coming-Out and Self-Actualization". Education Doctoral. Paper 154. http://fisherpub.sjfc.edu/education_etd/154 
Rood, A. N. (2008). Minorities in the majority: College adjustment of Latinas and Latinos at a Hispanic-serving institution. (Ph.D., Our Lady of the Lake University). ProQuest Dissertations and Theses.

Rosario, M., Schrimshaw, E. W., \& Hunter, J. (2004). Ethnic/racial differences in the coming-out process of lesbian, gay, and bisexual youths: A comparison of sexual identity development over time. Cultural Diversity and Ethnic Minority Psychology, 10(3), 215.

Rose, S. \& Mechanic, M. (2002). Psychological distress, crime features, and help-seeking behaviors related to homophobic bias incidents, American Behavioral Scientist, 46, 14-26.

Rose, S. M. (2003). Community interventions concerning homophobic violence and partner violence against lesbians. Journal of lesbian studies, 7(4), 125-139.

Rothaus, S. (2010, October). Suicide surge: schools confront anti-gay bullying after deaths of Tyler Clementi and other youths. Retrieved from: http://miamiherald.typepad.com/ gaysouthflorida/2010/10/suicide-surge-schoolsconfront-anti-gay-bullying-after-deaths-of-tyler-clementi-and-other-youths.html

Rothman, E. F., Exner, D., \& Baughman, A. L. (2011). The prevalence of sexual assault against people who identify as gay, lesbian, or bisexual in the United States: A systematic review. Trauma, Violence, \& Abuse, 1524838010390707.

Ryan, C., Huebner, D., Diaz, R. M., \& Sanchez, J. (2009). Family rejection as a predictor of negative health outcomes in White and Latino lesbian, gay, and bisexual young adults. Pediatrics, 123(1), 346-352.

Saavedra, C. U. R. (2001). Chicana Schism: The Relationship Between Chicana Feminist and Chicana Feminist Lesbians.

Sandfort, T. G., Melendez, R. M., \& Diaz, R. M. (2007). Gender nonconformity, homophobia, and mental distress in Latino gay and bisexual men. Journal of Sex Research, 44(2), 181-189.

Sanlo, R.L. (ed.). (1998). Working with lesbian, gay, bisexual, and transgender college students: A handbook for faculty and administrators. Westport, CT: Greenwood Press.

Sanlo, R. (2004). Lesbian, gay, and bisexual college students: Risk, resiliency, and retention. Journal of College Student Retention Research Theory and Practice, $6(1), 97-110$ 
Severson, N., Muñoz-Laboy, M., Garcia, J., Perry, A., Wilson, P., \& Parker, R. (2013). Generational changes in the meanings of sex, sexual identity and stigma among Latino young and adult men. Culture, health \& sexuality, 15(7), 804-818.

Solorzano, D., Ceja, M., \& Yosso, T. (2000). Critical race theory, racial micro aggressions and campus racial climate: The experiences of African American college students. Journal of Negro Education, 69, 60-73.

Sternberg, P. (2000). Challenging machismo: Promoting sexual and reproductive health with Nicaraguan men. Gender \& Development, 8 (1), 89-99.

Strauss, A., \& Corbin, J. (1998). Basics of qualitative research (2nd ed.). Thousand Oaks, CA: Sage.

Sue, D. W. (2010). Microaggressions in everyday life: Race, gender, and sexual orientation. John Wiley \& Sons.

Sullivan, M. K. (2013). Sexual minorities: Discrimination, challenges and development in America. Routledge.

Surtees, N., \& Gunn, A. C. (2010). (Re) marking heteronormativity: Resisting practices in early childhood education contexts.

Teddlie, C., \& Tashakkori, A. (2011). Mixed methods research. The Sage handbook of qualitative research, 285.

Tegel, S. (2013). Latin American has a homophobic killing problem. Retrieved from:http://www.globalpost.com/dispatch/news/regions/americas/131219/latinamerica-homophobic-killing-lgbt

Teman, E. D., \& Lahman, M. K. E. (2010). Supporting students of diverse sexual orientation in higher education: An ethnography of an LGBTAQ center. Denver, CO: University of Northern Colorado.

Tetreault, P. A., Fette, R., Meidlinger, P. C., \& Hope, D. (2013). Perceptions of campus climate by sexual minorities. Journal of homosexuality, 60(7), 947-964.

The Americas Barometer by the Latin American Public Opinion Project (LAPOP), www.LapopSurveys.org.

Tomlinson, M. J., \& Fassinger, R. E. (2003). Career development, lesbian identity development, and campus climate among lesbian college students. Journal of College Student Development, 44(6), 845-860.

Toro-Morn, M. I. (2012). Familismo. Encyclopedia of immigrant health, 672-674. 
Torres, L., \& Pertusa, I. (2003). Tortilleras: Hispanic and U.S. Latina lesbian expression. Philadelphia, PA: Temple University Press.

Torres, L. (2002). Becoming Visible: US Latina Lesbians Talk Back and Act Out. Counterpoints, 169, 151-162.

Torres, V., Jones S.R., \& Renn, K.A. (2009). Identity development theories in student affairs: origins, current status, and new approaches. Journal of College Student Development, 50 (1), 577-596.

Macmillan Dictionary. (2016). Retrieved online from http://www.macmillandictionary.com/us/dictionary/american/trifecta.

Troiden, R.R. (1979). Becoming a Homosexual: A Model of Gay Identity Acquisition. Psychiatry, 42, Nov., 362-373.

Turner, K. (2004). Success Factors of Young African American Women at a Historically Black College (review) Journal of College Student Development, 45(1), 101-103.

Tyre, Y. (2009). Understanding african american lesbians and gay identity development within a historically black college environment. (Doctoral Dissertation, Auburn University.)

Tyler Clementi Higher Education Anti-Harassment Act of 2015, HR 1421, 114 Cong. (2015). Retrieved from https://www.congress.gov/bill/114th-congress/housebill/1421/text).

Unnever, J., Cullen, F.T. \& Applegate, B. K. (2005). Turning the Other Cheek: Reassessing the Impact of Religion on Punitive Ideology. Justice Quarterly 22:304-338.

United Nations Educational, Scientific and Cultural Organization. (2016). Education \& curriculum. Retrieved November 2016, from http://www.unesco.org/ new/en/education /themes/ strengthening-education-systems/qualityframework/core resources/curriculum/

U.S. Census Bureau. (2011). State \& county quick facts: Miami-Dade County, FL. Retrieved August 2013, from http://quickfacts.census.gov.

U.S. Department of Justice. (2012). Federal bureau of investigations. Uniform crime report: hate crime statistics. http://www.fbi.gov/aboutus/cjis/ucr/hatecrime/2012/resources/summary_final.pdf

Van Manen, M. (1990). Researching lived experience. Ontario, Canada: The University of Western Ontario. 
Van Manen, M. (2011). Phenomenology online: A resource for phenomenological inquiry. Retrieved July 2014, from http://www.phenomenologyonline.com

Villegas, J., Lemanski, J., \& Valdéz, C. (2010). Marianismo and machismo: The portrayal of females in Mexican TV commercials. Journal of International Consumer Marketing, 22(4), 327-346

Wall, V.A., \& Evans, N.J. (2000). Towards acceptance sexual orientation issues on campus. Lanham, MD: University Press of America.

Walls, N. E. (2008). Toward a multidimensional understanding of heterosexism: The changing nature of prejudice. Journal of Homosexuality, 55(1), 20-70.

Walton, G. M., \& Cohen, G. L. (2007). A question of belonging: race, social fit, and achievement. Journal of personality and social psychology, 92(1), 82.

Weber, G. (2008). Using to numb the pain: Substance use and abuse among lesbian, gay, and bisexual individuals. Journal of Mental Health Counseling, 30(1), 31-48.

Wickens, C. M., \& Sandlin, J. A. (2010). Homophobia and heterosexism in a college of education: A culture of fear, a culture of silence. International Journal of Qualitative Studies in Education, 23(6), 651-670.

Windmeyer, S. (2006). The Advocate guide for LGBT students. New York, NY: Alyson Books.

Windmeyer, S., Humphrey, K., \& Barker, D. (2013). An institutional responsibility: Tracking retention \& academic success of out LGBT students. Campus Pride Blog. April, 8 .

Winston, R. B., Jr., Creamer, D. G., \& Miller, T. K. (2001). The professional student affairs administrator: Educator, leader, and manager. New York, NY: BrunnerRoutledge.

Woodford, M. R., Howell, M. L., Kulick, A., \& Silverschanz, P. (2013). "That's so gay" Heterosexual male undergraduates and the perpetuation of sexual orientation microagressions on campus". Journal of interpersonal violence, 28, 416-435.

Woodford, M.R., Howell M.L., Kulick A., \& Silverschanz, P. (2013). “That's so Gay”: Heterosexual Male Undergraduates and the Perpetuation of Sexual Orientation Microagressions on Campus." Journal of Interpersonal Violence, 28: 416.

Woodford, M. R., Krentzman, A. R., \& Gattis, M. N. (2012). Alcohol and drug use among sexual minority college students and their heterosexual counterparts: the 
effects of experiencing and witnessing incivility and hostility on campus. Substance Abuse and Rehabilitation, 3, 11.

Woodford, M. R., Levy, D., \& Walls, N. E. (2013). Sexual prejudice among Christian college students, denominational teachings, and personal religious beliefs. Review of Religious Research, 55(1), 105-130.

Yes Institute (2015). Gender Transition Guide. Retrieved December 2015 from: yesinstitute.org/gender/gender-guide.pdf

Young, J. (2009). Clinical pediatrics in the Mexican immigrant community. Contemporary Pediatrics, 26(4), 58-64.

Zea, M.C., Reisen, C.A., \& Díaz, R.M. (2003). Methodological issues in research on sexual behavior with Latino gay and bisexual men. American Journal of Community Psychology, 31(3), 281-291. 


\section{APPENDICES}

APPENDIX A

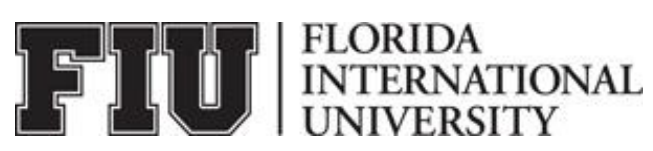

\section{Invitation to Participate in the Study}

Dear fellow FIU Student:

My name is Gisela Vega and I am a doctoral candidate here at FIU. I am currently conducting a study for my dissertation which focuses on the experiences of sexual minority students at a predominantly Hispanic-Serving Institution (HSI) and their perceived sexual identity development. My interest in this topic stem from my experiences both personal and professional in higher education regarding this population.

I am currently seeking undergraduate students who would be willing to speak with me regarding their experiences as a sexual minority student at FIU. Participation in the study will consist of an interview which will require about an hour of your time. The questions are all open-ended and will be digitally recorded.

This study would help inform future higher education educators regarding the experience of sexual minorities. Educators and administrators who read this study will gain a deeper understanding of the needs of Sexual Minority College students at a Hispanic-Serving Institution. All participants' information will be kept confidential. If you would like to participate in this study please feel free to contact me at 305-348-1952 or xvegag@fiu.edu. Thank you for your consideration.

Respectfully,

Gisela P. Vega, Doctoral Candidate: Higher Education Administration 


\section{APPENDIX B}

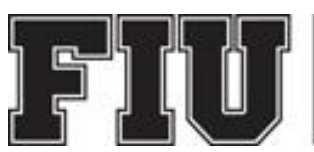

\section{FLORIDA}

INTERNATIONAL

UNIVERSITY

Demographic Survey

Please complete the following:

1. Where are you from?

2. What country were you born in?

3. What country were your parents born in?

4. Where do you currently reside?

5. What language or languages do you currently speak?

6. What is your family's country of origin? 


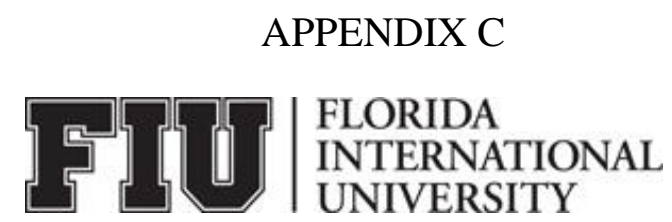

Interview Protocol

\section{Latina Lesbian Students: Understanding Their Experiences and Perceived Sexual Identity Development at a Hispanic-Serving Institution}

\section{Culture \& Family Background}

1. Tell me about yourself?

2. Describe your culture, and what being Latina means to you.

3. Describe your family and the values they taught you.

4. What influenced your decision to attend an HSI?

\section{Identity}

5. Describe your sexual orientation and when you realized you were not heterosexual.

6. What does being a Latina lesbian mean to you?

7. Describe how your family views lesbians and gays and the messages you received.

8. Describe how your ethnic culture views lesbians and gays and the messages you received.

\section{Alienation "the experience of seeing oneself as different"} In Society

9. Describe when you became aware that your sexual orientation affected the way you were treated by others and how did you feel.

10. How important is your sexual identity to you? Why?

\section{With family}

11. Describe the instant when you became aware that your sexual orientation was different than your parents and how did you feel.

12. How important is your sexual identity to your family?

\section{In College}

13. Describe a time in college when you felt welcomed because of your sexual orientation.

14. Describe a time at college when you felt excluded because of your sexual orientation.

15. Describe college events or interactions with various offices (i.e. admission, registration, in classes, financial aid etc.) that stand out for you as a sexual minority and how they made you feel.

16. Describe what it means to be a Latina lesbian student at FIU. 


\section{Social Exclusion "not fitting into the heteronormative majority" With family}

17. Describe a time when you became aware that your sexual orientation affected the way you were treated by your family.

18. Describe how being a Latina lesbian affected your relationships with family members.

\section{In a Classroom/Academic Setting}

19. Describe your experiences with faculty regarding your sexual orientation.

20. Describe how being a Latina lesbian affected your studies or choice of major.

21. Describe how being a Latina lesbian affected your relationships with instructors.

\section{In extra-curricular and non-classroom settings}

22. Describe how being a Latina lesbian affected your choice of student clubs, activities or organizations you decide to join.

23. Describe your experiences with staff or administrators regarding your sexual orientation.

24. Describe how being a Latina lesbian affected your overall experience at this HSI.

With peers

25. Describe your experiences with other students regarding your sexual orientation.

26. Describe how being a Latina lesbian affected your relationships with students.

\section{Disclosure or "Coming out"}

27. Describe your coming out experience with your family.

28. Describe your coming out experience with your peers.

29. Describe your coming out experience with faculty and staff.

\section{Self-acceptance of a non-heterosexual identity}

30. Describe your journey as a Latina lesbian.

31. Describe the process of accepting yourself as a Latina lesbian and any success or challenges you have experienced.

32. Describe someone who has helped you accept your Latina lesbian identity.

\section{Concluding Questions}

33. Is there a question you think I should have asked but did not?

34. Is there anything you would like to add about your experience as a Latina lesbian on an HSI campus?

35. Describe what your HSI can do to improve your experience as a college student. 
APPENDIX D

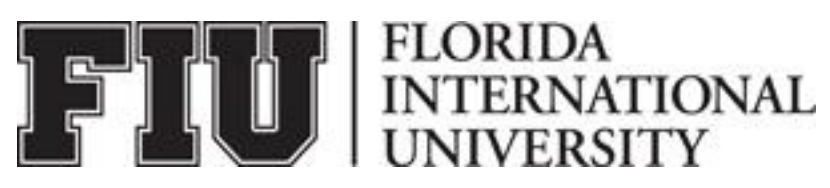

\section{ADULT WRITTEN CONSENT TO PARTICIPATE IN A RESEARCH STUDY LATINA LESBIAN STUDENTS: UNDERSTANDING THEIR EXPERIENCES AT A HISPANIC-SERVING INSTITUTION AND THEIR PERCEIVED SEXUAL IDENTITY DEVELOPMENT}

\section{PURPOSE OF STUDY}

You are being asked to be in a research study. The purpose of this phenomenological study is to gather insights into the experiences of Latina lesbian students and their sexual identity development at a predominately Hispanic-Serving Institution. The focus of this study will be to understand the experiences of current Latina lesbian students at a Hispanic-serving institution and gain insights into their sexual identity development.

\section{NUMBER OF STUDY PARTICIPANTS}

If you decide to be in this study, you will be one of 15 people in this research study.

\section{DURATION OF STUDY}

Your participation will require 60 to 90 minutes of your time, within a single interview session.

\section{PROCEDURES}

If you agree to be in the study, we will ask you to do the following:

1. Participants will be asked to complete a brief demographics survey prior to beginning the interview.

2. Participate in a digitally recorded interview. The face-to-face (or electronic interface) interview will be guided by a list of 35 questions. You will be asked to answer questions about your perceptions of your past cross-cultural mentoring experiences.

3. Upon completion of the data analysis you will be sent an email asking you to verify the analysis of your data and feedback. This review will require no more than an hour.

4. Complete a brief demographics questionnaire

\section{RISKS AND/OR DISCOMFORTS}

There are no known risks related to this study.

\section{BENEFITS}

Although there is no direct benefit from the study, you may benefit in the sense that:

- You will come to understand your own sexual identity development perceptions and how your experiences influenced your feelings and interactions. 
- Higher Education educators and administrators who read this study will gain a deeper understanding of the needs of Latina lesbian students at a HispanicServing Institution.

\section{ALTERNATIVES}

There are no known alternatives available to you other than not taking part in this study. However, any significant new findings developed during the course of the research which may relate to your willingness to continue participation will be provided to you.

\section{CONFIDENTIALITY}

The records of this study will be kept private and will be protected to the fullest extent provided by law. In any sort of report we might publish, we will not include any information that will make it possible to identify a subject. Research records will be stored securely and only the researcher will have access to the records. Your records may also be reviewed for audit purposes by authorized University or other agents who will be bound by the same provisions of confidentiality.

\section{COMPENSATION \& COST}

There is no payment or reimbursement for your participation, and you will not be responsible for any costs to participate in this study.

\section{RIGHT TO DECLINE OR WITHDRAW}

Your participation in this study is voluntary. You are free to participate in the study or withdraw your consent at any time during the study. Your withdrawal or lack of participation will not affect any benefits to which you are otherwise entitled. The investigator reserves the right to remove you without your consent at such time that they feel it is in the best interest.

\section{RESEARCHER CONTACT INFORMATION}

If you have any questions about the purpose, procedures, or any other issues relating to this research study you may contact Gisela P. Vega.

\section{IRB CONTACT INFORMATION}

If you would like to talk with someone about your rights of being a subject in this research study or about ethical issues with this research study, you may contact the FIU Office of Research Integrity by phone at 305-348-2494 or by email at ori@ fiu.edu.

\section{PARTICIPANT AGREEMENT}

I have read the information in this consent form and agree to participate in this study. I have had a chance to ask any questions I have about this study, and they have been answered for me. I understand that I am entitled to a copy of this form after it has been read and signed. 
Signature of Participant

Printed Name of Participant

Signature of Person Obtaining Consent

-

Date
Date 


\section{APPENDIX E}

\section{Coding Rubric}

\begin{tabular}{|c|c|c|c|}
\hline $\begin{array}{l}\text { Parent } \\
\text { Code }\end{array}$ & $\begin{array}{l}\text { Child } \\
\text { Code }\end{array}$ & Category & Definition \\
\hline $\mathrm{CB}$ & & Culture Background & Background information \\
\hline I & & Identity & Sexual identity information \\
\hline \multirow[t]{4}{*}{ A } & & Alienation & $\begin{array}{l}\text { The experience of seeing oneself as } \\
\text { different }\end{array}$ \\
\hline & AS & Alienation in Society & $\begin{array}{l}\text { The experience of seeing oneself as } \\
\text { different in society }\end{array}$ \\
\hline & $\mathrm{AF}$ & Alienation with Family & $\begin{array}{l}\text { The experience of seeing oneself as } \\
\text { different with family }\end{array}$ \\
\hline & $\mathrm{AC}$ & Alienation in College & $\begin{array}{l}\text { The experience of seeing oneself as } \\
\text { different in college }\end{array}$ \\
\hline \multirow[t]{5}{*}{ SE } & & Social Exclusion & $\begin{array}{l}\text { The experience of seeing oneself as } \\
\text { different }\end{array}$ \\
\hline & SEF & Social Exclusion with Family & $\begin{array}{l}\text { Not fitting into the heteronormative } \\
\text { majority with family }\end{array}$ \\
\hline & SECA & $\begin{array}{l}\text { Social Exclusion in a } \\
\text { Classroom/Academic Setting }\end{array}$ & $\begin{array}{l}\text { Not fitting into the heteronormative } \\
\text { majority in a classroom/academic } \\
\text { setting }\end{array}$ \\
\hline & SENC & $\begin{array}{l}\text { Social Exclusion in extra- } \\
\text { curricular and non-classroom } \\
\text { settings }\end{array}$ & $\begin{array}{l}\text { Not fitting into the heteronormative } \\
\text { majority in extra-curricular and non- } \\
\text { classroom settings }\end{array}$ \\
\hline & SEP & Social Exclusion with peers & $\begin{array}{l}\text { Not fitting into the heteronormative } \\
\text { majority with peers }\end{array}$ \\
\hline $\mathrm{D}$ & & Disclosure & The process of coming out to others \\
\hline SA & & Self-acceptance & $\begin{array}{l}\text { Acceptance of a non-heterosexual } \\
\text { identity }\end{array}$ \\
\hline
\end{tabular}


VITA

GISELA PONCE VEGA

Born, Chicago, Illinois

1988

1990

1992

$1988-1994$

$1994-1995$

$1995-1996$

$1996-2001$

$1996-2012$

2006 - Present

2012 - Present
Bachelors of Fine Arts in Art Education

University of Illinois at Chicago, Chicago, Illinois

Bachelors of Fine Arts in Graphic Design

University of Illinois at Chicago, Chicago, Illinois

Masters of Education in Instructional Leadership

University of Illinois at Chicago, Chicago, Illinois

University of Illinois at Chicago, Chicago, IL

Residence Director, Housing

Assistant to the University Ombudsman, Division of Student

Affairs

Minority Recruiter

Semester at Sea, University of Pittsburg, PA

Residence Director

Northeastern University, Boston, MA

Residence Director

Adjunct Instructor Freshman Seminar, SLS 1501

Florida International University, Miami, Florida

Department of Housing and Residential Life

Florida International University Miami, Florida

Associate Director for Housing and Residential Life

Assistant Director, Residential Life

Coordinator for Programming and Development

Residence Life Coordinator

Faculty, Center for Women's and Gender Studies

LGBT and Beyond: Non-Normative Sexualities in Global

Perspectives WST 3641

Florida International University, Miami, Florida

Florida International University, Miami, FL

Associate Director, Multicultural Programs \& Services, LGBTQA

Initiatives 


\section{PUBLICATIONS AND PRESENTATIONS}

Vega, G.P. (2016, April). Meeting the Needs of Transgender Students on Campus. Conference Presentation at TransCon held at Barry University, Miami, FL.

Vega, G.P. (2015, March). Developing an LGBTQA mentors program on campus. Paper presented at the National Meeting of the American College Personnel Association, Tampa, FL.

Vega, G.P. (2015, January). Understanding the needs of LGBTQ students. Presentation for FIU Center for Academic Success, Miami, FL.

Vega, G.P. (2015, February). Working with sexual minority and gender variant clients. Presentation for School of Social Work at Florida International University, Miami, FL.

Whitehead, C.L., Gionti, L.A., Meeker, C., and Vega, G.P. (2014). Perspective on marginalized adult populations in Education. Presented at the 2014 SFERC: Thirteenth Annual South Florida Education Research Conference, Miami, FL.

Vega, G.P. (2014, September). Diversity Training Workshop. Citi Year Miami, Senior Core Members \& Staff. Presented at Miami Dade College, Miami, FL.

Vega, G.P., Camp, A., and Thompson, R. (2005). Advancing Minority Employees' Experience: Enhancing Organizational Culture. Presented at the National Meeting of the American College Personnel Association, Nashville, TN.

Onorato, S.M, Thompson, R., and Vega, G. (2004, March). Exploring the impact of peer tutoring on students' academic success. Paper presented at the National Meeting of the American College Personnel Association, Philadelphia, PA.

Onorato, S.M. and Vega, G. (2003, February). Global understanding: Challenging our voice of acceptance. Paper presented at the Florida Association of Women in Education conference, Fort Lauderdale, FL.

Akens, C. and Vega, G.P. (2002, March). Developing a campus commitment to diversity in the year 2000. Paper presented at the National Meeting of the American College Personnel Association, Washington, DC. 